\title{
The Interactions between Polyphenols and Microorganisms, Especially Gut Microbiota
}

\author{
Małgorzata Makarewicz (D), Iwona Drożdż, Tomasz Tarko (D) and Aleksandra Duda-Chodak *(D) \\ Department of Fermentation Technology and Microbiology, Faculty of Food Technology, \\ University of Agriculture in Krakow, 30-149 Kraków, Poland; malgorzata.makarewicz@urk.edu.pl (M.M.); \\ iwona.drozdz@urk.edu.pl (I.D.); tomasz.tarko@urk.edu.pl (T.T.) \\ * Correspondence: aleksandra.duda-chodak@urk.edu.pl; Tel.: +48-12-662-4792
}

check for

updates

Citation: Makarewicz, M.; Drożdż, I.; Tarko, T.; Duda-Chodak, A. The Interactions between Polyphenols and Microorganisms, Especially Gut Microbiota. Antioxidants 2021, 10, 188. https://doi.org/10.3390/ antiox10020188

Received: 22 December 2020

Accepted: 25 January 2021

Published: 28 January 2021

Publisher's Note: MDPI stays neutral with regard to jurisdictional claims in published maps and institutional affiliations.

Copyright: (c) 2021 by the authors. Licensee MDPI, Basel, Switzerland. This article is an open access article distributed under the terms and conditions of the Creative Commons Attribution (CC BY) license (https:// creativecommons.org/licenses/by/ $4.0 /)$.

\begin{abstract}
This review presents the comprehensive knowledge about the bidirectional relationship between polyphenols and the gut microbiome. The first part is related to polyphenols' impacts on various microorganisms, especially bacteria, and their influence on intestinal pathogens. The research data on the mechanisms of polyphenol action were collected together and organized. The impact of various polyphenols groups on intestinal bacteria both on the whole "microbiota" and on particular species, including probiotics, are presented. Moreover, the impact of polyphenols present in food (bound to the matrix) was compared with the purified polyphenols (such as in dietary supplements) as well as polyphenols in the form of derivatives (such as glycosides) with those in the form of aglycones. The second part of the paper discusses in detail the mechanisms (pathways) and the role of bacterial biotransformation of the most important groups of polyphenols, including the production of bioactive metabolites with a significant impact on the human organism (both positive and negative).
\end{abstract}

Keywords: intestinal microbiota; inhibition; metabolism; catabolism; biotransformation; bioactive compounds; health; metabolites; diversity

\section{Introduction}

The intestinal microbiome plays an important, if not crucial, role in the metabolism of chemical compounds delivered with food, especially those that are undigested in the upper digestive tract. The enormous number of bacterial cells inhabiting the large intestine forms a complex ecosystem called the "intestinal microbiome". The word microbiome was introduced for the first time in 2001 to define the collective genomes of the microbiota [1]. Since then, much research and many projects were dedicated to assessing the impact of intestinal microbiota on a host's health, especially by determining its role in food metabolism, xenobiotics biotransformation and various disease development.

It is estimated that the microbiota of an adult is composed of $\sim 10^{14}$ bacteria cells [2] belonging to 1000-1150 species, with each individual harboring at least 160 species (usually about 500 species) [3]. Based on the large-scale $16 \mathrm{~S}$ rRNA or metagenomic studies, scientists stated that $\sim 80 \%$ of the bacteria identified by molecular tools in the human gut are uncultured and hence can be characterized only by metagenomic studies $[4,5]$. There are significant interindividual differences in the bacterial species found in the gastrointestinal tract. The composition, as well as the ratio of different species that form the intestinal microbiome, is very diverse within the human population, and each individual has his or her own unique profile of microbial species, which can be compared to a fingerprint. The differentiation of gut microbiota composition and profile is caused by the influence of multiple and diverse factors, such as age, origin, geographical location, environment, dietary habits (including probiotics), health, the application of antibiotics or even in the way an individual is born [6-8]. However, despite the great diversity of bacterial species, the majority of them belong to only four bacterial phyla: Firmicutes $(64 \%)$, Bacteroidetes $(23 \%)$, Proteobacteria 
(8\%) and Actinobacteria (3\%), whereas other taxons highly diverse [2]. Among the key functions of microbiota is occupying the intestinal surfaces and production of antimicrobial compounds that prevent the invasion of pathogens. Both commensal bacteria and gut pathogens (such as Salmonella, Shigella, Helicobacter, Vibrio, Campylobacter, Yersinia, Clostridia, Aeromonas, Listeria, Streptococcus, and Staphylococcus, as well as pathogenic strains of Escherichia coli, Klebsiella pneumoniae, Enterococcus faecalis) require similar ecological niches to colonize and proliferate in the intestine $[9,10]$. Therefore, various mechanisms designed to compete with each other have evolved. Commensal bacteria produce bacteriocins that specifically inhibit members of the same or similar bacterial species (e.g., E. coli versus pathogen enterohemorrhagic $E$. coli). Commensal bacteria produce short-chain fatty acids and cause $\mathrm{pH}$ reduction, thereby preventing the colonization by pathogens whose optimal $\mathrm{pH}$ for growth is neutral [11]. An altered bacterial community structure may facilitate the gut colonization by enteric pathogens but can also favor the overgrowth of potentially harmful subsets of indigenous bacteria, like virulent $E$. coli or Clostridium difficile.

The great diversity of bacterial species forming the gut microbiota implicates the large number of genes which they contain [2] and the enormous metabolic capacity of the intestinal microbiome, which is approximately 100 -fold greater than that of the human liver [2,12]. The intestinal microbiota is equipped with a large set of different enzymes able to hydrolyze glycosides, glucuronides, sulfates, amides, esters and lactones through the action of enzymes such as $\alpha$-rhamnosidase, $\beta$-glucuronidase, $\beta$-glucosidase, sulfatase and various esterases. Other reactions catalyzed by the gut microbial enzymes are aromatic ring cleavage, reductions (reductases, hydrogenases), decarboxylation (decarboxylase), demethylation (demethylase), isomerization (isomerase), and dehydroxylation (dehydroxylase) [13,14].

Intestinal bacteria contribute to the breakdown of polysaccharides and polyphenols as well as participate in the synthesis of vitamins (K, B12) and amino acids [8]. Many metabolites produced by gut microbiota are involved in various important physiological processes of the host, including energy metabolism and immunity. For example, the essential aromatic amino acid tryptophan can be metabolized by-among others-Peptostreptococcus russellii, Clostridium sporogenes, and Lactobacillus spp. to indole derivatives, which are ligands for aryl hydrocarbon receptor (AhR). This transcription factor plays an important role in the human immunological response, and via modulating $\mathrm{T}$ cell differentiation, Th17 development and IL-22 production may inhibit inflammation [15]. Branched-chain amino acids (BCAAs) (such as leucine, isoleucine, and valine) are essential amino acids that possess an aliphatic side chain with a branch, and that cannot be synthesized by humans. Therefore, they are provided by diet or synthesized by gut microbiota. The main species that contribute to the BCAAs production are Prevotella copri and Bacteroides vulgatus [15].

To date, thousands of microbial metabolites with known and unknown functions have been identified as components of the human metabolome. Well-known are short-chain fatty acids (SCFAs) with the acetate, propionate, and butyrate, being the metabolite of resistant starch and dietary fiber fermentation [15]. SCFAs are generally considered to have beneficial effects on host health, and they modulate metabolism, inflammation, hormone production, lipogenesis, and gut homeostasis. Gut microbiota can also metabolize dietary L-carnitine, choline, and lecithin into trimethylamine (TMA), which is then converted to trimethylamine-N-oxide (TMAO) in the liver of a host.

Owing to the multitude of direct and indirect interactions with the host organism, the intestinal microbiome is hence closely linked to the health of a host [16,17]. Dysbiosis, an imbalanced or disturbed microbiota composition, may play a significant role in etiology or the development of various gastrointestinal diseases such as inflammatory bowel disease (IBD), irritable bowel syndrome (IBS), colon cancer, and antibiotic-associated diarrhea [12,18]. The gut microbiota also plays a critical role in the transformation of dietary polyphenols into absorbable biologically active compounds. It is estimated that about $90-95 \%$ of the total polyphenol intake remains unabsorbed and colonic bacteria act enzymatically on their backbone, producing metabolites with a different physiological significance [19]. 


\section{The Structure and Role of Polyphenols}

Polyphenols are secondary metabolites playing an important role in plant tissues. They provide the color to flowers and fruits (mainly anthocyanins), which attracts pollinators and seed dispersers; they are also responsible for flavor in fruit and vegetables, as well as protecting plant tissues against herbivores and other biotic and abiotic stressors, like UV radiation, cold, heat or salinity [20]. Flavonoids take part in energy transfers, the regulation of photosynthesis and morphogenesis, regulation of growth factors, and sex determination and-due to antimicrobial activity—protect against the spread of pathogens in plant tissues [21]. Polyphenols also influence human health. Because of antioxidant properties and free-radical scavenging activity, they are believed to protect against various diseases, e.g., cancer, stroke and myocardial infarction, cardiovascular diseases, and some immunological and neurological disorders; they are also thought to have a beneficial impact on humans with diabetes and obesity [22-31]. Several in vitro and in vivo animal studies have demonstrated the antioxidant and anti-inflammatory effects of polyphenols in the brain-liver-gut axis [32], and polyphenols have been shown to target different stages of the inflammatory cascade to reduce the severity of inflammation. Polyphenols can also modulate various signal pathways, for example, through interaction with AMP-activated protein kinase (AMPK), CCAAT/enhancer-binding protein $\alpha(\mathrm{C} / \mathrm{EBP} \alpha)$, peroxisome proliferatoractivated receptor $\gamma(\mathrm{PPAR} \gamma)$, and peroxisome proliferator-activated receptor-gamma coactivator 1-alpha (PGC-1 $\alpha$ ), sirtuin 1, and sterol regulatory element-binding protein-1c (SREBP1c) involved mainly in cellular energy metabolism and adipogenesis, as well as uncoupling proteins 1 and 2 (UCP1 and UCP2), and NF- $\mathrm{KB}$ that regulate antioxidant and anti-inflammatory responses [28].

Polyphenols are a large group of compounds that comprise phenolic acids, flavonoids, tannins, lignans, stilbens and coumarins (Figure 1 presents the chemical structure of flavonoids, Figure 2-non-flavonoids). In a human diet, they are provided mainly by plant food such as fruit, vegetables, tea, wine, coffee, and cocoa. However, even when phenolic compounds occur in the human diet in large quantities, they do not always show high biological activity after consumption.

Polyphenols' influence on human health depends both on their amount of food and on their bioavailability, bioaccessibility and the biological activity of metabolites produced in the human body. Some phenolic compounds have limited absorption in the digestive tract, while the others undergo an intensive metabolism to derivatives with a lower activity or they undergo a rapid elimination (degradation). The uniqueness of the gut microbiota composition causes that in one individual, a given polyphenol will undergo bacterial metabolism and will have an effect (beneficial or negative), whereas in another human being, the metabolism of the same polyphenol will follow a different path, and there will be no effect. 
flavans

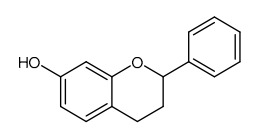

7-hydroxyflavan (1)

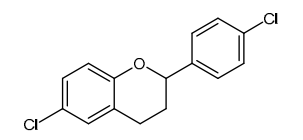

6,4'-dichloroflavan (2)

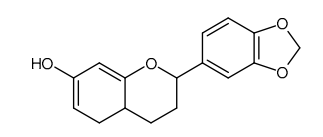

7-hydroxy-3,4'-

(methylenedioxy)flavan (3)

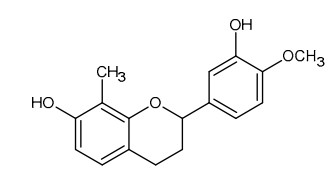

7,3'-dihydroxy-4'-methoxy 8-methylflavan

(4)<smiles>Oc1cc(O)c2c(c1)O[C@H](c1ccc(O)c(O)c1)[C@H](O)C2</smiles>

(+)-catechin (7)<smiles>Oc1cc(O)c2c(c1)O[C@H](c1ccc(O)c(O)c1)[C@H](O)C2</smiles>

(-)-catechin (10)<smiles>Cc1cc(C(=O)OC2Cc3c(O)cc(O)cc3O[C@@H]2c2ccc(O)c(O)c2)cc(O)c1O</smiles>

(+)-gallocatechin gallate (GCG) (13)

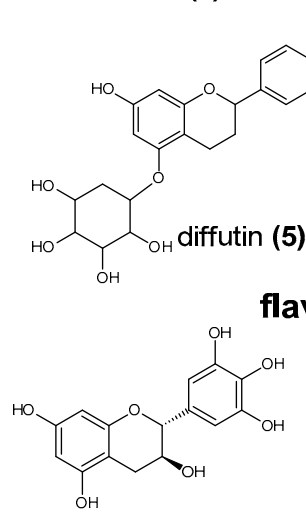

(+)-gallocatechin (8)<smiles>Oc1cc(O)c2c(c1)O[C@H](c1cc(O)c(O)c(O)c1)[C@H](O)C2</smiles>

(-)-gallocatechin (11)<smiles>O=C(O[C@H]1Cc2c(O)cc(O)cc2OC1c1ccc(O)c(O)c1)c1cc(O)c(O)c(O)c1</smiles>

(-)-catechin gallate (CG) (16)

\section{flavan-3-ols}

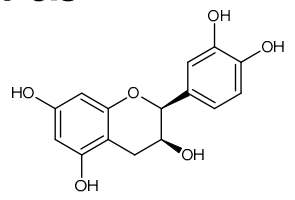

(+)-epicatechin (9)<smiles>Oc1cc(O)c2c(c1)O[C@H](c1ccc(O)c(O)c1)[C@H](O)C2</smiles>

(-)-epicatechin (12)<smiles>O=C(O[C@H]1Cc2c(O)cc(O)cc2O[C@H]1c1ccc(O)c(O)c1)c1cc(O)c(O)c(O)c1</smiles>

(-)-epicatechin gallate (ECG) (17)

isoflavans

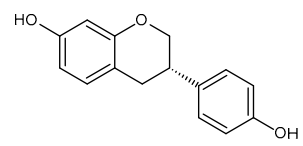

4',7-dihydroxyisoflavan (S-equol) (6)<smiles>Oc1cc(O)c2c(c1)OC(c1cc(O)c(O)c(O)c1)C(O)C2</smiles>

(+)-epigallocatechin (15)<smiles>Oc1cc(O)c2c(c1)O[C@H](c1cc(O)c(O)c(O)c1)[C@H](O)C2</smiles>

(-)-epigallocatechin (14)<smiles>O=C(O[C@H]1Cc2c(O)cc(O)cc2O[C@H]1c1cc(O)c(O)c(O)c1)c1cc(O)c(O)c(O)c1</smiles>

(-)-epigallocatechin gallate (EGCG) (18)

procyanidins<smiles>Oc1cc(O)c2c(c1)CC(O)C(c1ccc(O)c(O)c1)C2C1c2c(O)cc(O)cc2OC(c2ccc(O)c(O)c2)C1O</smiles>

procyanidin B1 (19)

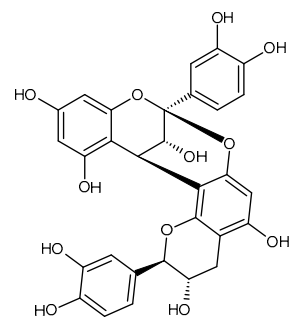

procyanidin A1 (23)

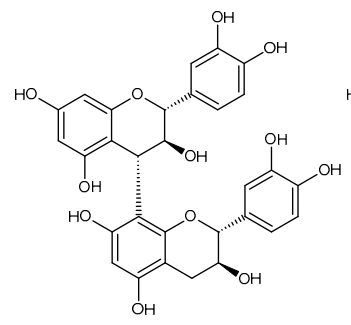

procyanidin B3 (21)<smiles>OCC1Oc2c(c(O)cc(O)c2C2c3c(O)cc(O)cc3OC(c3ccc(O)c(O)c3)C2c2ccc(O)c(O)c2)CC1O</smiles>

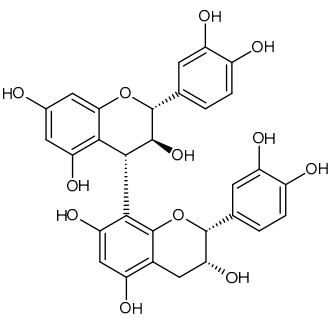

procyanidin B4 (22)

Figure 1. Cont. 
<smiles></smiles>

pelargonidin (25)<smiles></smiles>

peonidin (29)<smiles></smiles>

malvidin (33)<smiles></smiles>

cyanidin (26)<smiles></smiles>

petunidin (30)

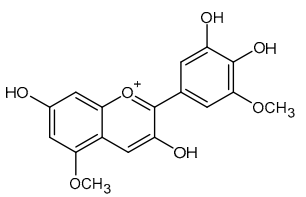

europinidin (34)<smiles>Oc1cc(O)c2cc(O)c(-c3cc(O)c(O)c(O)c3)cc2c1</smiles>

delphinidin (27)<smiles></smiles>

capensinidin (31)<smiles>Oc1cc(O)c2cc(-c3cc(O)c(O)c(O)c3)c(O)cc2c1</smiles>

pulchellidin (35)<smiles></smiles>

aurantinidin (28)<smiles>COc1cc(O)c2c(c1)[N+]=C(c1ccc(O)c(OC)c1)C(O)=C2</smiles>

rosinidin (32)<smiles>COc1cc2c(O)cc(O)cc2[o+]c1-c1ccc(O)c(O)c1</smiles>

cyanidin 3-O-glucoside (kuromanin) (36)

\section{flavones}<smiles>O=c1cc(-c2ccccc2)oc2c(O)c(O)ccc12</smiles>

7,8-dihydroxyflavone (37)

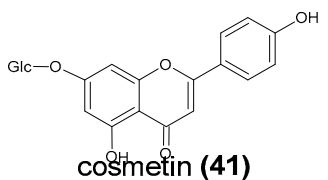

(apigenin 7-O-glucoside)

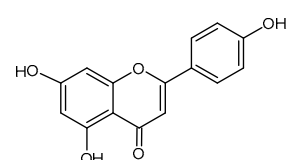

apigenin (38)

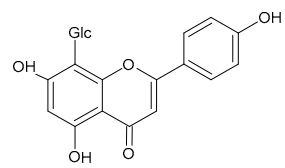

vitexin (42)

(apigenin 8-C-glucoside)<smiles>O=c1cc(-c2ccc(O)cc2)oc2cc(O)c(O)c(O)c12</smiles>

baicalein (45)<smiles>O=c1cc(-c2ccc(O)c(O)c2)oc2cc(O)cc(O)c12</smiles>

Iuteolin (49)<smiles>COc1cc(O)c2c(=O)cc(-c3ccc(O)c(O)c3)oc2c1</smiles>

Iuteolin 7-O-glucoside

(53)

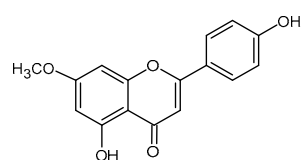

genkwanin (39) (apigenin 7-methyl ether)

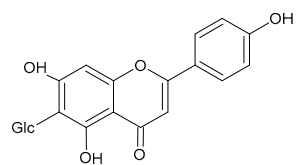

isovitexin (43)

(apigenin 6-C-glucoside)<smiles>O=c1cc(-c2ccccc2)oc2cc(O)cc(O)c12</smiles>

chrysin (47)

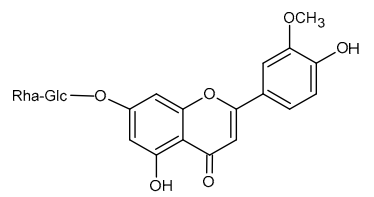

diosmin (51)

(diosmetin 7-O-rutinoside)

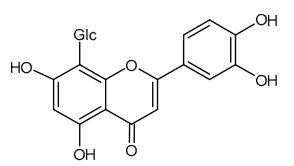

orientin (54)

(luteolin 8-C-glucoside)<smiles>COc1ccc(-c2cc(=O)c3c(O)cc(O)cc3o2)cc1</smiles>

acacetin (40)<smiles>O=c1cc(-c2ccc(O)cc2)oc2cc(O)c(O)c(O)c12</smiles>

scutellarein (44)

(5,6,7,4'-tetrahydroxyflavone)<smiles>COc1ccc(-c2cc(=O)c3c(O)c(C)c(OC)c(C)c3o2)cc1</smiles>

eucalyptin (48)

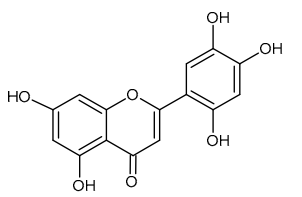

isoetin (52)

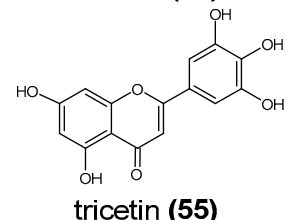

$\left(5,7,3^{\prime}, 4^{\prime}, 5^{\prime}\right.$-pentahydroxyflavone)

Figure 1. Cont. 
Antioxidants 2021, 10, 188

6 of 70

flavones - cont.

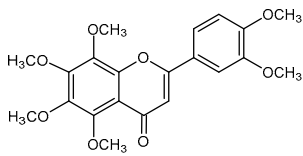

nobiletin (56)

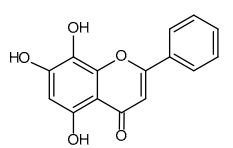

norwogonin (60)

norwogonin (60)
$(5,7,8$-trihydroxyflavone)

tangeretin (57)

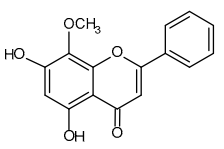

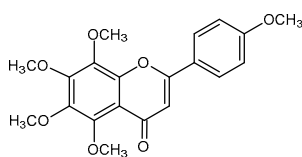

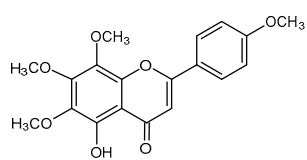

gardenin B (58)

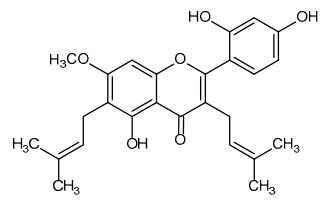

artocarpin (62)

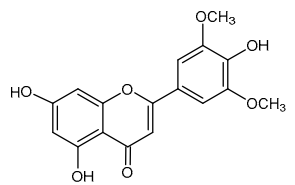

tricin (59)

(3',5'-O-dimethyltricetin)

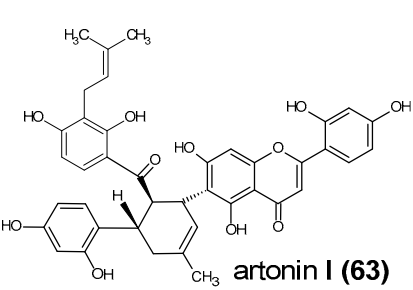

isoflavones

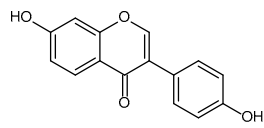

daidzein (64)

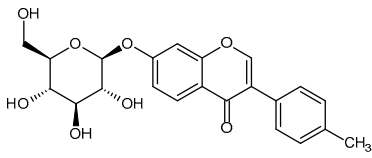

daidzin (67) (daidzein 7-O-glucoside)

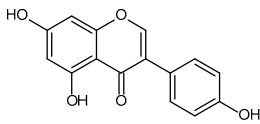

genistein (65)

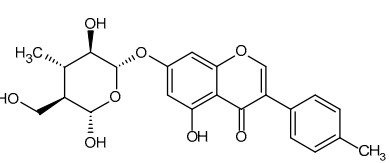

genistin (68) (genistein 7-O-glucoside)

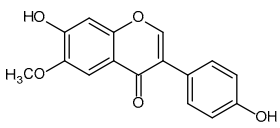

glycitein (66)

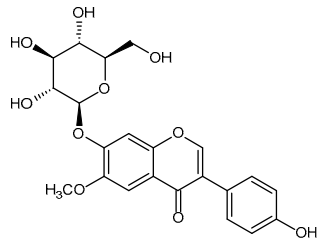

glycitin (69)

(glycitein 7-O-glucoside)

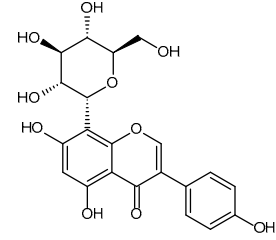

puerarin (70) (daidzein 8-C-glycoside)
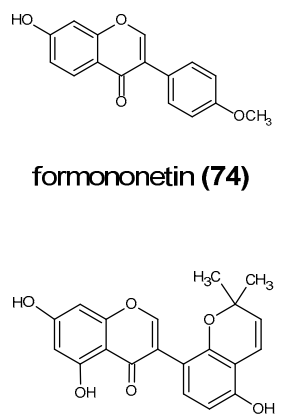

sophoraisoflavone A (77)

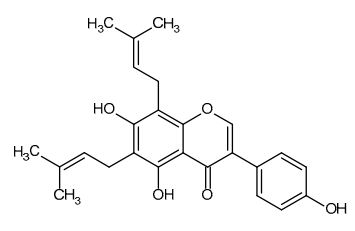

6,8-diprenylgenistein (71)

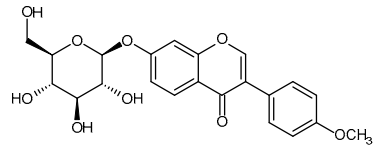

ononin (75) (formononetin 7-O-glucoside)

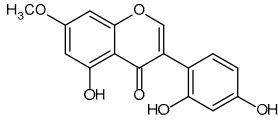

cajanin (72)

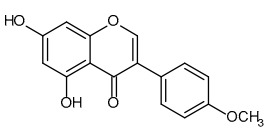

biochanin A (76)

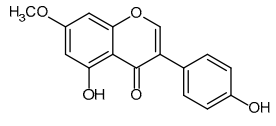

prunetin (73)
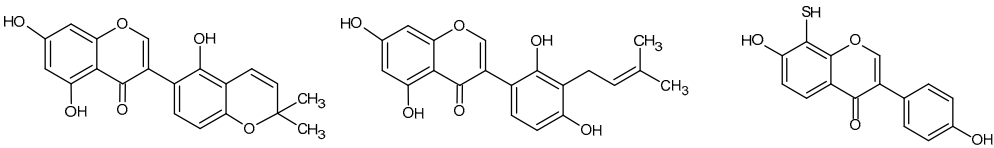

8-hydroxydaidzein (80) (7,8,4'-trihydroxyisoflavone

Figure 1. Cont. 
flavanones

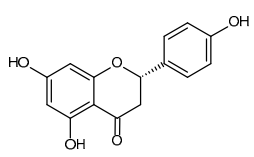

naringenin (81)

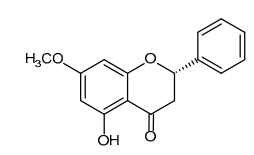

pinostrobin (82)

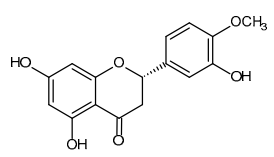

hesperetin (83)<smiles>COc1cc(O)c2c(c1)O[C@@H](c1ccc(O)cc1)CC2=O</smiles>

sakuranetin (84) (naringenin 7-methyl ether)

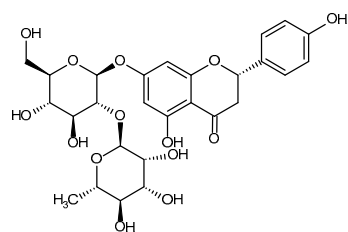
naringin (85)

(naringenin 7-O-neohesperidoside)<smiles>COc1ccc([C@H]2CC(=O)c3c(O)cc(OC4OC(COC5O[C@@H](C)[C@H](O)[C@H](O)[C@H]5O)[C@@H](O)[C@H](O)[C@H]4O)cc3O2)cc1O</smiles>

hesperidin (86)

(hesperetin 7-O-rhamnoglucoside)<smiles>COc1ccc([C@H]2CC(=O)c3c(O)cc(O)cc3O2)cc1</smiles>

isosakuranetin (87) (4'-methylnaringenin) (n)

narirutin (88) (naringenin 7-O-rutinoside) hesperetin 7-O-glucoside

(89)<smiles>COc1ccc([C@H]2CC(=O)c3c(O)cc(OC4OC(CO)[C@@H](O)[C@H](O)[C@H]4O[C@@H]4O[C@@H](C)[C@@H](O)[C@H](O)[C@H]4O)cc3O2)cc1</smiles>

poncirin (90)

(isosakuranetin 7-O-neohesperidoside)<smiles>O=C1C[C@H](c2ccc(O)cc2)Oc2cc(OC3OC(CO)[C@@H](O)[C@H](O)[C@H]3O)cc(O)c21</smiles>

prunin (91) (naringenin 7-O-glucoside)

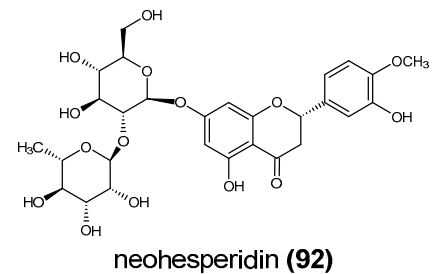

(hesperetin 7-O-neohesperidoside)<smiles>COc1ccc([C@H]2CC(=O)c3c(O)cc(OC4OC(COC5O[C@@H](C)[C@@H](O)[C@H](O)[C@H]5O)C(O)[C@H](O)[C@H]4O)cc3O2)cc1</smiles>

didymin (93)

(isosakuranetin 7-O-rutinoside)<smiles>O=C1C[C@H](c2ccc(O)c(O)c2)Oc2cc(O)cc(O)c21</smiles>

eriodictyol (94)<smiles>C=C(C)C(CC=C(C)C)Cc1c(O)cc(O)c2c1O[C@H](c1ccc(O)cc1O)CC2=O</smiles>

sophoraflavanone G

(98)

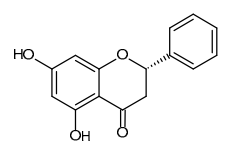

pinocembrin (95)<smiles>O=C1C[C@H](c2ccc(O)cc2)Oc2cc(O)ccc21</smiles>

liquiritigenin (96)

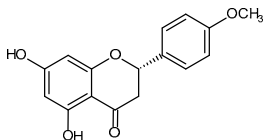

ponciretin (97)<smiles>CC(C)=CCC/C(C)=C\Cc1c(O)cc(O)c2c1O[C@H](c1ccc(O)cc1O)CC2=O</smiles>

sophoraflavanone C<smiles>CC(C)=CCC/C(C)=C/Cc1c(O)cc(O)c2c1O[C@H](c1ccc(O)cc1O)CC2=O</smiles>

sophoraflavanone $A(\mathbf{1 0 0})$ (8-geranylnaringenin)<smiles>CC(C)=CCc1c(O)cc(O)c2c1O[C@H](c1ccc(O)cc1)CC2=O</smiles>

sophoraflavanone B (101) (8-prenylnaringenin)<smiles>COc1cc(O)c(CC=C(C)C)c2c1C(=O)C[C@@H](c1ccc(O)cc1)O2</smiles>

6-prenylnaringenin (102) isoxanthohumol (104)<smiles>CC(C)=CCC/C(C)=C/Cc1c(O)cc2c(c1S)C(=O)C[C@@H](c1ccc(O)cc1)O2</smiles>

bonannione A (105) (6-geranylnaringenin)

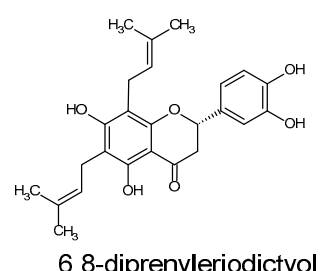

(106)
Figure 1. Cont. 


\section{flavonols}<smiles></smiles>

fisetin (107)<smiles>O=c1c(O)c(-c2ccc(O)c(O)c2)oc2cc(O)cc(O)c12</smiles>

quercetin (111)

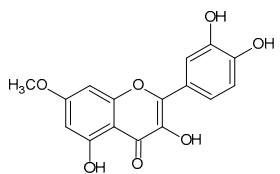

rhamnetin (115)

(7-O-methylquercetin)<smiles></smiles>

azaleatin (119) (quercetin 5-methyl ether)<smiles>C[C@@H]1O[C@H](OC2C(=O)c3c(O)cc(O)cc3OC2c2ccc(O)c(O)c2)[C@H](O)[C@H](O)[C@H]1O</smiles>

quercitrin (123) quercetagetin (124)

hyperoside (120)

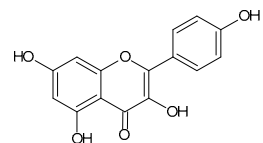

kaempferol (108)<smiles></smiles>

3-O-methylquercetin (112)<smiles></smiles>

isorhamnetin (116)

(3'-O-methylquercetin)

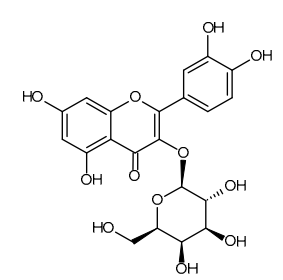
(quercetin 3-O-galactoside)

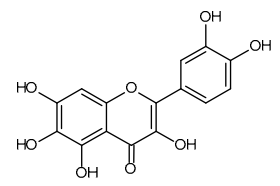

3,3',4',6', 7-pentahydroxyflavone (125)

myricetin 3-O-galactoside

(127)

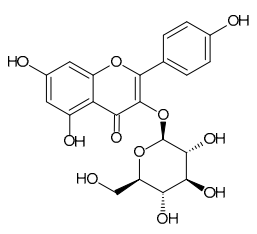

trifolin (128)

astragalin (129)

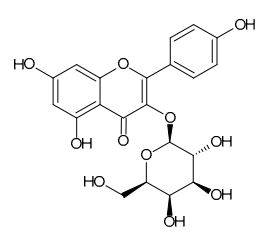

(kaempferol 3-O-galactoside) (kaempferol 3-O-glucoside)

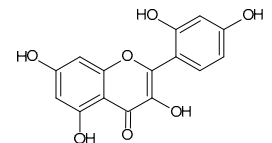

morin (110)<smiles></smiles>

myricetin (114)<smiles></smiles>

myricitrin (118)

(myricetin 3-O-rhamnoside)<smiles></smiles>

robinetin (122)

(5-deoxymyricetin)

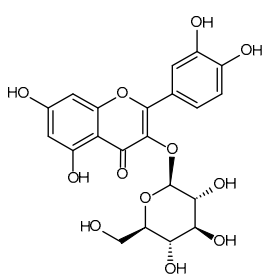

isoquercetin (126) (quercetin 3-O-glucoside)

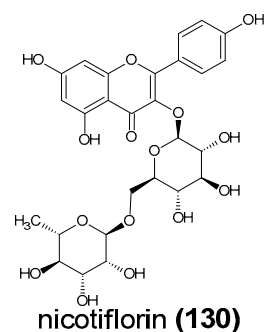

(kaempferol 3-O-rutinoside)

Figure 1. Cont. 
<smiles>O=C1c2ccc(O)cc2OC(c2cc(O)c(O)c(O)c2)C1O</smiles>

fustin (131)

2,3-dihydrorobinetin<smiles>O=C1c2ccc(O)cc2OC(c2ccc(O)cc2)C1O</smiles>

garbanzol (135)

(3,7,4'-trihydroxyflavanone)

\section{dihydroflavonols}<smiles>O=C1c2ccc(O)cc2OC(c2ccc(O)c(O)c2)C1O</smiles>

2,3-dihydrofisetin (132)<smiles></smiles>

aromadendrin (133)

2,3-dihydrokaempferol<smiles>O=C1c2c(O)cc(O)cc2OC(c2ccc(O)c(O)c2)C1O</smiles>

taxifolin (134)

(2,3-dihydroquercetin)<smiles>O=C1c2c(O)cc(O)cc2OC(c2cc(O)c(O)c(O)c2)C1O</smiles>

ampelopsin (136)

(2,3-dihydromyricetin)<smiles>O=C1c2c(O)cc(O)cc2OC(c2ccccc2)C1O</smiles>

pinobanksin (137)

(3,5,7-trihydroxyflavanone)<smiles>COc1cc(C2Oc3cc(C4Oc5cc(O)cc(O)c5C(=O)[C@H]4O)ccc3OC2CO)ccc1O</smiles>

silibinin (138)

(sylimarin)

chalcones<smiles>O=C(/C=C/c1ccccc1O)c1ccc(O)cc1O</smiles>

2,2',4'-trihydroxychalcone naringenin chalcone (140) (139)

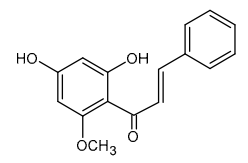

cardamonin (143)<smiles>O=C(C=Cc1ccc(O)cc1)c1c(O)cc(O)cc1O</smiles>
2',4,4',6'-tetrahydroxychalcone<smiles>CC(C)(C)[C@H](O)/C=C/c1ccc(O)c(O)c1</smiles>

okanin (141)<smiles>O=C(/C=C/c1ccc(O)cc1)c1ccc(O)cc1O</smiles>

isoliquiritigenin (142)

2',4,4'-trihydroxychalcone<smiles>CC(C)=CCc1c(O)cc(O)c(C(=O)/C=C/c2ccc(O)cc2)c1O</smiles>

desmethylxanthohumol (146)<smiles>CC1(C)C=Cc2c(ccc(C(=O)/C=C/c3ccc(O)cc3)c2O)O1</smiles>

4-hydroxylonchocarpin (149)<smiles>O=C(/C=C/c1ccc(O)c(O)c1)c1ccc(O)cc1O</smiles>

butein (144) 2',3,4,4'-tetrahydroxychalcone<smiles>CC(C)=CCc1c(O)cc(O)c(C(=O)/C=C/c2ccc(O)cc2)c1O</smiles>

xanthogalenol (147)<smiles>C=CC(C)(C)c1cc(/C=C/C(=O)c2ccc(O)cc2)c(O)cc1O</smiles>

licochalcone A (150)<smiles>COc1cc(O)c(CC=C(C)C)c(O)c1C(=O)C=Cc1ccc(O)cc1</smiles>

xanthohumol (145)<smiles>CC(C)=CCc1c(O)ccc(C(=O)C=Cc2ccc(O)cc2)c1O</smiles>

isobavachalcone (148)<smiles>COc1c(/C=C/C(=O)c2ccc(O)cc2)ccc(O)c1CC=C(C)C</smiles>

licochalcone $C$ (151)

\section{dihydrochalcones}<smiles>O=C(CCc1ccc(O)cc1)c1c(O)cc(O)cc1O</smiles>

phloretin (152)<smiles>O=C(CCc1ccc(O)cc1)c1c(O)cc(O)cc1OCCO</smiles>

phloridzin (153)

(phloretin 2'-glucoside)

Figure 1. The chemical structure of various classes of flavonoids. Based on [16,24,33-40]. 


\section{hydroxybenzoic acid derivatives}

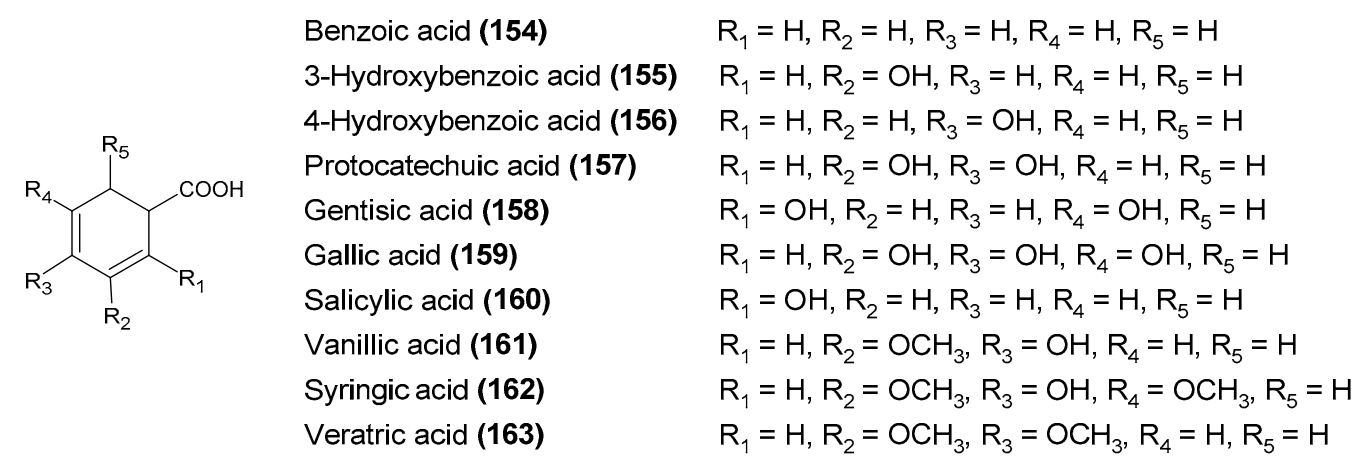

\section{hydroxycinnamic acid derivatives}

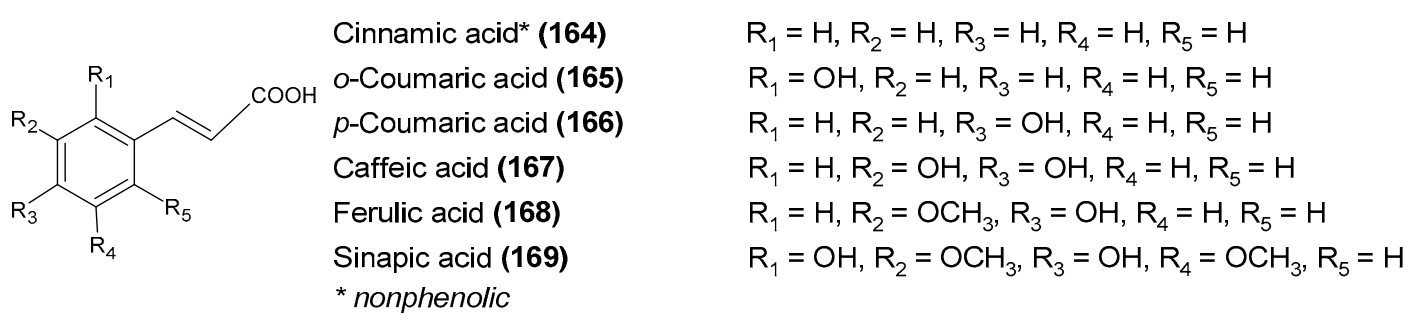

chlorogenic acids and other phenolic acids derivatives

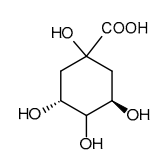

quinic acid (170)

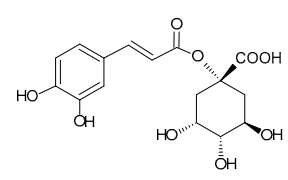

1-O-caffeoylquinic acid (171)

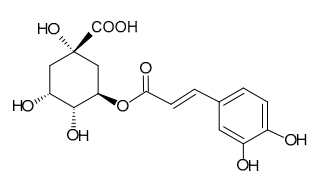

chlorogenic acid (172) (3-O-caffeoylquinic acid)

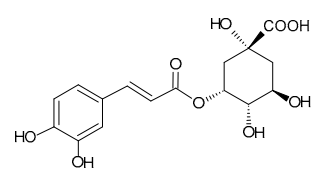

5-O-caffeoylquinic acid (173) (neochlorogenic acid)

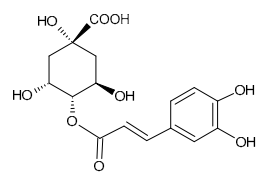

cryptochlorogenic acid (174) (4-O-caffeoylquinic acid)

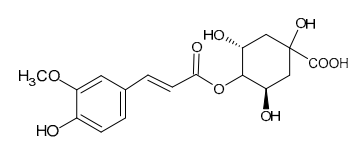

4-O-feruloylquinic acid (177)

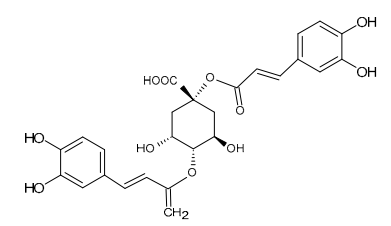

1,4-O-dicaffeoylquinic acid (180)

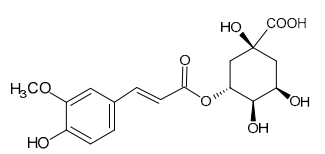

3-O-feruloylquinic acid (175)

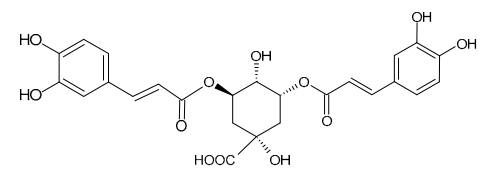

3,5-O-dicaffeoylquinic acid (178)

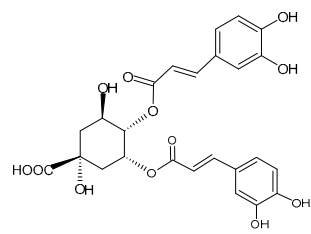

4,5-O-dicaffeoylquinic acid (181)

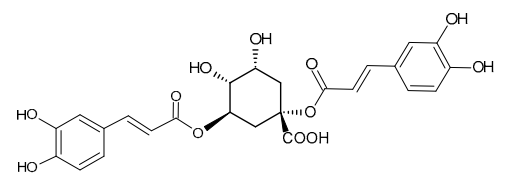

1,3-O-dicaffeoylquinic acid (176)

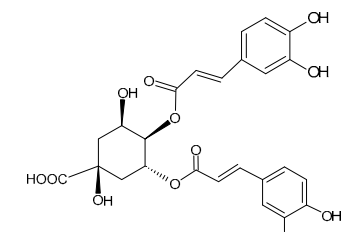

3,4-O-dicaffeoylquinic acidd (179)

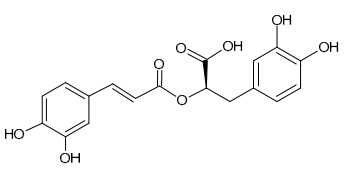

rosmarinic acid (182)

Figure 2. Cont. 


\section{carboxylic acids}<smiles>CC(C)c1ccc(O)c(O)c1</smiles>

carvacrol (183)<smiles>Cc1ccc(C(C)O)c(O)c1</smiles>

thymol (184)<smiles>C=CCc1ccc(O)c(OC)c1</smiles>

eugenol (185)<smiles>O=C(O)Cc1ccccc1</smiles>

phenyacetic acid (186)<smiles>O=C(O)CCc1cccc(O)c1</smiles>

dihydro-3-coumaric acid (187) (3-(3'-hydroxyphenyl)propionic acid)<smiles>O=C(O)CCc1ccccc1</smiles>

hydroxycinnamic acid (188) (3-phenylpropionic acid)<smiles>O=C(O)CCc1ccc(O)cc1</smiles>

phloretic acid (189)

(3-(4'-hydroxyphenyl)propionic acid)

\section{lignans}<smiles>COc1cc(CC2COC(c3ccc(O)c(O)c3)C2CO)ccc1O</smiles>

lariciresinol (190)<smiles>COc1cc(CC(CO)C(CO)Cc2ccc(O)c(OC)c2)ccc1O</smiles>

secoisolariciresinol (194)<smiles>COc1cc(C2OCC3C(c4ccc(O)c(OC)c4)OCC23)ccc1O</smiles>

pinoresinol (191)<smiles>COc1cc(C2OCC3C(c4cc(OC)c(O)c(OC)c4)OCC23)cc(OC)c1O</smiles>

syringaresinol (192)<smiles>COc1cc(CC2COC(=O)C2Cc2ccc(O)c(OC)c2)ccc1O</smiles>

matairesinol (193) sesaminol (196)

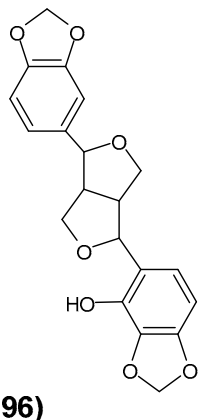

sesamin (195)

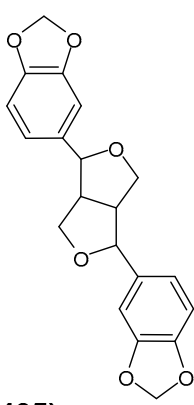

\section{coumarins}<smiles>O=c1ccc2ccccc2o1</smiles>

coumarin (197)<smiles>O=c1ccc2cc(O)c(O)cc2o1</smiles>

esculetin (198)<smiles>O=c1ccc2cc(O)c(OC3CCCCC3)cc2o1</smiles>

esculin (199)

(6,7-dihydroxycoumarin) (escultein 6-O-glucoside)<smiles>COc1cc2ccc(=O)oc2cc1O</smiles><smiles>O=c1ccc2cc3ccoc3cc2o1</smiles>

scopoletin (200)

Figure 2. Cont. 


\section{stilbenoids}

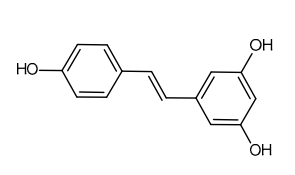

trans-resveratrol (202)

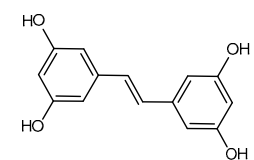

piceatannol (203)

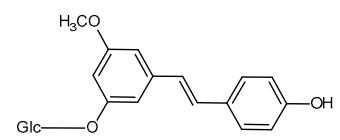

piceid (206)

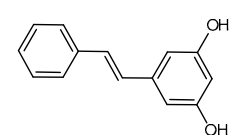

pinosylvin (204)

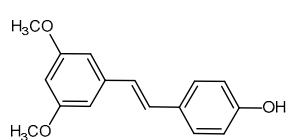

pterostilbene (205)

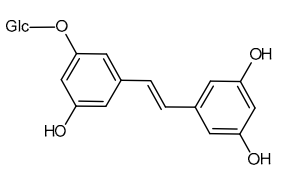

astringin (207)

\section{ellagitanins}<smiles>O=c1oc2c(O)c(O)cc3c(=O)oc4c(O)c(O)cc1c4c23</smiles>

ellagic acid (208)

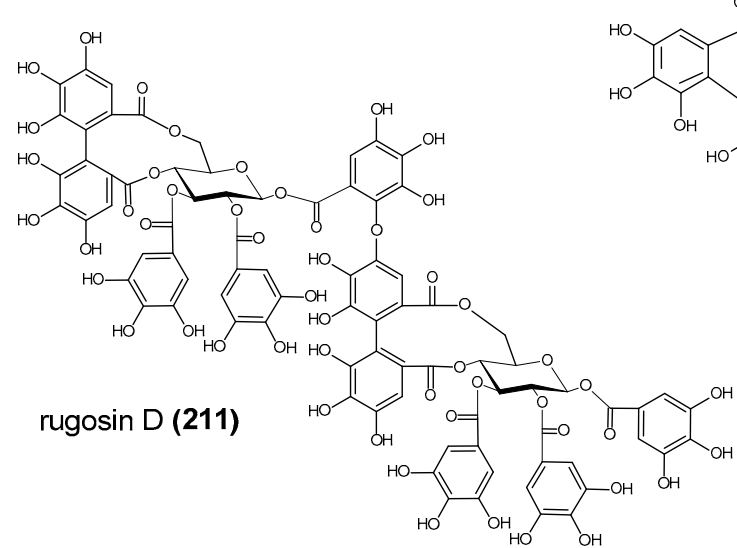

castalagin (209)

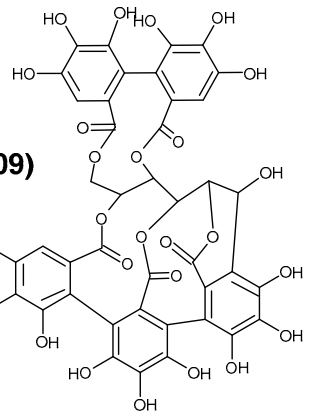

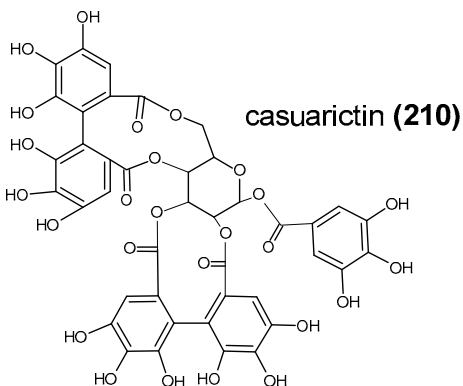
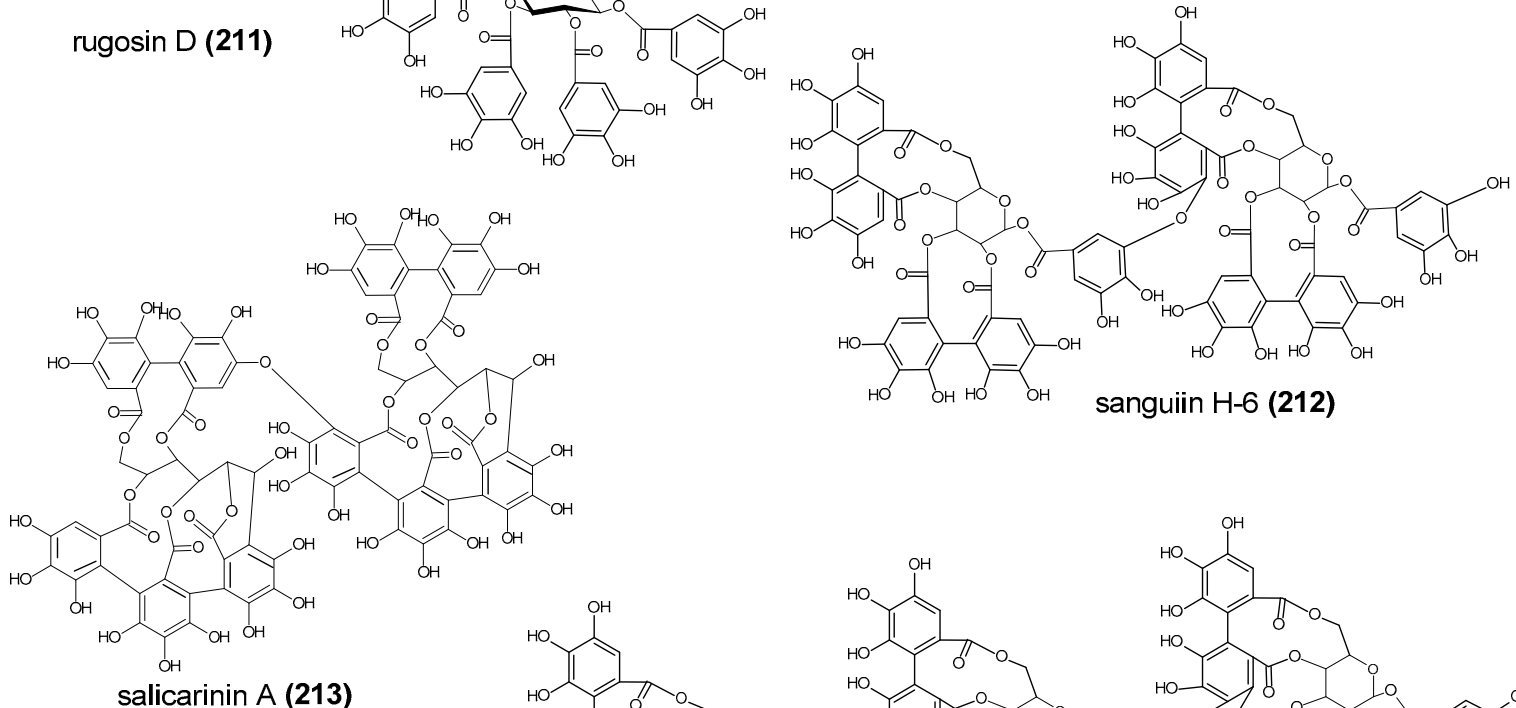

sanguiin H-6 (212) salicarinin A (213)

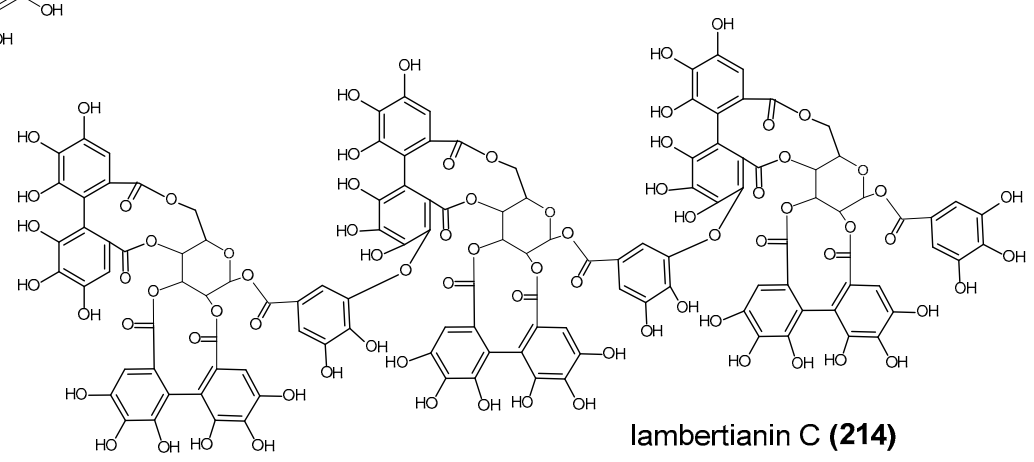

Figure 2. Cont. 


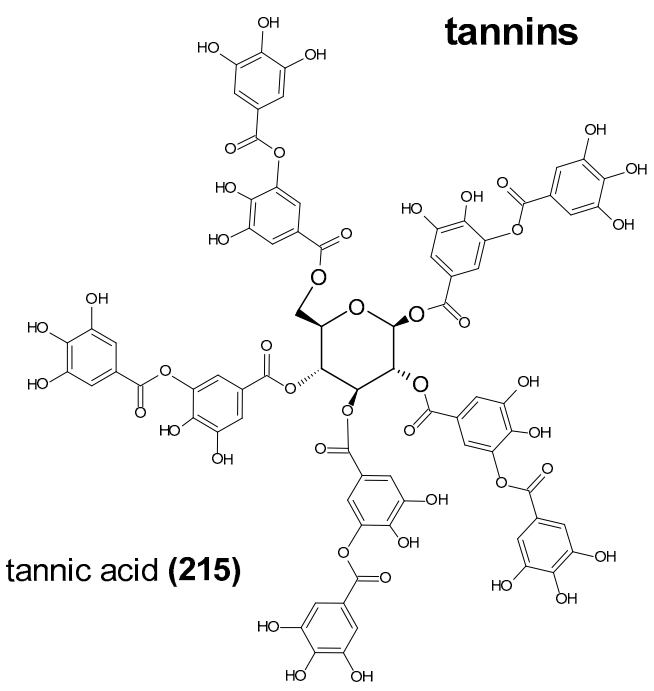

curcuminoids<smiles>COc1cc(/C=C/C(=O)CC(=O)/C=C/c2ccc(O)c(OC)c2)ccc1O</smiles>

curcumin (216)

Figure 2. The chemical structure of various groups of non-flavonoid polyphenols. Based on [16,24,33-40].

\section{The Impact of Polyphenols on Microorganisms and the Mechanism of Their Action}

Herbs and spices have a long history of being used as natural food preservatives and within folk medicine. It is due to substances with the antimicrobial activity they contain, such as flavonoids, anthocyanins, alkaloids, glycosides, saponins, coumarins, tannins, vitamins, phenolic acids and many more. Essential oils (a complex mixture of various bioactive compounds, inter alia, polyphenols), plant extracts and pure polyphenols are large groups of compounds with strong antibacterial properties. It has been proven many times that thyme, oregano, rosemary, sage, mint and other herbs and spices can inhibit Gram-positive and Gram-negative bacteria, including pathogens [20]. There are many scientific reports and publications demonstrating that pure polyphenols or bioactive compounds present in various types of plant preparations (e.g., aqueous, ethanolic or methanolic extracts, essential oils, enriched extracts) can exert both negative and positive impact on microorganisms. Some examples of such impact are presented in Table 1.

Table 1. Examples of the negative and positive impact of pure polyphenols or plant preparations (aqueous, ethanolic, methanolic or other extracts, essential oils, enriched extracts) on food-associated bacteria or the representatives of the human gastrointestinal tract microbiota.

Plant Material Preparation or Source
Pure Bioactive Compounds or Polyphenols Identified in Plant Material
Ethanolic extracts of:

rosemary, pomegranate peel, grape seed
Impact on Microorganisms

Reference

Antimicrobial activity of rosemary extract against $S$. aureus, E. coli, P. aeruginosa, K. pneumonia, B. subtilis, M. luteus and C. albicans.

Pomegranate peel extract inhibited all mentioned microorganism except $P$. aeruginosa. Inhibitory impact on S. aureus, E. coli, B. subtilis, M. luteus and C. albicans.

Antibacterial activity against B. subtilis, S. aureus, S. enteritidis, P. aeruginosa, E. coli.

[42]

Extracts had stronger antibacterial activity that the essential oils. of sage (Salvia officinalis)

flower, leaf and stem and essential oils
Manool, $\alpha$-pinene, camphene, camphor, limonene, bornyl, 1,8-cineole, linalool, cis- and trans-thujone, acetate, $\alpha$-humulene 
Table 1. Cont.

\begin{tabular}{|c|c|c|c|}
\hline $\begin{array}{c}\text { Plant Material, } \\
\text { Preparation or Source }\end{array}$ & $\begin{array}{l}\text { Pure Bioactive Compounds } \\
\text { or Polyphenols Identified in } \\
\text { Plant Material }\end{array}$ & Impact on Microorganisms & Reference \\
\hline $\begin{array}{c}\text { Ethanolic extracts of } \\
\text { Heliotropum europaeum }\end{array}$ & & $\begin{array}{c}\text { Antimicrobial activity against B. subtilis, E. coli, } \\
\text { P. aeruginosa, P. fluorescens, S. aureus, MRSA, } \\
\text { S. epidermidis, S. odorifera P. vulgaris, } \\
\text { K. pneumoniae, E. faecium and clinic isolate of } \\
\text { E. faecalis. } \\
\text { No impact on E. aerogenes, multidrug resistant } \\
\text { strains of E. coli and K. pneumoniae, E. faecalis } \\
\text { ATCC } 29212, \text { L. monocytogenes, S. haemolyticus, } \\
\text { S. boydi, A. baumannii, and S. flexneri. }\end{array}$ & [43] \\
\hline $\begin{array}{l}\text { Ethanolic extracts from thyme } \\
\text { (Thymus vulgaris) and sage } \\
\text { (Salvia officinalis) leaves }\end{array}$ & $\begin{array}{l}\text { Flavonoids } \\
\text { tannins } \\
\text { rosmarinic acid (182), } \\
\text { caffeic acid (167), } \\
\text { chlorogenic acid (172), } \\
\text { carnosol }\end{array}$ & $\begin{array}{l}\text { Inhibited growth of S. aureus, Vibrio tubiashii, } \\
\text { L. pneumophila, M. luteus, Streptococcus sp., } \\
\text { B. cereus. }\end{array}$ & {$[44]$} \\
\hline $\begin{array}{c}\text { Aqueous and methanol } \\
\text { extracts of Salvadora persica L. }\end{array}$ & & $\begin{array}{c}\text { Aqueous extract inhibited in dose-dependent } \\
\text { manner all tested microorganisms, especially } \\
\text { Streptococcus mutans, S. faecalis, S. pyogenes, as } \\
\text { well as S. aureus, L. acidophilus, P. aeruginosa, and } \\
\text { C. albicans. } \\
\text { Methanol extract was inactive against } \\
\text { L. acidophilus and P. aeruginosa. }\end{array}$ & [45] \\
\hline $\begin{array}{l}\text { Hydrodistilled essential oils } \\
\text { from Mentha piperita and } \\
\text { Rosmarinus officinalis }\end{array}$ & $\begin{array}{c}\text { Mint: } \alpha \text {-terpinene, } \\
\text { piperitenone oxide, } \\
\text { isomenthone, trans-carveol } \\
\text { and } \beta \text {-caryophyllene. } \\
\text { Rosemary: piperitone, } \\
\alpha \text {-pinene, linalool, camphor, } \\
\text { 1,8-cineole }\end{array}$ & $\begin{array}{l}\text { Inhibition of the growth of Streptococcus mutans } \\
\text { and S. pyogenes. } \\
\text { Inhibition of biofilm formation by S. mutans. }\end{array}$ & [46] \\
\hline $\begin{array}{l}\text { Phenolic extracts from } \\
\text { blueberry, lingonberry, } \\
\text { blackcurrant, raspberry, } \\
\text { cloudberry, cranberry and } \\
\text { strawberry } \\
\text { Pure polyphenols }\end{array}$ & $\begin{array}{c}\text { Extracts contained } \\
\text { anthocyanins, flavonols, } \\
\text { flavan-3-ols, } \\
\text { hydroxycinnamate. } \\
\text { myricetin (114), } \\
\text { luteolin (49), } \\
\text { apigenin (38), } \\
\text { kaempferol (202), } \\
\text { quercetin (111) } \\
\text { rutin (121) } \\
\text { isoquercitrin (126) } \\
\text { (+)-catechin (7) } \\
\text { phenolic acids: } \\
\text { trans-cinnamic acid (164), } \\
\text { m-coumaric acid, } \\
\text { caffeic acid (167), } \\
\text { ferulic acid (168), } \\
\text { chlorogenic acid (172) }\end{array}$ & $\begin{array}{c}\text { Strong antimicrobial activity against Salmonella } \\
\text { enterica ser. Thyphimurium SH5014, E. coli } \\
\text { CM871 and E. coli 50. Inhibition of Lactobacillus } \\
\text { rhamnosus and L. rhamnosus GG growth by } \\
\text { cloudberry, raspberry and strawberry extracts at } \\
\text { higher concentrations. Strawberry extract was } \\
\text { effective inhibitor against E. faecalis and } \\
\text { Bifidobacterium lactis. } \\
\text { Strong inhibition of the growth of all lactic acid } \\
\text { bacteria derived from the human gut, and E. coli } \\
\text { growth by myricetin; but no impact on Salmonella } \\
\text { Typhimurium and Lactobacillus plantarum from } \\
\text { beer. Bacteriostatic impact of luteolin on some } \\
\text { Lactobacillus species, Bifidobacterium lactis and } \\
\text { Enterococcus faecalis, no impact on Gram-negative } \\
\text { bacteria. No impact of (+)-catechin, kaempferol, } \\
\text { apigenin, isoquercitrin, and rutin. } \\
\text { Phenolic acids at concentration } 0.5 \text { mg/well } \\
\text { phenolic acids inhibited the growth of E. coli, and } \\
\text { S. enterica. }\end{array}$ & [47] \\
\hline
\end{tabular}


Table 1. Cont.

\begin{tabular}{|c|c|c|c|}
\hline $\begin{array}{c}\text { Plant Material, Preparation } \\
\text { or Source }\end{array}$ & $\begin{array}{c}\text { Pure Bioactive Compounds } \\
\text { or Polyphenols Identified in } \\
\text { Plant Material }\end{array}$ & Impact on Microorganisms & Reference \\
\hline $\begin{array}{l}\text { Methanolic extracts of six } \\
\text { species of Hypericum }\end{array}$ & $\begin{array}{c}\text { tannin, flavonoid and } \\
\text { phenolic acids, among them } \\
\text { quercitrin (123), } \\
\text { hyperoside (120), } \\
\text { isoquercitrin (126), } \\
\text { chlorogenic acid (172) } \\
\text { were identified }\end{array}$ & $\begin{array}{l}\text { H. caprifoliatum - the most active, inhibition of } \\
\text { S. aureus. } \\
\text { H. polyanthemum and } H \text {. ternum extracts } \\
\text { antibacterial activity against } B \text {. subtilis. } \\
\text { No activity of extracts against activity against } \\
\text { S. epidermidis and E. coli. }\end{array}$ & [48] \\
\hline $\begin{array}{l}\text { Extracts of meadowsweet, } \\
\text { willow herb, cloudberry, } \\
\text { raspberry, bilberry and } \\
\text { crowberry } \\
\text { Extracts of } \\
\text { white birch, pine, potato }\end{array}$ & $\begin{array}{l}\text { Extract contained flavonoids } \\
\text { and phenolic acid } \\
\text { Pure compounds: } \\
\text { quercetin (111), } \\
\text { morin (110), } \\
\text { rutin (121), } \\
\text { naringenin (81), } \\
\text { naringin (85), } \\
\text { kaempferol (202) }\end{array}$ & $\begin{array}{c}\text { E. coli and S. aureus growth inhibition. } \\
\text { Only S. aureus growth inhibition. } \\
\text { Quercetin, morin, naringenin inhibited S. aureus, } \\
\text { S. epidermidis, E. coli, B. subtilis, M. luteous, } \\
\text { P. aeruginosa. Glycosides rutin and naringin } \\
\text { were inactive. } \\
\text { Kaempferol inhibited only S. aureus. }\end{array}$ & [49] \\
\hline $\begin{array}{c}\text { Peppermint essential oil and } \\
\text { various extracts }\end{array}$ & & $\begin{array}{l}\text { Strong inhibition of S. aureus and S. pyogenes } \\
\text { growth, less impact on of E. coli and } \\
\text { Klebsiella pneumoniae. } \\
\text { Petroleum ether, chloroform and ethyl acetate } \\
\text { extracts were more effective antibacterial agents } \\
\text { than ethanol and aqueous extracts. } \\
\text { The strength of inhibition by extracts: } \text { S. aureus }> \\
\text { K. pneumoniae }>\text { S. pyogenes }>\text { E. coli. }\end{array}$ & [50] \\
\hline $\begin{array}{c}\text { Peppermint oil } \\
\text { Green tea polyphenols (GTP) }\end{array}$ & $\begin{array}{c}53 \text { constituents of oil, e.g., } \\
\text { menthol, menthone, } \\
\text { neomenthol, menthofuran, } \\
\text { (+)-limonene, piperiton, } \\
\text { 3-octanol, cis-jasmone, mint } \\
\text { lactone, (-)-myrtenol, } \\
\text { piperitol, eugenol (185), } \\
\text { carvacrol (183), 2-ethylfuran, } \\
\text { ocimene } \\
\text { (-)-epigallocatechin (14), } \\
\text { (-)-epigallocatechin-3-gallate } \\
\text { (18) }\end{array}$ & $\begin{array}{l}\text { Mentioned compounds had strong antibacterial } \\
\text { activity against non-pathogenic E. coli. } \\
\text { Oil, menthol, menthone and neomenthol killed } \\
\text { the enterohemorrhagic strain E. coli O157:H7 at } \\
\text { concentrations } 400 \mu \mathrm{g} / \mathrm{mL} \text { within } 1 \mathrm{~h} \text {. } \\
\text { GTP inhibited } E \text {. coli } \mathrm{O} 157: \mathrm{O} \text { growth at } \\
\text { concentration of } 800 \mu \mathrm{g} / \mathrm{mL} \text { within } 18 \mathrm{~h} \text {. } \\
\text { The synergistic effect was reported for } \\
\text { peppermint oil + GTP and menthol + GTP. }\end{array}$ & [51] \\
\hline $\begin{array}{l}\text { Cranberry, blueberry and } \\
\text { grape seed extracts } \\
\text { and their synergy mixtures }\end{array}$ & & $\begin{array}{c}\text { Dose-dependent inhibitory activity against } \\
\text { Helicobacter pylori. } \\
\text { The synergy mixtures with higher concentrations } \\
\text { of polymeric phenolics (procyanidins and } \\
\text { tannins) had higher antimicrobial activity } \\
\text { against } H \text {. pylori. }\end{array}$ & [52] \\
\hline Chinese green tea extract & $\begin{array}{c}\text { (-)-epicatechin gallate (ECG) } \\
(\mathbf{1 7 )}, \\
(-) \text {-epigallocatechin-3-gallate } \\
\text { (EGCG) (18) }\end{array}$ & $\begin{array}{l}\text { Crude green tea extract caused growth inhibition } \\
\text { (by } 44-100 \% \text { ) of food-borne pathogens } \\
\text { Escherichia coli O157:H7, Salmonella Typhimurium } \\
\text { DT104, L. monocytogenes, S. aureus, a diarrhoea } \\
\text { food-poisoning pathogen Bacillus cereus. } \\
\text { The lowest MIC90 values had EGCG: against } \\
\text { S. aureus MSSA was } 58 \mu \mathrm{g} / \mathrm{mL} \text {, while against } \\
\text { MRSA } 37 \mu \mathrm{g} / \mathrm{mL} \text {. } \\
\text { ECG had MIC } 309 \text { and } 105 \mu \mathrm{g} / \mathrm{mL} \text {, respectively. }\end{array}$ & [53-59] \\
\hline
\end{tabular}


Table 1. Cont.

\begin{tabular}{|c|c|c|c|}
\hline $\begin{array}{c}\text { Plant Material, Preparation } \\
\text { or Source }\end{array}$ & $\begin{array}{l}\text { Pure Bioactive Compounds } \\
\text { or Polyphenols Identified in } \\
\text { Plant Material }\end{array}$ & Impact on Microorganisms & Reference \\
\hline $\begin{array}{l}\text { Green tea, } \\
\text { Chung tea, } \\
\text { Black tea }\end{array}$ & $\begin{array}{c}\text { (-)-epicatechin (EC) (12), } \\
\text { (-)-epigallocatechin (EGC) } \\
\text { (14), } \\
\text { (-)-epigallocatechin-3-gallate } \\
\text { (EGCG) (18), } \\
\text { (-)-epicatechin gallate (ECG) } \\
\text { (17), } \\
\text { Teaflavins, } \\
\text { quercetin (111) }\end{array}$ & $\begin{array}{c}\text { EC and EGC strongly inhibited S. aureus ATCC } \\
29213 \text { (MIC } 12.5 \mu \mathrm{g} / \mathrm{mL} \text { ), while ECG had MIC } \\
50 \mu \mathrm{g} / \mathrm{mL} \text {, } \\
\text { ECG and EGCG strongly inhibited E. coli ATCC } \\
25922 \text { (MIC } 12.5 \mu \mathrm{g} / \mathrm{mL} \text { ). } \\
\text { ECG inhibited Enterobacter cloacae } 1321 \mathrm{E} \text { (MIC } \\
12.5 \mu \mathrm{g} / \mathrm{mL} \text { ) and S. pyogenes (MIC } 25 \mu \mathrm{g} / \mathrm{mL} \text { ), } \\
\text { EC inhibited the growth of P. aeruginosa (MIC } \\
25 \mu \mathrm{g} / \mathrm{mL} \text { ) }\end{array}$ & [54] \\
\hline \multirow[t]{6}{*}{$\begin{array}{l}9 \text { Hot water extracts of } \\
\text { various tea (oolong, green, } \\
\text { black, white) }\end{array}$} & $\begin{array}{c}\text { gallic acid (159), } \\
\text { quercetin (111), } \\
\text { caffeine, } \\
\text { (+)-catechin (7), } \\
\text { (-)-epicatechin (12), } \\
\text { (-)-epigallocatechin (14) }\end{array}$ & $\begin{array}{l}\text { 5-min extracts inhibited the growth of } \\
\text { Helicobacter pylori, but growth of probiotics } \\
\text { Bifidobacterium longum and Lactobacillus } \\
\text { acidophilus was not affected. }\end{array}$ & [55] \\
\hline & $\begin{array}{c}\text { (-)-epigallocatechin-3-gallate } \\
\text { (18) }\end{array}$ & $\begin{array}{l}\text { EGCG inhibited intracellular groth of Listeria } \\
\text { monocytogenes in macrophages }\end{array}$ & [56] \\
\hline & $\begin{array}{c}\text { (-)-epigallocatechin-3-gallate } \\
\mathbf{( 1 8 )}\end{array}$ & $\begin{array}{c}\text { EGCG inhibits major functions of cellular and } \\
\text { surface proteins, leading to growth inhibition of } \\
\text { Bacillus subtilis }\end{array}$ & [57] \\
\hline & $\begin{array}{c}\text { (-)-epigallocatechin-3-gallate } \\
\text { (18), } \\
\text { (-)-epigallocatechin (EGC) } \\
\text { (14) }\end{array}$ & $\begin{array}{c}\text { EGCG inhibits S. aureus, MRSA, S. mutans, E. coli, } \\
\text { P. aeruginosa, K. pneumoniae. } \\
\text { EGC inhibits E. coli }\end{array}$ & [58] \\
\hline & $\begin{array}{l}\text { (+)-catechin } \mathbf{( 7 )} \\
(-) \text {-epicatechin }(\mathbf{1 2})\end{array}$ & $\begin{array}{l}\text { Catechin caused significant decrease in the } \\
\text { growth of the Clostridium histolyticum group and } \\
\text { a marked increase in the growth of the beneficial } \\
\text { bacterial group of C. coccoides-Eubacterium rectale, } \\
\text { Lactobacillus spp. and Bifidobacterium spp. } \\
\text { Epicatechin caused a significant increase in the } \\
\text { growth of the Eubacterium rectale-C. coccoides. }\end{array}$ & {$[59]$} \\
\hline & $\begin{array}{l}\text { Pure polyphenols, inter alia: } \\
\text { baicalein (45), } \\
\text { quercetin (111), } \\
\text { myricetin (114), } \\
\text { naringenin (81), } \\
\text { naringin (85), } \\
\text { hesperetin (83), } \\
\text { hesperidin (86), } \\
\text { resveratrol (202), } \\
\text { gallic acid (159) }\end{array}$ & $\begin{array}{l}\text { Aglycones quercetin, naringenin, hesperetin } \\
\text { inhibited growth of tested bacteria, while their } \\
\text { glycoside did not. } \\
\text { The lowest MIC were reported for: } \\
\text { baicalein, myricetin, hesperetin and kaempferol } \\
\text { against E. coli O157; } \\
\text { baicalein nad myricetin against S. aureus; } \\
\text { and baicalein against Salmonella Typhimurium, } \\
\text { Enterobacter sakazakii and Vibrio parahemolyticus. }\end{array}$ & {$[60]$} \\
\hline \multirow[t]{2}{*}{ Citrus fruit } & $\begin{array}{l}\text { hesperetin (83), } \\
\text { naringenin (81), } \\
\text { poncirin (90), } \\
\text { diosmetin (50) }\end{array}$ & Inhibition of the growth of $H$. pylori. & [61] \\
\hline & $\begin{array}{l}\text { rutin (121), } \\
\text { quercetin (111) }\end{array}$ & Inhibition of L. monocytogenes growth. & {$[62]$} \\
\hline
\end{tabular}


Table 1. Cont.

\begin{tabular}{|c|c|c|c|}
\hline $\begin{array}{c}\text { Plant Material, Preparation } \\
\text { or Source }\end{array}$ & $\begin{array}{c}\text { Pure Bioactive Compounds } \\
\text { or Polyphenols Identified in } \\
\text { Plant Material }\end{array}$ & Impact on Microorganisms & Reference \\
\hline & $\begin{array}{l}\text { (+)-catechin (7), } \\
\text { quercetin (111), } \\
\text { naringenin (81), } \\
\text { hesperetin (83), } \\
\text { rutin (121), } \\
\text { naringin (85), } \\
\text { hesperidin (86) }\end{array}$ & $\begin{array}{l}\text { Aglycones naringenin and hesperetin, inhibited } \\
\text { growth of almost all analysed bacteria } \\
\text { (MIC } \geq 250 \mu \mathrm{g} / \mathrm{mL} \text { ). Catechin, and glycosides } \\
\text { naringin, hesperidin, and rutin had no impact on } \\
\text { tested intestinal bacteria. Quercetin had strong } \\
\text { inhibitory impact (MIC } 20-50 \mu \mathrm{g} / \mathrm{mL} \text { ) on } \\
\text { Ruminococcus gauvreauii, Bacteroides galacturonicus } \\
\text { and Lactobacillus sp. growth. }\end{array}$ & {$[63]$} \\
\hline & $\begin{array}{c}13 \text { phenolic acids: } \\
\text { benzoic acid (154), } \\
\text { 3-hydroxybenzoic acid (155), } \\
\text { 4-hydroxybenzoic acid (156), } \\
\text { 4-hydroxy-3-methoxy- } \\
\text { benzoic acid, } \\
\text { 3,4-dihydroxybenzoic acid, } \\
\text { phenylpropionic acid (188), } \\
\text { 3-hydroxyphenylpropionic } \\
\text { acid (187), } \\
\text { 4-hydroxyphenylpropionic } \\
\text { acid (189), } \\
\text { 3,4-dihydroxyphenylpro- } \\
\text { pionic acids, } \\
\text { phenylacetic acid (186), } \\
\text { 3-hydroxyphenylacetic acid, } \\
\text { 4-hydroxyphenylacetic acid, } \\
\text { 3,4-dihydroxyphenylacetic } \\
\text { acid }\end{array}$ & $\begin{array}{l}\text { No impact on P. aeruginosa PAO1. Impact on E. } \\
\text { coli was strain dependent. E. coli ATCC } 25922 \\
\text { inhibition by benzoic and } \\
\text { 4-hydroxy-3-methoxy-benzoic, phenylacetic and } \\
\text { phenylpropionic acids at a concentration of } \\
\qquad 1000 \mathrm{mg} / \mathrm{mL} \text {. } \\
\text { E. coli O157:H7 (CECT 5947) was susceptible to } \\
\text { benzoic, 3-hydroxybenzoic, 4-hydroxybenzoic, } \\
\text { 4-hydroxy-3-methoxy-benzoic acids, } \\
\text { phenylacetic, 3-hydroxy-phenylacetic, } \\
\text { 4-hydroxyphenylacetic and } \\
\text { 3,4-dihydroxyphenylacetic acids, } \\
\text { phenylpropionic, 3-hydroxyphenylpropionic } \\
\text { acid and 4-hydroxyphenylpropionic acids. } \\
\text { Lactobacillus paraplantarum LCH7 was the most } \\
\text { susceptible to the action of phenolic acids, while } \\
\text { L. fermentum LPH1 was the most resistant. The } \\
\text { susceptibility was strain-dependent. } \\
\text { The most active compound were: } \\
\text { 4-hydroxybenzoic acid for L. fermentum CECT } \\
\text { 5716, L. fermentum LPH1, L. brevis LCH23, and } \\
\text { L. plantarum LCH17; 4-hydroxybenzoic acid.and } \\
\text { phenylpropionic acid for L. paraplantarum LCH7 } \\
\text { and L. coryniformis CECT 5711, while } \\
\text { 3-hydroxyphenylpropionic acid for L. fermentum } \\
\text { CECT 5716. }\end{array}$ & [64] \\
\hline $\begin{array}{c}\text { Extracts from } \\
3 \text { Eucalyptus species }\end{array}$ & $\begin{array}{c}\text { 2',6'-dihydroxy-3'-methyl-4'- } \\
\text { methoxy-dihydrochalcone, } \\
\text { eucalyptin (48), } \\
\text { 8-desmethyl-eucalyptin }\end{array}$ & $\begin{array}{c}\text { Significantly inhibited growth of Gram-positive } \\
\text { bacteria: S. aureus, MRSA, B. cereus, E. faecalis, } \\
\text { Alicyclobacillus acidoterrestris, } \\
\text { Propionibacterium acnes. } \\
\text { Not show strong antibacterial activity against } \\
\text { Gram-negative E. coli and P. putida. }\end{array}$ & [65] \\
\hline $\begin{array}{c}\text { Essential oils from Origanum } \\
\text { vulgare and Thymus vulgaris } \\
\text { Ocinum basilicum oil }\end{array}$ & & $\begin{array}{c}\text { Minimal Bactericidal Concentration /MBC/ } \\
\leq 5 \mathrm{mg} / \mathrm{mL} \text { against pathogens (E. coli, } \\
\text { Salmonella Enteritidis, and } S \text {. Typhimurium), and } \\
\text { beneficial bacteria (Lactobacillus acidophilus and } \\
\text { Bifidobacterium breve). } \\
\text { Higher activity against pathogenic bacteria } \\
\text { (MBCs } \leq 10 \mathrm{mg} / \mathrm{mL}) \text { than beneficial bacteria } \\
\text { (MBCs of } 80 \mathrm{mg} / \mathrm{mL}) .\end{array}$ & {$[66]$} \\
\hline
\end{tabular}


Table 1. Cont.

\begin{tabular}{|c|c|c|c|}
\hline $\begin{array}{c}\text { Plant Material, Preparation } \\
\text { or Source }\end{array}$ & $\begin{array}{l}\text { Pure Bioactive Compounds } \\
\text { or Polyphenols Identified in } \\
\text { Plant Material }\end{array}$ & Impact on Microorganisms & Reference \\
\hline & $\begin{array}{c}13 \text { common flavonoids } \\
\text { (flavones, flavonols, } \\
\text { flavanones) and } 6 \text { organic } \\
\text { acids (aliphatic and aromatic } \\
\text { acids) } \\
\text { kaempferol (108), } \\
\text { quercetin (111), } \\
\text { chlorogenic acid (172), } \\
\text { salicylic acid (160) }\end{array}$ & $\begin{array}{c}\text { Antimicrobial activity against Gram-negative } \\
\text { bacteria E. coli and P. aeruginosa, higher than } \\
\text { impact on Gram-positive ones: E. faecalis and } \\
\text { S. aureus. } \\
\text { Kaempferol, quercetin and chlorogenic acid had } \\
\text { no significant influence on } \text { P. aeruginosa. } \\
\text { Salicylic acid - the highest inhibitory activity } \\
\text { against all tested bacterial species } \\
\text { (MIC }=250-500 \mu \mathrm{g} / \mathrm{mL}) \text {. }\end{array}$ & [67] \\
\hline \multirow[t]{2}{*}{$\begin{array}{l}\text { A flavan-3-ol enriched grape } \\
\text { seed extract }\end{array}$} & & $\begin{array}{c}\text { Inhibited growth of Streptococcus thermophilus, } \\
\text { Bifidobacterium lactis BB12, Lactobacillus } \\
\text { fermentum, L. acidophilus and L. vaginalis. } \\
\text { Stimulated growth of some Lactobacillus } \\
\text { plantarum, L. casei, and L. bulgaricus strains. } \\
\text { No impact on Bifidobacterium breve 26M2 and } \\
\text { B. bifidum HDD541 growth }\end{array}$ & {$[68]$} \\
\hline & $\begin{array}{c}\text { naringenin (85), } \\
\text { hes-peridin (86), } \\
\text { rutin (121), } \\
\text { quercetin (111), } \\
\text { gal-lic acid (159), } \\
\text { caffeic acid (167), } \\
\text { p-coumaric acid (166), } \\
\text { ferulic acid (168), } \\
\text { chlorogenic acid (172), } \\
\text { vanillic acid (161), } \\
\text { sinapic acid (169), } \\
\text { hesperidin (86), } \\
\text { quercetin (111) }\end{array}$ & $\begin{array}{l}\text { All polyphenols influenced the growth of } \\
\text { Bifidobacterium adolescentis and B. bifidum was } \\
\text { assessed. Both the stimulatory and inhibitory } \\
\text { effects of polyphenols were observed. } \\
\text { Coumaric acid had strongest stimulatory effect } \\
\text { on B. bifidum, while vanillic and caffeic acid } \\
\text { stimulated B. adolescentis. } \\
\text { Inhibitory dose-dependent impact of hesperidin } \\
\text { and quercetin, on B. bifidum and B. adolescentis. }\end{array}$ & [69] \\
\hline $\begin{array}{l}\text { Tea phenolics and their } \\
\text { derivatives }\end{array}$ & $\begin{array}{l}\text { 3-phenylpropionic acid (188), } \\
\text { caffeic acid (167), } \\
\text { gallic acid (159) }\end{array}$ & $\begin{array}{l}\text { Inhibition of pathogenic Clostridium perfringens, } \\
\text { C. difficile and Bacteroides spp. } \\
\text { Less effect on commensal Clostridium spp., } \\
\text { Bifidobacterium spp. and probiotic Lactobacillus sp. } \\
\text { The growth of Lactobacillus ssp. and } \\
\text { Bifidobacterium spp. inhibited by caffeic acid, } \\
\text { 3-phenylpropionic acid and to the lesser extent } \\
\text { by gallic acid, while Lactobacillus casei Shirota } \\
\text { growth inhibited only by } \\
\text { 3-phenylpropionic acid. }\end{array}$ & [70] \\
\hline Red wine polyphenols & & $\begin{array}{l}\text { Stimulated growth of Bifidobacterium } \\
\text { and Lactobacillus. }\end{array}$ & {$[71]$} \\
\hline Tannin-rich diet & & $\begin{array}{l}\text { Significantly decreased growth of Clostridium } \\
\text { spp. with a corresponding shift toward } \\
\text { Entero-bacteriaceae and Bacteroides }\end{array}$ & [72] \\
\hline \multirow[t]{3}{*}{ Pomegranate extract } & ellagitannins & $\begin{array}{l}\text { Enhancing the growth of beneficial bacteria } \\
\text { Akkermansia muciniphila. }\end{array}$ & [73] \\
\hline & resveratrol (202) & $\begin{array}{c}\text { Enhancing the growth of beneficial bacteria } \\
\text { Akkermansia muciniphila, Lactobacillus and } \\
\text { Bifidobacterium. }\end{array}$ & $\begin{array}{l}74] \\
{[75]}\end{array}$ \\
\hline & polymeric procyanidins & $\begin{array}{c}\text { Enhancing the growth of beneficial bacteria } \\
\text { Akkermansia muciniphila. } \\
\text { Markedly decreased the } \\
\text { Firmicutes/Bacteroidetes ratio }\end{array}$ & [76] \\
\hline
\end{tabular}


Table 1. Cont.

\begin{tabular}{|c|c|c|c|}
\hline $\begin{array}{c}\text { Plant Material, Preparation } \\
\text { or Source }\end{array}$ & $\begin{array}{l}\text { Pure Bioactive Compounds } \\
\text { or Polyphenols Identified in } \\
\text { Plant Material }\end{array}$ & Impact on Microorganisms & Reference \\
\hline \multirow[t]{2}{*}{ Grape polyphenols } & & $\begin{array}{l}\text { Enhancing the growth of beneficial bacteria } \\
\text { Akkermansia muciniphila, and decreasing the } \\
\text { proportion of Firmicutes to Bacteroidetes. }\end{array}$ & [77] \\
\hline & rutin (121) & $\begin{array}{l}\text { The beneficial impact on Lactobacillus } \\
\text { and Bifidobacterium }\end{array}$ & [63] \\
\hline Cocoa & polyphenols & $\begin{array}{l}\text { The beneficial impact on Lactobacillus } \\
\text { and Bifidobacterium }\end{array}$ & [78] \\
\hline Red wine polyphenols & & $\begin{array}{l}\text { Significantly increased the number of } \\
\text { Enterococcus, Prevotella, Bacteroides, } \\
\text { Bifidobacterium, Bacteroides uniformis, } \\
\text { Eggerthella lenta, and Blautia } \\
\text { coccoides-Eubacterium rectale groups }\end{array}$ & [79] \\
\hline Blueberry & anthocyanidins & $\begin{array}{l}\text { The beneficial impact on Lactobacillus acidophilus } \\
\text { and Bifidobacterium spp }\end{array}$ & [80] \\
\hline \multirow[t]{2}{*}{ Red wine } & polyphenols & $\begin{array}{l}\text { Significantly increase of the number of faecal } \\
\text { bifidobacteria and Lactobacillus (intestinal barrier } \\
\text { protectors), Faecalibacterium prausnitzii and } \\
\text { Roseburia (butyrate-producing bacteria) }\end{array}$ & [81] \\
\hline & $\begin{array}{c}\text { flavan-3-ols } \\
\text { epigallocatechin gallate (18), } \\
(-) \text {-epigallocatechin (14), } \\
\text { procyanidin B1 (19), } \\
\text { procyanidin B2 (20) }\end{array}$ & $\begin{array}{l}\text { Significant inhibition of L. acidophilus LA-5 and } \\
\text { L. plantarum IFPL379 adhesion, except } 4 \\
\text { compounds. } \\
\text { Enhanced L. acidophilus LA-5 adhesion to } \\
\text { Caco-2 cells. } \\
\text { Increased L. casei LC115 adhesion to Caco-2 cells. } \\
\text { Increased the adhesion of Lactobacillus casei } \\
\text { LC115 to HT- } 29 \text { cells. }\end{array}$ & [82] \\
\hline Extract from apples & $\begin{array}{l}\text { procyanidin B2 (20), } \\
\text { chlorogenic acid (172) }\end{array}$ & $\begin{array}{l}\text { The increase of adhesion of Lactobacillus gasseri } \\
\text { and Lactobacillus casei to intestinal epithelial cells. }\end{array}$ & [83] \\
\hline \multirow[t]{2}{*}{ Cranberry } & $\begin{array}{l}\text { proanthocyanidins with } \\
\text { A-type linkages }\end{array}$ & $\begin{array}{l}\text { Inhibition of the adhesion of both } \\
\text { antibiotic-susceptible and antibiotic-resistant } \\
\text { strains of uropathogenic P-fimbriated E. coli. }\end{array}$ & {$[84,85]$} \\
\hline & $\begin{array}{c}\text { anthocyanidins: } \\
\text { pelargonidin (25), } \\
\text { cyanidin (26), } \\
\text { delphinidin (27), } \\
\text { cyanidin-3-glucoside (36) }\end{array}$ & $\begin{array}{c}\text { Inhibition of the growth of E. coli strain CM871. } \\
\text { No effect on E. faecalis strain E-203, S. enterica } \\
\text { SH-5014 and strains of the Lactobacillus } \\
\text { and Bifidobacterium. }\end{array}$ & [47] \\
\hline Wine extract & $\begin{array}{l}\text { quercetin (111), } \\
\text { flavan-3-ols, } \\
\text { anthocyanins }\end{array}$ & $\begin{array}{l}\text { No impact on species belonging to the } \\
\text { Lactobacillus, Enterococcus, Bacteroides, and } \\
\text { Bifidobacterium genera. }\end{array}$ & [86] \\
\hline \multirow[t]{2}{*}{ Grape seeds and pomace } & tannic acid (215) & $\begin{array}{l}\text { Potent growth-promoting effects on } \\
\text { L. acidophilus. }\end{array}$ & [87] \\
\hline & $\begin{array}{l}\text { gallic acid (159), } \\
\text { and free anthocyanins, } \\
\text { vanillic acid (161), } \\
\text { protocatechuic acid (157) }\end{array}$ & $\begin{array}{l}\text { Activated cell growth and the rate malolactic } \\
\text { fermentation of Leuconostoc oenos. } \\
\text { Vanillic acid showed a slight inhibiting effect, } \\
\text { while protocatechuic acid had no effect. }\end{array}$ & [88] \\
\hline
\end{tabular}

As can be seen in the table, not only pathogenic bacteria growth can be inhibited by polyphenols. It was proved that some beneficial microorganisms, inter alia lactic acid bacteria and probiotics strains, can also be inhibited. However, the bacteriostatic or bactericidal effect depends both on the polyphenol structure and bacteria species. Susceptibility to some 
polyphenols was also proved to be strain-dependent $[43,47,50,64]$. It was proved that some polyphenols exert a beneficial influence on bacteria. They can stimulate growth or at least change the composition of the microbiome in favor of beneficial bacteria such as Bifidobacterium and Lactobacillus, which both contribute to gut barrier protection; Akkermansia muciniphila and Faecalibacterium prausnitzii that possess anti-inflammatory effect by inhibiting the activation of NF-kB; and Roseburia sp.- the butyrate-producer [15]. Akkermansia muciniphila is an anaerobic, mucin-degrading bacterium residing in the healthy intestinal tract of a host that is believed to have several health benefits in humans [89]. Many studies show that various diseases, e.g., obesity, type II diabetes and inflammatory bowel diseases have an association with reducing $A$. muciniphila abundance [90]. Taking into account that polyphenols have been proven to increase the growth of Akkermansia muciniphila [72,73,75-77], the beneficial impact of polyphenols on human health may result from other than antioxidant activity. All these findings (Table 1) suggest that polyphenols reaching the large intestine may not only be catabolized to small phenolic acids but also elicit potentially beneficial effects of intestinal probiotic bacteria. Taken together, polyphenols appear to be able to alter gut microecology and, by affecting the total number of beneficial species in the gut, may confer positive gut health benefits.

\section{Mechanism of Antibacterial Activity of Polyphenols}

As was reported above, the influence of pure polyphenols and plant extract, as well as the strength of that impact on bacteria, differs depending on the kind of both phenolic compounds and bacteria strain. The mechanism of antimicrobial activity of polyphenols against bacteria can differ and also depends both on the polyphenol type and bacteria species. Among the most important mechanisms of the antibacterial action of polyphenols are [58,91-98]:

- $\quad$ Reactions with proteins;

- Inhibition of nucleic acid synthesis by bacterial cells or DNA damage;

- Interaction with the bacterial cell wall or inhibition of cell wall formation;

- Alteration of cytoplasmic membrane function, such as modifications of the membrane permeability or fluidity, cytoplasmic membrane damage and-in the result-the membrane disruption;

- Inhibition of energy metabolism;

- Changes in cell attachment and inhibition of biofilm formation;

- Substrate and metal deprivation.

\subsection{Reactions with Proteins}

The antibacterial activity of flavonoids may result from their ability to form complexes with proteins through nonspecific forces such as hydrogen bonding and hydrophobic effects, as well as by covalent bond formation [99]. Due to protein binding by polyphenols, they are sequestered into soluble or insoluble complexes, which affects the function of both polyphenol and protein [100]. Proteins modified by polyphenols binding have some amino acids blocked or undergo conformation transitions, which can cause changes in protein structure, solubility, hydrophobicity, thermal stability, and the isoelectric point. In consequence, protein-phenolic complexation leads to changes in their physicochemical and biological properties, including the digestibility and utilization of food proteins as well as the activity of digestive enzymes [101]. It has been demonstrated that naturally occurring polyphenols, e.g., condensed tannins, can inhibit a number of digestive enzymes, including $\alpha$-glycosidase, $\alpha$-amylase, lipase, pepsin, trypsin, and chymotrypsin, changing the availability of nutrients and hence modulating the microbiota composition [102-106]. Furthermore, polyphenols can bind to important bacterial proteins such as adhesins, enzymes, cell envelope transport proteins and-by inactivating them-exert an antimicrobial impact. On the other hand, polyphenols complexation with proteins may influence the bioaccessibility and activity of phenolic compounds. 
Quinones are known to complex irreversibly with nucleophilic amino acids in proteins, which leads to inactivation and loss of function in the proteins. They possibly interact with cell wall polypeptides, membrane-bound enzymes and surface-exposed adhesins of pathogenic bacteria [107].

Kaempferol-3-rutinoside (nicotiflorin) (130) was demonstrated to inhibit Streptococcus mutans. The affected protein was sortase A, a membrane enzyme that actively plays a crucial role in bacteria adhesion and the invasion of host cells [108]. A purified S. mutans sortase A was inhibited by curcumin (216) at a half-maximal inhibitory concentration; curcumin was also found to release the Pac protein to the supernatant and reduce $S$. mutans biofilm formation [109]. The sortase enzymes (cysteine transpeptidases) are used by Gram-positive bacteria to display proteins in a cell surface (e.g., glycoproteins), and they can attach to proteins in the cross-bridge peptide of the cell wall. Hence they are an important virulence factor. Morin (110), myricetin (114), and quercetin (111) exhibited strong inhibitory activity against sortase A and B from S. aureus [110].

Some flavones were active against Escherichia coli by forming complexes with extracellular and soluble proteins [111]. Chen et al. [112] proved that baicalein (45) decreased the expression of intracellular adhesin in S. aureus. EGCG can bind to porins, so probably this way, it affects the permeability of the outer membrane of Gram-negative bacteria via porin pores [113].

Nakayama et al. [114] demonstrated with two-dimensional electrophoresis that epigallocatechin gallate (18) strongly interacted with one of the outer membrane porin proteins of E. coli, especially with basic amino acids such as Arg, Lys and His. The docking simulation revealed that EGCG enters into the porin pore and binds to Arg residues present on the inner surface of the pore channel through hydrogen bonding, resulting in inhibition of the porin function.

It also has been shown that tea catechins [115] and various polyphenols [20] have the capacity to sensitize strains of methicillin-resistant Staphylococcus aureus to antibiotics. Taylor et al. [115] postulated that catechin gallates (compounds 13-18) intercalate into phospholipid bilayers, and probably they affect both virulence and antibiotic resistance by perturbing the function of the key processes associated with the bacterial cytoplasmic membrane.

The inhibitory impact of polyphenols on the action of the bacterial efflux pump, which changes transport through the cell wall and cytoplasmic membrane, is also taken into account $[91,116]$. It has been demonstrated that quinones and chalcones are substrates of bacterial efflux pumps and could be used in combination with the efflux inhibitors in order to improve the accumulation of the drug in the cells to fight against MRSA infections [117]. Kaempferol (108) and galangin (109) were found to be effective efflux pump inhibitors in S. aureus [118].

Flavonoids can modulate the activity of bacterial enzymes, which are crucial for cell life, such are those catalyzing the synthesis of cell wall elements, cell membrane fatty acids or ATP. Fatty acid synthase II (FAS-II) is a key enzyme for the synthesis of fatty acids building the bacterial membranes. It catalyzes fatty acid chain elongation, from 16-24 carbons obtained de novo by FAS-I to long-chain fatty acids of 36-48 carbons as well as mycolic acids [92]. Flavonoids such as isoliquiritigenin (142), butein (144), fisetin (107) and 2,2', $4^{\prime}$-trihydroxychalcone (139) inhibited FAS-II, thus preventing the growth of Mycobacterium smegmatis [119].

Epigallocatechin gallate (EGCG) (18) and the related tea catechins potently inhibited both the FabG and FabI reductase steps in the fatty acid elongation cycle [120]. The authors suggested that the presence of the galloyl moiety was essential for inhibitory activity, and EGCG was a competitive inhibitor of FabI and a mixed-type inhibitor of FabG, demonstrating that EGCG interfered with cofactor binding in both enzymes. Furthermore, EGCG inhibited acetate incorporation into fatty acids in vivo. Molecular docking studies conducted by Xiao et al. [121] revealed the importance of the 3-O-galloyl or 3-O-glycosides side chain at the flavonoid pyran ring in the mechanism of the inhibition of reductase flavoprotein, dihydroorotate dehydrogenase (PyrD), dihydrofolate reductase (DYR), NADH-dependent 
enoyl-ACP reductase, and the DNA gyrase subunit in E. coli. Results obtained in the study demonstrated that EGCG has the strongest binding with NADH-dependent enoyl-ACP reductase (FabI) in comparison with other flavonoids, while quercitrin (111) was also the strongest inhibitor of DNA gyrase subunit B (GyrB) among tested 19 flavonoids. The results also indicated that flavonoids that have galloyl moieties, such as EGCG (18), (-)-catechin gallate (16), (-)-epicatechin gallate (17), and (-)-gallocatechin gallate (13), exhibited higher binding affinities to PyrD, FabI, and DYR than their cognates lacking the galloyl group, i.e., (-)-epigallocatechin (14), (+)-catechin (7), (-)-epicatechin (12), and (-)-gallocatechin (11), respectively.

Quercetin (111), apigenin (38), and sakuranetin (84) inhibited the activity of $\beta$ hydroxyacyl-acyl carrier protein dehydratase from Helicobacter pylori (HpFabZ), which is necessary for bacterial fatty acid biosynthesis. These three flavonoids are all competitive inhibitors against $\mathrm{HpFabZ}$ by binding to the substrate tunnel and preventing the substrate from accessing the active site [122]. Similarly, $\beta$-ketoacyl acyl carrier protein synthase (KAS) III is a key catalyst in bacterial fatty acid biosynthesis. The docking studies between Enterococcus faecalis KAS III (efKAS III), and flavonoids proved that naringenin (81), eriodictyol (94), and taxifolin (134), with high-scoring functions and good binding affinities, docked well with efKAS III, causing the E. faecalis growth inhibition. Hydrogen bonds between the 5- and 4'-hydroxy groups and the side-chain of Arg38 and the backbone carbonyl of Phe308 were the key interactions for efKAS III inhibition [123].

Both Gram-positive and Gram-negative bacteria produce hyaluronidases, which are an important virulence factor. They enable the bacteria to avoid the immune system and host defense mechanisms. Terpenes (e.g., glycyrrhizin) have been identified as hyaluronic acid lyases (Hyal B from Streptococcus agalactiae, Hyal S from Streptomyces hyalurolyticus, and Hay C form Streptococcus equisimilis). Compounds with many hydroxyl groups inhibited hyaluronate lyase stronger than those with only a few [124].

Flavonoid 5,6-dihydroxy-4', 7,8-trimethoxyflavone, isolated from Limnophila heterophylla Benth, was found to effectively kill Bacillus subtilis by cell lysis. Moreover, they enhanced the activity of gluconeogenic fructose 1,6-bisphosphatase, but the decreased activity of phosphofructokinase and isocitrate dehydrogenase, the key enzymes of the Embden-Meyerhof-Parnas pathway and the tricarboxylic acid cycle, respectively, was demonstrated [125].

Isoflavones (4-(p-hydroxyphenethyl) pyrogallol and 7,8,4'-trihydroxyisoflavone (80) are potent inhibitors of urease, an enzyme produced by Helicobacter pylori, which catalyzes the hydrolysis of urea to produce ammonia and carbon dioxide and to protect the bacteria in the acidic environment of the stomach [126]. The structure-activity relationship of these polyphenols revealed that the two o-hydroxyl groups were essential for the inhibitory activity of polyphenol. When the C-ring of isoflavone was broken, the inhibitory activity markedly decreased.

It was observed [127] that treatment Pseudomonas aeruginosa with cranberry type-A proanthocyanidins $(23,24)$ caused downregulation of a wide variety of proteins, including those related to ATP synthesis (likely cytochrome C PA2482), purine, carbohydrate, aminoacid and fatty acid metabolism (HmgA, GuaB, FdhE, FoaB, LdcA, PurU1) and involved in nucleic acid synthesis and repair (e.g., TopA, Rne, RplC, and Mfd). In addition, several citric acid cycle proteins, such as subunits of the acetyl-CoA carboxylase, aconitate hydratase and fumarase, were found to be significantly reduced. However, more than 30 proteins, mainly related to metal cation utilization, were upregulated.

\subsection{Inhibition of Bacterial DNA Synthesis and Interaction with Nucleic Acids}

Flavonoids from Elaeagnus glabra were tested for their antibacterial activity against Proteus vulgaris and Staphylococcus aureus. A free $3^{\prime}, 4^{\prime}, 5^{\prime}$-trihydroxy B-ring and a free 3$\mathrm{OH}$ group were necessary for antibacterial activity. DNA synthesis was predominantly inhabited by the active flavonoids in P. vulgaris, whereas RNA synthesis was inhibited in S. aureus [128]. The most active inhibitors of DNA synthesis were robinetin (122), myricetin 
(114), and (-)-epigallocatechin (14). It is probable that the B ring of the flavonoids could intercalate or form a hydrogen bond with the stacking of nucleic acid bases and further lead to the inhibition of nucleic acid synthesis in bacteria. The results of Lou et al. [129] demonstrated that $p$-coumaric acid (166) had dual mechanisms of bactericidal activity: disrupting bacterial cell membranes and binding to bacterial genomic DNA leading to inhibition of cellular functions, and ultimately to cell death.

Depolarization of membrane and inhibition of DNA, RNA, and proteins synthesis was observed in $S$. aureus and-in higher concentrations-cell lysis, when treated with flavonoids from Dorstenia sp., such as 6,8-diprenyleriodictyol (106), isobavachalcone (148), and 4-hydroxylonchocarpin (149) [130].

The synthesis of nucleic acid can be inhibited by polyphenols also through topoisomerase inhibition. Flavonoids are inhibitors of topoisomerases, and it plays an important role in their antimycobacterial activity. Docking studies have proved that quercetin (111) effectively binds to the subunit B of DNA gyrase through interaction with residues that are in the Toprim domain of the protein. Due to this activity, it inhibited the growth of Mycobacterium smegmatis and Mycobacterium tuberculosis [131].

Bandele et al. [132,133] have found that polyphenols may act against topoisomerase II in different a manner; (-)-epigallocatechin gallate (18) and (-)-epigallocatechin (14) were redox-dependent topoisomerase II poisons, kaempferol (108) and quercetin (111) were topoisomerase II "poisons", myricetin (114) utilized both mechanisms, while (-)epicatechin gallate (18), and (-)-epicatechin (12) displayed no significant activity. Based on the observation, a set of rules has been formed to predict the mechanism of bioflavonoid action against topoisomerase II: while the $\mathrm{C} 4^{\prime}-\mathrm{OH}$ in $\mathrm{B}$ ring is critical for the compound to act as a traditional poison, the addition of $-\mathrm{OH}$ groups at $\mathrm{C}^{\prime}$ and $\mathrm{C}^{\prime}$ increases the redox activity of the $\mathrm{B}$ ring and allows the compound to act as a redox-dependent poison. The second rule is that the aromatic and planar structure of the $\mathrm{C}$ ring in the flavonols that includes a C4-keto group allows the formation of a proposed pseudo ring with the $\mathrm{C} 5-\mathrm{OH}$. Disruption of these elements abrogated enzyme binding and precluded the ability to function as a traditional topoisomerase II poison [132,133].

Although the above studies were conducted with human cells, and flavonoids are assumed to be poisons of human topoisomerase II $\alpha$ and II $\beta$, there are some data about flavonoids as inhibitors of bacterial type II topoisomerases: DNA gyrase and topoisomerase IIA (also called topoisomerase IV) [92]. Gyrases are enzymes that modify the DNA topology, and they are present only in prokaryotes, making them an attractive target for antibacterial drugs. DNA gyrase consists of two catalytic subunits; GyrA is responsible for DNA breakage and reunion, while the subunit GyrB contains the ATP-binding site. Coumarins and cyclothialidines are natural products that inhibit the ATPase activity of DNA gyrase by blocking the binding of ATP to subunit GyrB [134]. Plaper et al. [135] demonstrated that quercetin (111) inhibits the supercoiling activity of the bacterial gyrase and induces DNA cleavage, and the mechanism is probably based on interaction with DNA. They showed that quercetin (111) binds to the $24 \mathrm{kDa}$ fragment of gyrase B of Escherichia coli with a K(D) value of $15 \mu \mathrm{M}$ and inhibits ATPase activity of gyrase B. Its binding site overlaps with the ATP binding pocket and could be competitively replaced by either ATP or novobiocin. The proposed mechanism is that quercetin (111) inhibits gyrases through either the interaction with DNA or with the ATP binding site of gyrase [135]. Other polyphenols that can inhibit bacterial DNA gyrase by binding to the ATP binding site of the gyrase B subunit are catechins, with epigallocatechin gallate (18) being the most active, followed by epicatechin gallate (17) and epigallocatechin (14) [136]. Furthermore, quercetin (111), apigenin (38), and 3,3', 4',6,7-pentahydroxyflavone (167) demonstrated inhibitory activity against Escherichia coli DNA gyrase [137].

The quantitative structure-activity relationship (QSAR) and molecular docking of flavonoids were analyzed in the study of Fang et al. [138]. The QSAR models demonstrated that hydrophobicity, H-bond donor, steric and electronic properties are key factors for the antibacterial activity of flavonoids. Structure requirements including hydroxyl group at 
C-3, C-5, C-7 and C-3', C2-C3 unsaturated double bond and the carbonyl group at C-4 are essential, while the presence of hydroxyl group at C-6, methoxyl group at C-8 and C $-3^{\prime}$ could decrease the antibacterial activity. Docking results indicated that half of the tested flavonoids inhibited GyrB by interacting with ATP pocket in the same orientation. Polymethoxyl flavones, flavonoid glycosides, and isoflavonoids changed their orientation, resulting in a decrease in inhibitory activity. Hydroxyl group at C-3, C-5, C-7 and C-4', carbonyl group at C-4 are key active substituents of flavonoids for inhibiting GyrB by interacting with its key residues. Structure changes, including glycosylation, polymethoxylation or isoflavonoids, will change the action mode and result in a decrease in inhibitory activity [138].

Three flavonoids isolated from cottonseed flour which promoted Escherichia coli topoisomerase IV-dependent DNA cleavage were identified as rutin (121), quercetin 3-Orhamnogalactoside, and isoquercetin (126). Moreover, rutin (121) also inhibited topoisomerase IV-dependent decatenation activity and induced the $\mathrm{SOS}$ response of a permeable E. coli strain [139].

Arima et al. [140] observed that morin alone, at a concentration of $50 \mu \mathrm{g} / \mathrm{mL}$ inhibited the synthesis of DNA in the cells of Salmonella enteritidis, while its concentration equaled to a concentration of $12.5 \mu \mathrm{g} / \mathrm{mL}$ was enough if rutin (121) was added to the medium at a concentration of $12.5 \mu \mathrm{g} / \mathrm{mL}$. Morin (110) alone also inhibited RNA and protein synthesis, but the rutin added did not influence the inhibition process.

Tannic acid (215) is strongly bound to DNA, which possibly had led to the covalent modification of DNA bases. Furthermore, tannic acid in the presence of $\mathrm{Cu}$ (II) caused strand cleavage in supercoiled plasmid DNA [141].

\subsection{Interaction with the Bacterial Cell Wall or Inhibition of Cell Wall Formation}

Various strengths of antimicrobial activity against bacteria may be caused by differences in cell surface structures between Gram-negative and Gram-positive species [20,64]. The major function of the cell wall is to provide shape and cell integrity and to act as an osmotic barrier. Gram-negative bacteria were reported to be resistant toward many antibacterial substances due to the hydrophilic surface of their outer membrane and associated enzymes in the periplasmic space, which is capable of breaking down many molecules introduced from outside [142,143]. Moreover, the negatively charged lipopolysaccharide (LPS) of the outer membrane protects the bacterial cell against catechins [144]. Gram-positive bacteria seem to be more susceptible to the action of phenolic acids than Gram-negative bacteria [64]. One of the explanations is that the Gram-positive bacterium lacks an outer membrane, which would facilitate diffusion of the phenolic acids through the cell wall and intracellular acidification. Vattem et al. [145] postulated the hyperacidification at the plasma membrane interphase, being a consequence of dissociation of phenolic acids, as one of the possible mechanisms of the antimicrobial action of phenolic acids. This hyperacidification would alter cell membrane potential, making it more permeable, and cause irreversible alterations in the sodium-potassium ATPase pump, therefore leading to cell death.

Wu et al. [146] have demonstrated that quercetin (111) and apigenin (38) influence the synthesis of the bacterial cell walls by the inhibition of D-alanine:D-alanine ligase (an essential enzyme that catalyzes the ligation of d-Ala-d-Ala in the assembly of peptidoglycan precursors). Moreover, these two flavonoids could inhibit the FabZ enzyme from H. pylori [122]. Tasdemir et al. [38] found that quercetin (111) could inhibit three consecutive enzymes, $\beta$-ketoacyl-ACP reductase (FabG), $\beta$-hydroxyacyl-ACP dehydrase (FabZ) and enoyl-ACP reductase (FabI), in the FAS II pathway of Plasmodium falciparum, whereas apigenin (38) could only inhibit FabI.

Flavones form a complex with cell wall components and consequently inhibit further adhesions and microbial growth as well. The inhibition of bacterial enzymes (such as tyrosyl-tRNA synthetase) was observed for C-7-modified flavonoids containing the naringenin (81) core [147]. It was also demonstrated that they were also inhibitors of S. aureus, 
E. coli, and Pseudomonas aeruginosa growth. Baicalein (45) was an effective bactericide, and when combined with cefotaxime, the synergistic effects were observed by inhibiting extended-spectrum $\beta$-lactamase CTX-M-1 mRNA expression [148]. Inhibition of the bacterial efflux pump and increase in the susceptibility of existing antibiotics (by inducing depolarization of the cell membrane) is another possible mechanism of antibacterial activity. Artonin I (63), from Morus mesozygia, was effective against $S$. aureus due to blocking the efflux mechanism and causing depolarization of the cell membrane [149]. Artonin I (63) reversed multidrug resistance and increased the susceptibility of existing antibiotics by lowering their minimum inhibitory concentrations.

Many researchers have proved that polyphenols can interact with the cell wall or outer membrane and with their components such as peptidoglycan, lipopolysaccharide. Zhao et al. [150] demonstrated that unlike dextran and lipopolysaccharide, peptidoglycan from S. aureus blocked both the antibacterial activity of EGCG (18) and the synergism between EGCG and oxacillin, suggesting EGCG may directly bind to the cell wall of S. aureus and interfere with its integrity. These results were confirmed by Yoda et al. [113]. As the bactericidal activity of EGCG (18) for S. aureus was blocked, dose-dependently by purified peptidoglycan, but not by lipopolysaccharide or dextran, it was suggested that EGCG binds directly to the peptidoglycan in the cell wall. These results are consistent with the opinion that the structure of the bacterial cell wall is responsible for the different susceptibilities of Gram-positive and Gram-negative cells to polyphenols.

Gram-negative bacteria (e.g., Escherichia coli, Salmonella, Shigella) have in their outer cell membrane a strong "endotoxin"-lipopolysaccharide (LPS). The fraction of procyanidins from cranberries composed of polymers with an average degree of polymerization of 21 can efficiently bind lipopolysaccharide and prevent the interaction of LPS with receptors on the surface of mammalian target cells [151]. On the other side, phenolic extracts of cloudberry and raspberry rich in ellagitannins disintegrated the outer membrane of examined Salmonella sp. [152] and released LPS from bacteria cells.

\subsection{Alteration of Cytoplasmic Membrane Function}

The (inner) bacterial cell membrane is responsible for many essential functions: osmoregulation and respiration processes, transport, biosynthesis and the cross-linking of peptidoglycan and synthesis of lipids [153]. Any disturbance in its structure or functionality can result in metabolic dysfunction and cell death; hence the membrane disruption is postulated to be one of the mechanisms of the antibacterial activity of polyphenols. For example, catechins were shown to rupture the bacterial membrane by binding to the lipid bilayer and by inactivating or inhibiting the synthesis of intracellular and extracellular enzymes [154].

Apigenin (38) induced fungal membrane dysfunction and increased cell permeability [155], which caused the release of small intracellular constituents such as ions and sugars, but not proteins. Epicatechin-3-gallate (17) and caffeic acid (167) targeted both the cell wall and cytoplasmic membrane of P. aeruginosa [156]. The cellular membrane destruction and ensuing membrane permeability perturbation of $P$. aeruginosa had led to the ascending access of hydrophobic antibiotics, a release of potassium ions, and leakage of nucleotides. Phenolic acids, due to their partially lipophilic nature, pass through the cell membrane by passive diffusion and cause an increase in membrane permeability. They possibly reduce the intracellular $\mathrm{pH}$ and induce protein denaturation [157]. Methanol extract of Coriolus versicolor rich in polyphenols disabled S. aureus cell division (i.e., the formation of septa) and led to the accumulation of peptidoglycan and teichoic acid precursors in the cytoplasm [157]. In this case, the extract acted directly on the cytoplasmatic membrane, whereas in Gram-negative Salmonella Enteritidis, the cell envelope was damaged. On the other side, at high concentrations, catechins were found to generate an oxidative burst by the generation of reactive oxygen species (ROS) that cause alteration in the membrane permeability and membrane damage [158]. Purified flavonoids from Graptophyllum glandulosum possessed antimicrobial activities against multidrug-resistant 
Vibrio cholerae and caused cell lysis and disruption of the cytoplasmic membrane upon membrane permeability [159].

Flavonoids (acacetin (40) and apigenin (38)) and flavonols (morin (110) and rhamnetin (115)) caused destabilization of the membrane structure by disordering and the disorientation of the membrane lipids and induced leakage from the vesicle [160]. The inverse correlation between the number of hydroxyl groups in the flavonoids and their capacity to leakage induction was noted. Studies of Chabot et al. [161] suggested that flavonoids lacking hydroxyl groups on their B rings (genistein (65), hesperetin (83), chrysin (47), galangin (109)) were more potent inhibitors of microbial growth than those with the -OH groups. On the other hand, Adamczak et al. [67] have demonstrated that the presence of hydroxyl groups in the phenyl rings A and B usually did not influence the level of the antibacterial activity of flavones. A significant increase in the activity of the hydroxy derivatives of flavone was observed only for S. aureus. What is interesting, in contrary to other studies, the compounds tested in the study were generally more active against Gram-negative bacteria: Escherichia coli and Pseudomonas aeruginosa than Gram-positive ones: Enterococcus faecalis and Staphylococcus aureus.

Tsuchiya [162] reported that the catechin impact on membrane fluidity also depended on the stereospecificity. (-)-Epicatechin (12), (+)-epicatechin (9), (-)-catechin (10) and $(+)$-catechin (7) reduced membrane fluidity in increasing order of intensity; it means that epicatechins in a cis form were more effective for reducing membrane fluidity than catechins in a trans form. Stereospecificity in the membrane effects of catechin stereoisomers may be induced by the different hydrophobicity of geometrical isomers and the chirality of membrane lipid components. Lipophilic flavonoids may also disrupt microbial membranes [107]. It was suggested that the mode of action of terpenes and their related alcohols involves disruption of microbial membranes by their lipophilic components [163]. According to Tsuchiya [164], bioactive components with amphiphilic or hydrophobic structures interact with biological membranes resulting in the modification of membrane fluidity, microviscosity, order, elasticity, and permeability. The author postulated that interactions of flavonoids with lipid bilayers involve two mechanisms; the first is associated with the partition of the more nonpolar compounds in the hydrophobic interior of the membrane, while the second one includes the formation of hydrogen bonds between the polar head groups of lipids and the more hydrophilic flavonoids at the membrane interface. The membrane interactions and localization of flavonoids play a vital role in altering membrane-mediated cell signaling cascades [165].

The studies of Arora et al. [166] demonstrated that flavonoids and isoflavonoids preferentially enter into the hydrophobic core of membranes. In plant tissues, flavonoids occur mainly in the form of glycoside, and the presence of glycosidic residues in the flavonoid skeleton influences the hydrophobicity of flavonoids. Flavonoids with a greater hydrophobicity have been reported to influence the transmembrane potential to a greater extent than the less hydrophobic flavonols, probably because they can enter deeper into the lipid bilayer, thereby disrupting the compact packing of lipids [157]. Moreover, the spatial configuration is also important; a substantially higher affinity for artificial membranes was reported for flavonols (planar) than flavanones (tilted) [167]. Using the fluorescence anisotropy technique, it was reported that naringenin and naringin enhanced membrane fluidity, while membrane interaction with quercetin (111), daidzein (64), luteolin (49), galangin (109), kaempferol (108) and genistein (65) resulted in rigidified membranes [165]; however, the impact depended on the lipid composition of membranes.

Wu et al. [168] have shown the positive correlation between antibacterial capacity and membrane rigidification effect of the polyphenolic compounds. Authors have observed that flavonoids decreased the membrane fluidity with the potency being kaempferol (108) $>$ chrysin (47) > baicalein (45) > quercetin (111) > luteolin (49), whereas isoflavonoids increased the membrane fluidity with the potency being puerarin $(\mathbf{7 0})>$ ononin $(\mathbf{7 5})>$ daidzein (64) > genistin (68) [168]. Kaempferol (108), located deeply in the hydrophobic core of the lipid bilayer, decreased the membrane fluidity most and exhibited the highest 
antibacterial capacity against $E$. coli. The number and the position of hydroxyl groups influenced the membrane interaction with polyphenols; the $\mathrm{OH}$ group at $\mathrm{C}-3$ in the $\mathrm{C}$ ring was important for decreasing membrane fluidity. He et al. [169] suggested that for flavonoids to be effective antimicrobial agents, interaction with the polar head-group of the model membrane followed by penetration into the hydrophobic regions must occur. The antimicrobial efficacies of the flavonoids were consistent with liposome interaction activities and decreased in the order: kaempferol (108) > hesperetin (83) > (+)-catechin (7) $>$ biochanin A (76).

Sophoraflavanone B (8-prenylnaringenin) (101) caused cell wall weakening, membrane damage and intracellular constituents leaking from the cell of methicillin-resistant S. aureus [170]. In the study, the direct binding of sophoraflavanone B (101) to peptidoglycan was demonstrated. It also has been proposed that sophoraflavanone G (98) and (-)-epigallocatechin gallate (18) inhibited cytoplasmic membrane function [171].

\subsection{Inhibition of Energy Metabolism}

Many aspects of cellular metabolism revolve around ATP production and consumption, and ATP is regarded as the universal energy exchange factor that connects anabolism and catabolism but also enables processes such as motile contraction, phosphorylation, and active transport (uptake) of nutrients. Membrane-bound F1F0 ATP synthase from bacteria is an enzyme responsible for ATP production through oxidative phosphorylation or photophosphorylation. It has been demonstrated that morin (110), baicalein (45), silibinin (138), and epicatechin caused complete inhibition of ATPase activity, while hesperidin (86), chrysin (47), kaempferol (108), diosmin (51), apigenin (38), genistein (65), or rutin (121) exert partial inhibition of about $40-60 \%$ [172].

Dadi et al. [173] demonstrated that resveratrol (202), piceatannol (203), quercetin (111), quercitrin (123), or quercetin-3- $\beta$-D glucoside (126) inhibited E. coli ATP synthase, but to different degrees. The most potent inhibitor was piceatannol (203) ( $\sim$ residual activity); inhibition by other compounds was partial and ranged from $\sim 20 \%$ residual activity for quercetin (111) to $\sim 60 \%$ residual activity for quercitrin (123) or resveratrol (202). Inhibition was identical in both $\mathrm{F}_{1} \mathrm{~F}_{0}$ membrane preparations as well as in isolated, purified $\mathrm{F}_{1}$, but in all cases, inhibition was reversible. Interestingly, resveratrol (202) and piceatannol (203) inhibited both ATPase and ATP synthesis, whereas quercetin (111), quercitrin (123) or quercetin-3- $\beta$-D glucoside (126) inhibited only ATPase activity and not ATP synthesis. The membrane-bound ATPase activity of E. coli was also inhibited by eugenol (185) or carvacrol (183) [174]. Similar results were obtained for thymoquinone that completely inhibited both purified $\mathrm{F}_{1}$ and membrane-bound $\mathrm{F}_{1} \mathrm{~F}_{0}$ E. coli ATP synthase, and the process of inhibition was fully reversible [175].

It has been proposed that licochalcones A (150) and C (151) can inhibit energy metabolism [171]. Haraguchi et al. [176] have proved the antibacterial activity of licochalcones A (150) and C (151) against S. aureus and Micrococcus luteus, which resulted from inhibited oxidation of NADH in bacterial membranes. As licochalcones inhibited $\mathrm{NADH}$-cytochrome $\mathrm{c}$ reductase, they exerted their antibacterial activity by inhibiting the bacterial respiratory electron transport chain.

EGCG (18) directly interacts with proteins and phospholipids in the plasma membrane and regulates signal transduction pathways, transcription factors, DNA methylation, as well as mitochondrial function and autophagy [177].

\subsection{The Inhibition of Biofilm Formation and Interfering with Bacterial Quorum Sensing}

Biofilm is an assemblage of microbial cells that are irreversibly linked to a surface with bacteria embedded in an extracellular matrix of self-produced biopolymers. The ability to form biofilm is an important property of various bacteria such as pathogenic species and is associated with quorum sensing (QS) or cell-to-cell communication. Therefore, bacterial cell-to-cell communication has received attention to manifest the role of quorum signals in the attachment and growth of pathogenic bacteria in foods. QS participates 
in the biofilm formation as well as controls the expression of various virulence factors, inter alia, the production of proteases that degrade connective tissue, the production of siderophores that facilitate iron uptake, the releasing of toxins that disrupt cellular processes, the formation of phenazines that favor the reactive oxygen species generation, and production of exopolysaccharides that are necessary for the phagocytosis-resistant capsules structure [178].

An anti-quorum sensing (anti-QS) agent curcumin (216) from Curcuma longa (turmeric) was shown to inhibit the biofilm formation of pathogens, such as Escherichia coli, Pseudomonas aeruginosa PAO1, Proteus mirabilis and Serratia marcescens, possibly by interfering with their QS systems [179], because the biofilm maturation was disturbed by a biomass reduction and by the interruption of swimming motility. Chlorogenic acid (172) was proved to significantly inhibit the formation of biofilm by P. aeruginosa, its ability to swarm, and virulence factors including protease and elastase activities and rhamnolipid and pyocyanin production. Moreover, the QS related genes were downregulated in P. aeruginosa, and the inhibitory rates were as follows: lasI $85.09 \%$, lasR $48.63 \%$, rhlI $27.98 \%$, rhlR $34.7 \%$, pqsA $73.08 \%$, and pqsR $45.85 \%$, respectively [180].

Quercetin (111) efficiently reduced the biofilm formation and other QS regulated phenotypes like violacein inhibition, exopolysaccharide production and alginate production in foodborne pathogens K. pneumoniae, P. aeruginosa, and Y. enterocolitica [181]. Furthermore, quercetin (111) significantly inhibited the swimming and swarming behavior of P. aeruginosa and Y. enterocolitica.

L. paracasei exposed to resveratrol (202) displayed changes in the physicochemical properties of their surface, especially with a global increase in negative charges, a more basic nature and an increase in their hydrophobicity. These changes may largely contribute to the enhanced adhesion, induced formation of bacterial aggregates and biofilm formation abilities of resveratrol-treated L. paracasei [182]. However, the majority of studied polyphenols have shown the opposite impact on the ability of biofilm formation. Apple flavonoid phloretin (152) was reported to control E. coli O157:H7 biofilm formation by a mechanism that implies repressing the curli genes ( $\operatorname{csg} A$ and $\operatorname{csg} B)$, which are involved in fimbriae production [183]. Epigallocatechin-3-gallate (18) eliminates the biofilm matrix by directly interfering with the assembly of curli subunits into amyloid fibers and by triggering the $\sigma^{\mathrm{E}}$ cell envelope stress response and thereby reducing the expression of a crucial activator of curli and cellulose biosynthesis (CsgD) [184]. Recently, it has been shown that EGCG (18) act against biofilms by strongly interfering with the assembly of amyloid fibers and the production of phosphoethanolamine-modified cellulose fibrils [185].

EGCG (18) also inhibited the formation of Streptococcus mutans biofilms [186,187]. The growth of Streptococcus mutans decreased, and the biofilm formation was inhibited by pinocembrin (95), apigenin (38), quercetin (111), while caffeic acid phenethyl ester decreased, probably due to changes in bacterial architecture [188].

According to $\mathrm{Xu}$ et al. [189], the ECGC (18) activity against S. mutans is due to disrupting at the transcriptional level the adherence of bacteria to surfaces and hence inhibiting the biofilm formation. Authors hypothesized that EGCG at sublethal concentrations directly suppressed the expression of gift genes encoding glucosyltransferases, enzymes that synthesize polysaccharides necessary for biofilm formation [189]. Moreover, EGCG (18) was found to inhibit the enzymatic activity of the $\mathrm{F}_{1} \mathrm{~F}_{0}$-ATPase and lactate dehydrogenase [190].

Morin (110) at its sub-MICs demonstrated a significant dose-dependent inhibitory efficacy against Listeria monocytogenes biofilm formation [191]. Moreover, morin-treated Listeria showed a significant reduction in hemolysin secretion and a concentration-dependent decrease in the flagella directed swimming and swarming velocity. The biofilm formation and biofilm-related genes in L. monocytogenes also were inhibited by thymol (184), carvacrol (183) and eugenol (185) [192].

Bap (biofilm-associated protein) is expressed by Staphylococcus sp. in order to adopt functional amyloid-like structures as scaffolds of the biofilm matrix. Quercetin (111), myricetin (114) and scutellarein (44) specifically inhibited Bap-mediated biofilm formation 
of S. aureus and other staphylococcal species [97] by preventing the assembly of Bap-related amyloid-like structures.

The ability of bacteria to adhere was also inhibited by phenolic acids. Adhesion was less favorable when the bacteria were exposed to gallic acid (159) (P. aeruginosa, S. aureus and L. monocytogenes) and ferulic acid (168) (P. aeruginosa and S. aureus). Both phenolics were able to inhibit bacterial motility and prevented biofilm formation, as well as reducing the mass of biofilms formed by the Gram-negative bacteria [193]. Further studies proved that gallic (159) and ferulic (168) acids led to irreversible changes in membrane properties, such as its charge, intra and extracellular permeability, and physicochemical properties. Both acids caused changes in hydrophobicity and negative surface charge and induced the local rupture or pore formation in the cell membranes leading in consequence to essential intracellular constituent leakage [194].

\subsection{Substrate Deprivation}

When polyphenol forms complex with protein, the biological function might change. Depending on the function of a complexed protein, the influence on bacteria cells will differ. As mentioned above, a decreased or inhibited activity of enzymes can result in a lack of energy for bacteria and, in consequence, might lead to cell death. Lack of energy also means a disturbed transport of nutrients across the cell wall and cytoplasmic membranes, diminished bacteria proliferation and limited mobility, as well as inhibited ability to biofilm formation or even blocked sporulation [195].

The deprivation of the substrates required for microbial growth, especially essential mineral micronutrients such as iron and zinc (via proanthocyanidin chelation with the metals), together with the destabilization of the cytoplasmic membrane, the permeabilization of the cell membrane, the inhibition of extracellular microbial enzymes, direct actions on microbial metabolism, were supposed to be the mechanism of the antibacterial activity of the A-type proanthocyanidin $(\mathbf{2 3}, \mathbf{2 4})[196]$.

Scalbert [197] suggested that tannin toxicity for bacteria is due to the direct impact on bacterial metabolism by inhibiting the oxidative phosphorylation as well as by deprivation of the substrates required for microbial growth, especially an iron deprivation. Generally, tannins are reported to be strong inhibitors of many various hydrolytic enzymes such as $\alpha$-amylase, pectinase, cellulase, xylanase, lactate dehydrogenase, malate dehydrogenase, peroxidase, $\beta$-glucosidase, so they can inhibit the activity, growth or proliferation of microorganisms [198]

The inhibitory effect of tannic acid (215) on the growth of intestinal bacteria may be due to its strong iron-binding capacity. The growth of E. coli was restored by the addition of iron to the medium after the precipitate caused by tannic acid (215) was removed [199]. In the study, neither Bifidobacterium infantis nor Lactobacillus acidophilus required iron for growth, which probably contributes to their resistance to tannic acid. It is known that only a few bacteria, including lactobacilli, do not require iron. It is an essential trace element for most gut bacteria, and many have active Fe transport systems and other mechanisms to scavenge Fe [200]. For example, Bacteroides spp. are highly dependent on heme and iron, whereas many members of the Enterobacteriaceae have developed mechanisms, including siderophores, to acquire Fe in competition with other bacteria and the host.

It is well known that catechol and gallol structure (Figure 3) and hence many polyphenolic compounds are effective metal chelators. After deprotonation, which is required for metal binding, catecholate and gallate groups may be complexed with metal ions that prefer octahedral geometry, such as $\mathrm{Fe}^{2+}$ and $\mathrm{Fe}^{3+}$ (Figure 3) [201]. 
a

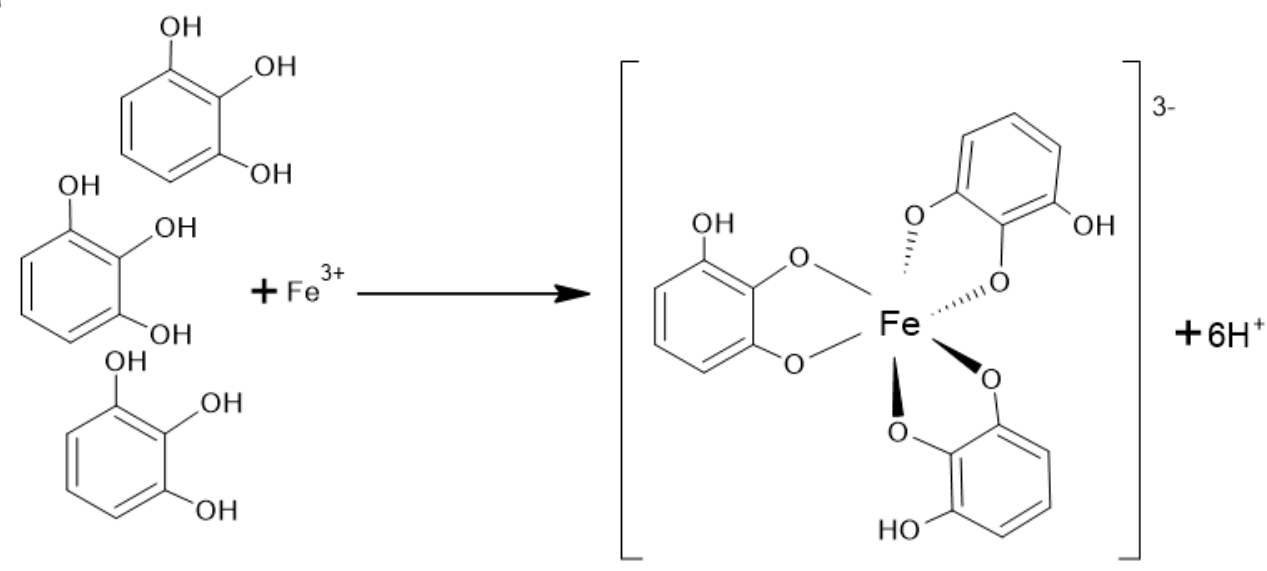

b<smiles>Oc1ccccc1O</smiles><smiles>OC1Oc2ccccc2Oc2ccccc2O1</smiles>

Figure 3. Expected octahedral coordination geometry of general iron-polyphenol complexes, (a) gallol, (b) catechols. Coordination requires deprotonation of the polyphenol ligands. Based on [201].

It was established for flavones and for the flavanone naringenin (81) that the binding metal sites are preferentially at the 5-hydroxyl and 4-oxo groups [202]. On the other hand, the study of Mladenka et al. [203] demonstrated that the most effective iron-binding site of flavonoids is 6,7-dihydroxy structure, present, for example, in baicalein (45). The simultaneous presence of 3-hydroxy-4-keto conformation, 2,3-double bond and the catecholic B ring were associated with significant iron chelation; however, the catecholic B ring did not play an essential role in more acidic conditions. Quercetin (111) and myricetin (114) that contain all mentioned structural requirements, had activity similar to baicalein (45) at the neutral conditions but were clearly less active in lower $\mathrm{pH}$. On the other hand, baicalein (45), additionally possessing the 6,7-dihydroxyl groups, was very efficient even in the acidic condition. The 5-hydroxy-4-keto configuration has only moderate activity at all $\mathrm{pH}$ conditions. It was also proved that isolated keto, hydroxyl, methoxyl groups or ortho methoxy-hydroxy groups were not associated with iron chelation at all.

Polyphenols also have strong binding interactions with $\mathrm{Cu}^{2+}$, and stability constants for $\mathrm{Cu}^{2+}$ catecholate complexes are even larger than for $\mathrm{Fe}^{2+}[201]$.

As bacteria contain various metalloenzymes, flavonoids by binding metal ions can inhibit their activity and lead to various metabolic disorders (enzyme inhibition, impairment of ion channel functions). Furthermore, the metabolic functions of the human gut microbiota that involve metalloenzymes may also be altered [204]. An enzyme methionine aminopeptidase (MetAP) carries out the removal of the initiator methionine residue from newly synthesized proteins, and this removal is critical for the activation, distribution and stability of many proteins. It was proved that the adjacent hydroxyl groups on the phenyl ring (catechol moiety) were essential for effective inhibition of the Fe (II)-a form of E. coli MetAP and growth inhibition of bacterial cells [205]. 
Polyphenols can also cause iron deficiency in the digestive tract, which will affect sensitive bacterial populations and change the composition of the intestinal microbiota. Oral bacterium Fusobacterium nucleatum is associated with colon cancer, causes erythrocytes lysis, and therefore releases hemoglobin, which provides an iron source to bacteria and other periodontopathogens, promoting their proliferation in periodontal pockets [206]. The tea polyphenols were proved to inhibit dose-dependently the hemolytic activity of F. nucleatum.

The virulence factors such as gelatinase, collagen-binding antigen, cytolysins, and proteases enhance colonization, survival and persistence of $E$. faecalis in the root canal. Treatment of E. faecalis with a sublethal concentration of EGCG (18) $(2.5 \mathrm{mg} / \mathrm{mL})$ significantly inhibited the expression of responsible genes (collagen adhesin (ace), cytolysins activator (cylA), gelatinase (gelE) and serine protease (sprE)) by $>75 \%$ compared to the untreated control [207]. The elastase, protease and pyocyanin production in P. aeruginosa were inhibited by curcumin (216) in a dose-dependent manner [179]. EGCG (18) caused the inhibition of glucose uptake by E. coli, which can suggest that EGCG inhibits the major function of porin proteins, namely the passive transport of small hydrophilic molecules such as glucose, leading to growth inhibition of E. coli [114].

\subsection{The Relationship between Polyphenols Structure and Antibacterial Activity}

The mechanism of inhibition by polyphenols may differ depending both on the structure of the polyphenolic compound and bacteria species. The amphipathic character of flavonoids plays a very important role as hydrophilic and hydrophobic moieties must be present together and well-spaced in these compounds [208].

Flavans with prenyl group at the A ring were potent antibacterial compounds against Staphylococcus aureus, and the number and position of prenyl groups on this ring influenced the activity [91].

The number of hydroxyl groups in the B ring in flavonols and flavones is associated with the antimicrobial activity against lactic acid bacteria (LAB). Myricetin (114) is a flavonol possessing three hydroxyl groups in the B ring as pyrogallol structure, whereas quercetin (111) and kaempferol (108) have one and two hydroxyl groups less in the B ring than in myricetin, respectively. Myricetin, as a pure compound, significantly inhibited the growth of all tested LAB that originated from the human gastrointestinal tract, as well as the Gram-positive Enterococcus faecalis and Bifidobacterium lactis, while quercetin (111) and kaempferol (108), with a more lipophilic nature, had no inhibitory impact on the above bacteria [47]. Flavone luteolin (49) has a structure similar to quercetin (111), but it lacks the $\mathrm{OH}$ group at position 3 in ring C. Luteolin (49) was bacteriostatic against some of the tested $\mathrm{LAB}$ as well as against E. faecalis and B. lactis, while other flavone apigenin (38), which has one hydroxyl group less in the $B$ ring had no such effects.

Baicalein (flavon) (45) and myricetin (flavonol) (114) show the most significant antibacterial effects among the tested flavonoids. Both have a pyrogallol structure, but baicalein in ring $\mathrm{A}(5,6,7-\mathrm{OH})$ and myricetin in ring $\mathrm{B}$. Results proved that the pyrogallol structure was an important element for the potent antibacterial activity for flavonoids [60]. Echeverria et al. [208] made the comparison between a flavone (planar) and flavanone (not planar) with similar lipophilicity and oxygenated substitution patterns in the A and B rings (e.g., pinocembrin (95) and 3-O-methylgalangin (113)) and showed that flavones have higher antibacterial activity. On the other hand, possessing at least one hydroxy group in the ring A (especially at position C-7) seems to be crucial for antibacterial activity of flavones, and an additional $\mathrm{OH}$ group in another position such as $\mathrm{C}-5$ and $\mathrm{C}-6$ can further increase the activity [91]. 
All the flavonols and flavanones with antibacterial activities had two hydroxyl substituents on C-5 and C-7 of ring A in common, such as quercetin (111), rutin (121), naringenin (81), and hesperetin (83) [60]. Moreover, the authors suggest that flavanones were more active than the corresponding flavones. For example, naringenin (81) showed antibacterial effects on all the tested bacteria, whereas apigenin (38) showed almost no effect. Such results indicate that the saturation of the $\mathrm{C} 2-\mathrm{C} 3$ double bond increased the antibacterial activity.

On the other side, Wu et al. [168] demonstrated that flavonoids were more effective E. coli inhibitors than isoflavonoids with relative activity being as follows: kaempferol (108) $>$ quercetin (111) $>$ chrysin (47) $>$ luteolin (49) $>$ baicalein (45) $>$ tangeretin (57) and daidzein (64) > genistin (68) > ononin (75) > puerarin (70). The only structural difference between quercetin (111) and luteolin (49) is that quercetin has a hydroxyl group at position 3 in the $\mathrm{C}$ ring, while luteolin has none. It means that the $3-\mathrm{OH}$ group is important to the activity of flavonoids against Gram-negative bacteria E. coli. Further analysis of structure-activity relationships revealed that the methylation of $\mathrm{OH}$ groups could decrease the antimicrobial activity of flavonols. It also has been shown a significant positive correlation between the antibacterial capacity of flavonoids and the membrane rigidification effect. A quantitative structure-activity relationship (QSAR) study revealed that the activity of the flavonoid compounds could be related to molecular hydrophobicity and charges on the $\mathrm{C}$ atom at position 3 [168].

The hydrophobic substituents such as prenyl groups, alkylamino chains, alkyl chains, and nitrogen or oxygen-containing heterocyclic moieties usually enhance the antibacterial activity for all the flavonoids [98]. It was concluded that hydroxyl groups on special sites are favorable for antibacterial activity, such as 5,7-dihydroxyl substitution for flavone and flavanone and $2^{\prime}$ or $4^{\prime}$ hydroxylation for chalcones. The hydroxyl group at position three on the $\mathrm{C}$ ring of flavone also increased the activity. However, the methylation of the hydroxyl groups generally decreased the activity. The lipophilicity of ring $\mathrm{A}$ is therefore of great importance for the activity of chalcones. In addition, hydroxy groups at $4^{\prime}, 4$, and 6 of $\mathrm{A}$ and $B$ rings increase the activity of chalcones [91].

The substitution of the flavonoid ring system with prenyl groups increases the lipophilicity of the molecule and results in a strong affinity to biological membranes. Prenylated flavonoids, i.e., featuring $C_{5}$ isoprenoid substituents, have a relatively narrow distribution in the plant kingdom and are constitutively expressed in plants, as compared with prenylated isoflavonoids, which are produced in response to an attack or damage [209]. Xanthohumol (145) is the main component (80-90\% of the total flavonoids) and is the most abundant prenylated chalcone in hops. It exerted high antimicrobial activity against Bacteroides fragilis, Clostridium perfringens and Clostridium difficile [210]. $\beta$-bitter acids (lupulones) were less effective, and the least effective against anaerobic pathogens were $\alpha$-bitter acids (humulones). Xanthohumol (145), naringenin (81), chalconaringenin (140) and 4hydroxy-4'-methoxychalcone inhibited the growth of S. aureus [211]. The presence of at least one hydroxyl group and especially at the C-4 position was crucial for the antibacterial activity against $S$. aureus. The lack of hydroxyl group or its replacement by a halogen atom $(-\mathrm{Cl},-\mathrm{Br})$, nitro group $\left(-\mathrm{NO}_{2}\right)$, ethoxy group $\left(-\mathrm{O}-\mathrm{CH}_{2} \mathrm{CH}_{3}\right)$, or aliphatic groups $\left(-\mathrm{CH}_{2} \mathrm{CH}_{3}\right),\left(-\mathrm{CH}_{3}\right)$ led to inactivation of the compounds. Prenylated flavonoids, such as artocarpin (62) and isobavachalcone (148), exhibited strong antibacterial activity towards B. cereus, E. coli, and Pseudomonas putida or only Gram-positive species, respectively [212]. It has been demonstrated that any isoflavonoid modification that results in the absence or cyclization of the prenyl group decreases the antibacterial activity of the compound. 
Campos et al. [213] had demonstrated that hydroxycinnamic acids (p-coumaric (166), caffeic (167) and ferulic (168) acids) induced greater potassium and phosphate leakage than hydroxybenzoic acids (protocatechuic (157), gallic (159), and vanillic (161) acids) across the membranes of Oenococcus oeni and Lactobacillus hilgardii.

Flavonoids can occur in two forms: free as "aglycons" or in the form of "glycosides", where an aglycon is combined with sugar moiety ("glycone"). Flavonoid glycosides occur in a diet generally in ring $\mathrm{A}$ or $\mathrm{C}$ as O-glycosides, and a corresponding substitution in ring $\mathrm{A}$ has a far greater impact on activity [180]. Aglycones of most flavonoids are more hydrophobic than their glycosides [91]. Both the number of glycosylation as well as the position and structure of saccharides are of great significance for the antioxidant, antibacterial, anticancer, anti-inflammatory and antidiabetic activity of a compound [180]. It has been postulated that glycosylation of flavonoids enhances antimicrobial activity, but their antioxidant, anti-inflammatory, anticancer and cardioprotective properties decreased [180]. However, it seems that the impact of glycosylation on antibacterial activity depends on the flavonoid class as well as the position at which sugar moiety is added. The results of DudaChodak [63] demonstrated that flavonoid aglycones, but not their glycosides, may inhibit the growth of some intestinal bacteria. In this study, rutin (quercetin 3-O-rutinoside) (121) had no inhibitory influence on the intestinal bacteria analyzed, and even slight stimulation of the growth of Lactobacillus spp. was observed. In contrast, its aglycone quercetin (111) exerted a dose-depended inhibitory effect on intestinal bacteria (except on Bifidobacterium catenulatum), and this was especially strong on Ruminococcus gauvreauii, Bacteroides galacturonicus and Lactobacillus spp. growth. The same was true for flavanones. Naringin (85) and hesperidin (flavanone 7-O-glycosides) (86) had no impact, but their aglycones (naringenin (81) and hesperetin (83), respectively) inhibited the growth of almost all bacteria analyzed. A similar result, showing that 7-O-glycosylation of flavanones (naringenin and hesperetin) and flavones (baicalein (45)) decreased the antimicrobial activity against E. coli, S. aureus, S. typhimurium, Enterobacter sakazakii and Vibrio parahemolyticus were demonstrated by Xie et al. [60]. The opposite results were obtained by Adamczak et al. [67]; flavonol aglycones kaempferol (108) and quercetin (111) displayed a moderate activity only against $E$. coli, while quercetin 3-O-rutinoside (121) demonstrated inhibitory influence on all strains tested.

Docking results have revealed that the substitution of galloyl or glycosides at position 3 of heterocyclic pyrane ring in flavonoids enhanced the binding affinity to three targets, i.e., fumarate reductase flavoprotein subunit (FrdA), dihydroorotate dehydrogenase (PyrD) and NADH-dependent enoyl-ACP reductase (FabI). Such a phenomenon was observed for flavonoids and their glycosides; quercetin 3-rhamnoside (123) and myricetin 3-galactoside (127) were more potent inhibitors to PyrD, FabI, and DYR than quercetin (111) and myricetin (114), respectively [121]. One of the most potent bacterial inhibitors among flavan-3-ol is EGCG (18), possessing both pyrogallol and galloyl structures in a moiety. EGCG is a stronger inhibitor of pathogens than other flavan-3-ols having fewer or no galloyl groups and pyrogallols. Antibacterial activity of tea flavan-3-ols was in decreasing order EGCG (18) > ECG (17) > EC (12) $\geq$ theaflavins $\geq$ gallic acid (159) > EGC (14) against $S$. aureus and P. aeruginosa [214]. The importance of these free galloyl groups for antibacterial activity was also proved in the study of Puljula et al. [215]. Salicarinin A (213) and rugosin D (211) possess many free galloyl groups, inhibited the growth of $S$. aureus completely at a $0.5 \mathrm{mM}$ concentration. Other ellagitannins, with lower numbers of galloyl or pyrogallol substituents, were less effective.

\subsection{The Impact of Food Matrix on Polyphenol Activity}

There are large discrepancies between the results, i.e., in some studies, it is shown that a given polyphenol class inhibits bacteria, and in others, it does not affect or even stimulates their growth. This may be due to the structure of the used polyphenol, including the molecule size, number and position of hydroxyl groups, their substitutions, the presence/absence and position of glycosylation, hydrophobicity and hydrophilicity of the moiety, and others. The observed discrepancies could also be attributed to the 
changes in the structure of polyphenols when dissolved in various solvents (water, ethanol, methanol, organic solvents and their mixtures) or after their addition to the medium with bacteria. It is because polyphenols do not dissolve in every solvent, and they can precipitate (affecting the actual concentration of the tested compound) after changing the solvent [216-218]. Polyphenols also have different rates of diffusion depending on the medium and environmental conditions.

Moreover, the type of microorganism (Gram-positive, Gram-negative, anaerobic or aerobic or microaerophile, etc.) also has a significant impact when the activity of polyphenols is assessed. It should be borne in mind that used assays, analytical methods, as well as conditions and incubation time, strains of microorganisms, inoculum size, and even concentrations of tested polyphenol may differ between scientific laboratories. There are also big differences between results when the impact of polyphenol on intestinal bacteria is assessed using pure polyphenols solution, plant extract containing polyphenols mixture of whole food in which polyphenols are bound to a food matrix. When in vitro studies are performed, usually pure cultures of bacteria are tested, and interactions with other members of gut microbiota, the impact of human digestive enzymes, the host health, or interactions with other components of a meal are not taken into account. However, all mentioned factors are important for the final results.

It is obvious that the results obtained from in vivo and in vitro studies should not be compared directly. When in vivo studies are conducted, the scientists introduce an ingredient into the diet and analyze changes in the abundance or composition of the gut microbiota, usually focusing on the effect on the entire bacterial population rather than on individual species. In such experiments, many factors contribute to the final results: the chemical composition of the food matrix, the bioaccessibility of polyphenols, their bioavailability, the interactions between particular bacterial strains present in the gut, the health of consumers and many more. Depending on the polyphenols present in the plant, different effects can be achieved because each polyphenol reacts differently with the components of plant tissues. Moreover, each plant differs in its composition. Tarko and Duda-Chodak [219] proved the differences between the bioaccessibility of polyphenolic compounds originating directly from fruits (black chokeberry, elderberry, hawthorn, Cornelian cherry, apple and Japanese quince) and that of those present in the fruit extracts during their digestion conducted in a simulated human gut. They proved significant differences in polyphenols bioavailability that resulted from their interactions with food matrixes. It was caused by polyphenols bounding to the matrix, which is known to modify the polyphenols extractability and susceptibility to digestive enzymes and bacterial metabolism [220]. The interaction with the food matrix also modulates the impact of polyphenols on bacteria inhabiting the colon.

During in vivo studies, it should also be considered that some polyphenols present in a diet are absorbed before they reach the colon, and hence, do not influence the microbiota. For example, quercetin glycosides can undergo partial hydrolysis by pepsin during their passage through the stomach [221], and the released aglycone quercetin (111) may be then absorbed in the stomach and secreted in the bile. Glycosides of other flavonoids can be hydrolyzed to aglycones in the small intestine due to the activity of human digestive enzymes, such as lactase phlorizin hydrolase and cytosolic $\beta$-glucosidase. It refers to the glycosides that contain glucose, xylose or galactose; as mentioned, humans enzymes e have an affinity for those sugars. It means that only polyphenols resistant to the action of human enzymes are not absorbed in the small intestine and pass to the colon, where they may exert their inhibitory or stimulatory activity towards microbiota, or they may be cleaved by bacterial enzymes to produce derivatives and metabolites of various activity. 
Another important issue is the diversity of the chemical composition of plant tissues. For example, chokeberries and apples contain much higher amounts of pectin than the elderberry fruit, which resulted in small amounts of polyphenols in the sediment obtained after elderberry digestion [219]. Further, fruits of the Cornelian cherry are rich in pectin and also in low-molecular-weight phenolic acids that can firmly bind with pectin and so pass to the colon intact [219]. However, the differences between the food matrix could also be related to the cell wall composition of the fruit, resulting in an observed different bioaccessibility of polyphenols present in apples, chokeberries and Japanese fruit [219]. The flesh of Japanese quince fruits contains much pectin, whereas, in the cell walls, cellulose dominates [222]. On the other hand, apples are rich both in pectin and cellulose, but they also contain lignin [223]. The presence of lignins was believed to reduce the proanthocyanidin adsorption in skin cell walls when compared to that of the flesh cell walls [224], causing that unbound proanthocyanidins were more sensitive to enzymatic digestion and acidic $\mathrm{pH}$ in the stomach.

Proanthocyanidins are of neutral charge, so they are easily absorbed by the cell wall polysaccharides, while anthocyanins-which are positively charged molecules-could rather selectively bind to a negatively charged pectin [225]. The ratio of bound to free proanthocyanidins depends mainly on their concentration and degree of polymerization. The susceptibility of anthocyanins, anthocyanidins, and proanthocyanidins to digestion can also depend both on the structure of the cell wall polysaccharide network in fruits and the structure of pectin. Voragen et al. [226] have demonstrated that $47 \%$ of the structural elements of pectin in apples are neutral side chains, while in bilberry or black currant, more than $60 \%$ are homogalacturonan]. Yet another structure was reported for Japanese quince pectin, which consisted of four different populations, mainly arabinans and highly methylated homogalacturonans [227]. The simultaneous presence of pectin, cellulose and hemicellulose in food favors the bounding of procyanidins and anthocyanins and protects them against digestive enzyme activity. In consequence, they are not released from the food matrix at this digestion stage. Moreover, during proanthocyanidins degradation, free (+)-catechin (7) could be released, which can bind effectively to cellulose [228].

Tarko and Duda-Chodak [219] also revealed that procyanidin B1 in hawthorn was almost insensitive to digestive enzymes, and probably the saponins, which presence in the hawthorn fruit is characteristic, had such a protective impact. Saponins are poorly absorbed in the intestine mainly due to their unfavorable physicochemical traits, such as large molecular mass $(>500 \mathrm{Da})$, high hydrogen binding capacity $(>12)$, and high molecular flexibility $(>10)$.

Concluding, the presence/absence of the food matrix, as well as its chemical composition, can affect the bioaccessibility, bioavailability and biological activity of polyphenols and their bidirectional interactions with the intestinal microbiota.

\section{Polyphenols Biotransformation by Intestinal Bacteria}

It is believed that only undigested and unabsorbed polyphenols can reach the large intestine and exert their impact on bacteria inhabiting there. As described above, many of the polyphenols can inhibit the growth of microbiota residing in the colon. However, some of the phenolic compounds act as prebiotics and stimulate the growth of particular species. Hence, polyphenols modulate the composition of human gut microbiota. On the other hand, only unabsorbed polyphenols can undergo biotransformation during the activity of bacterial enzymes. Products of bacterial metabolism can further be metabolized to various derivatives and absorbed into the human body [15]. 
Due to the great diversity of species forming the intestinal microbiota in different individuals, the profile of polyphenol metabolites that are generated and their final effect on the body are highly variable within the human population. The dietary polyphenols can be metabolized by various pathways leading to the formation of a number of different phenolic derivatives characterized by small and low molecular weight as well as a modified biological activity. For example, aglycones and oligomers are released by microbial glycosidases and esterases, which enhances their absorption [229]. On the other side, released aglycones can inhibit intestinal microbiota growth and activity, preventing the metabolism of other polyphenolic compounds from the diet. Some reactions of bacterial metabolism really improve the bioavailability and activity of polyphenolic compounds. In many situations, only the product of bacterial metabolism of a polyphenol can be absorbed and exert a beneficial impact in humans. However, other bacterial metabolites may be harmful to human cells or other members of the microbiota. Hence, apart from interindividual variation in a daily intake of polyphenols, interindividual differences in the composition of the human microbiota may lead to differences in bioavailability and bioefficiency of polyphenols and their metabolites and cause a different impact on host health [230-232].

The identified pathways of bacterial metabolism of the most important groups of polyphenolic compounds are presented below.

\subsection{Isoflavonoids}

One of the best examples of how significant the role is of the intestinal microbiota in polyphenols impact on human health are the nonsteroidal estrogens. A lack of particular species within the microbiota may cause that isoflavonoid cannot exert its expected effect even though it has been consumed. Isoflavonoids, including daidzein, genistein, and glycitein, are present in soybeans, but they are rather inactive. Only their metabolites, e.g., $\mathrm{S}$-equol or O-desmethylangolensin (O-DMA), are able to exert their pro-healthy effects. Equol, because of its high binding affinity to the estrogen receptor (S-equol preferentially activates estrogen receptor ER $\beta$ ), can alleviate the symptoms of menopause. Moreover, the antiandrogenic activity and inhibition of osteoclast formation, anticancer activities and anti-inflammatory effects have been observed [6]. It was demonstrated that equol has about 100 times higher estrogenic activity than the daidzein itself [232]. Although O-DMA did not exhibit agonistic or antagonistic activities toward the glucocorticoid receptor (TRa1, or TRb1) and has very weak agonistic activities against $E R \alpha$ and $E R \beta$, it can influence the growth of cancer cells, osteoclast formation, scavenging superoxide radical or exert leptin secretion inhibitory activity [233]. Bacteria strains producing small to moderate amounts of dihydrodaidzein and/or O-DMA from daidzein and dihydrogenistein from genistein are recognized more often than equol producers [234]. O-DMA is found in $80-90 \%$ of the human population, whereas equol is found in only $30-50 \%$ of the population [235].

The possible metabolic pathways of daidzin and genistin degradation by bacteria are presented in Figures 4 and 5, respectively. 


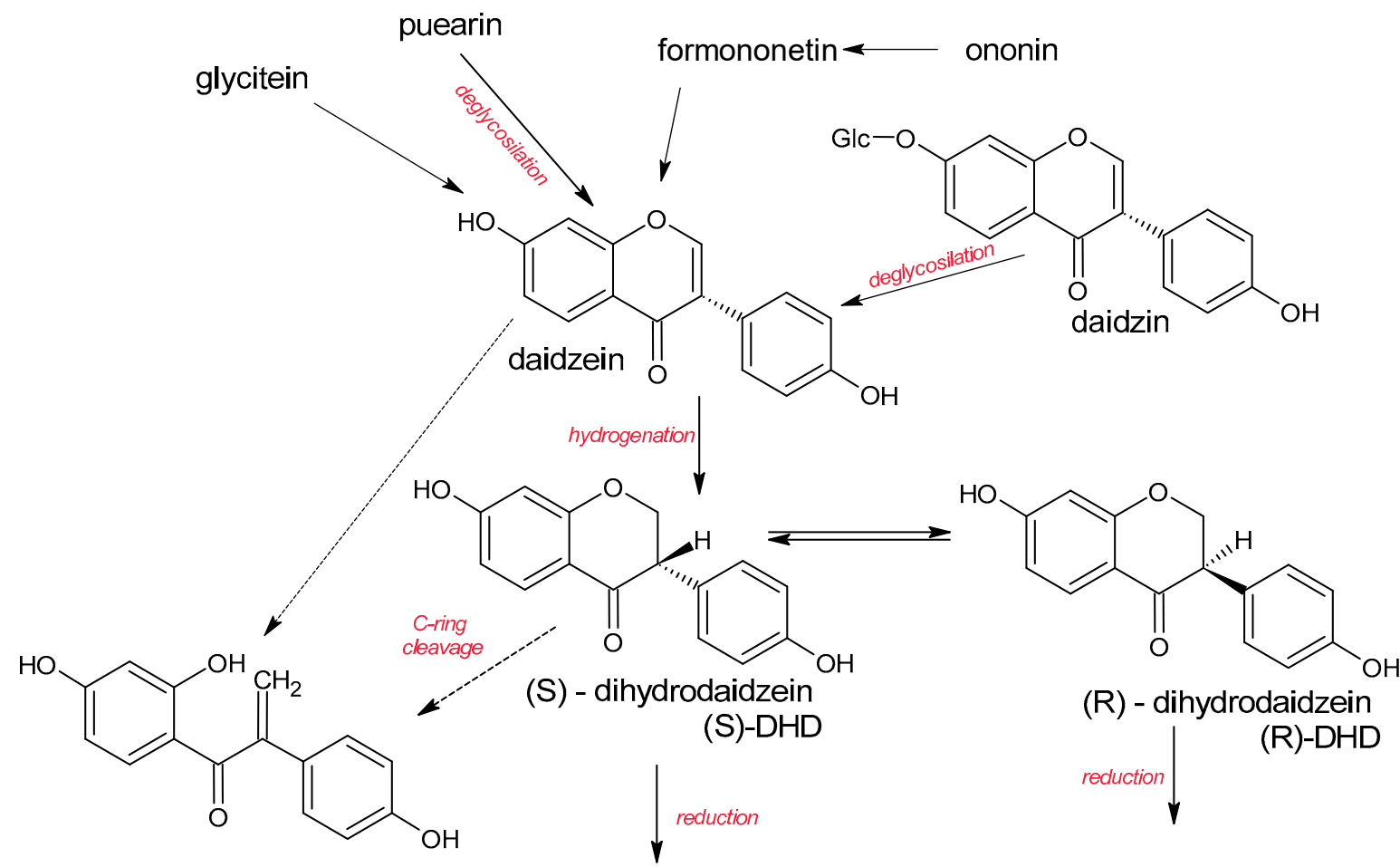

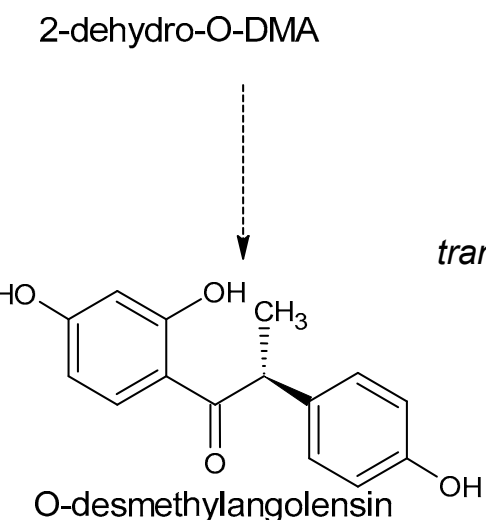<smiles>Oc1ccc([C@H]2COc3cc(O)ccc3[C@@H]2O)c(O)c1</smiles><smiles>Oc1ccc([C@@H]2COc3cc(O)ccc3[C@@H]2O)cc1</smiles>
cis-tetrahydrodaidzein cis-THD

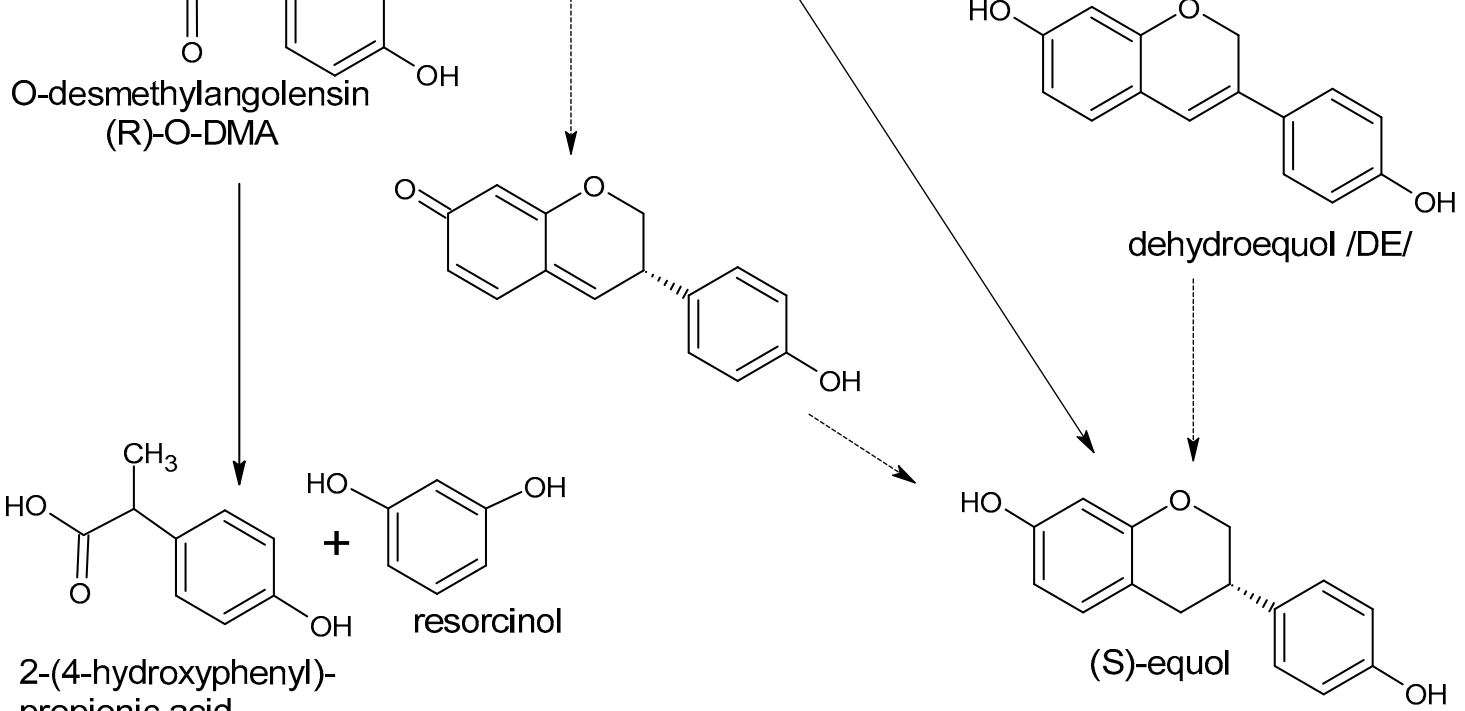

Figure 4. Possible pathways of microbial metabolism of daidzin and daidzein. Based on [236-243]. The dashed arrows indicate hypothesized reactions of microbiological degradation that were observed in vitro but were not reported in vivo. 


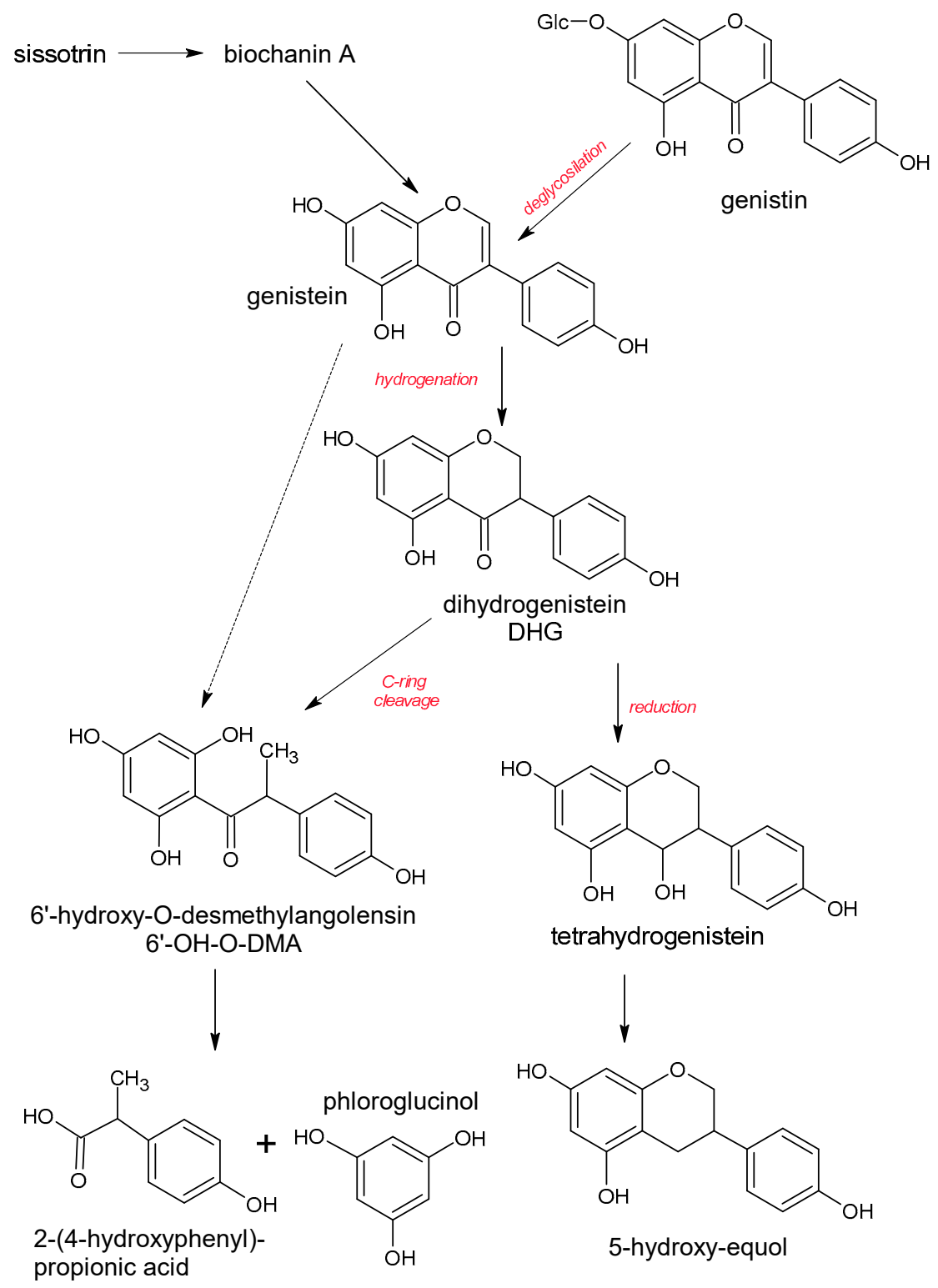

Figure 5. Possible pathways of microbial metabolism of genistin and genistein. Based on [236-243]. The dashed arrows indicate hypothesized pathways of microbiological degradation that were observed in vitro but were not reported in vivo.

The isoflavones biotransformation generally starts with glycoside hydrolysis to release the aglycon. For example, daidzin (daidzein 7-O-glycoside) can be hydrolyzed to daidzein by Eubacterium ramulus [244]. Then, the hydrogenation of the double bond between C2 and $\mathrm{C} 3$ in ring $\mathrm{C}$ of daidzein (DZN) and genistein $(\mathrm{GN})$ generates dihydroisoflavones such as dihydrodaidzein (DHD) and dihydrogenistein (DHG), respectively [236]. Dihydroisoflavones are further subjected to bacterial metabolism and can undergo: (a) the reductive pathway leading to equol formation, (b) the cleavage of the $\mathrm{C}$ ring, followed by the fission of the molecules into two moieties. Equol is generally produced from daidzein through the reductive metabolism, through dihydrodaidzein (DHD), tetrahydrodaidzein (cis-THD and/or trans-THD) and dehydroequol (DE) as intermediates; however, some equol-producing bacteria have also been shown to convert the genistein into dihydrogenistein and finally to 5 -hydroxy-equol $[245,246]$. Clostridium sp. strain HGH136 cleaved the C-ring of daidzein to produce O-desmethylangolensin, probably via 2-dehydro-Odemethylangolensin [241]. O-DMA may be further partially metabolized to resorcinol and 2-(4-hydroxyphenyl) propionic acid [233]. 
Daidzein was in part degraded by E. ramulus to O-desmethylangolensin, while genistein was completely degraded via 6'-hydroxy-O-desmethylangolensin to 2-(4-hydroxyphenyl)propionic acid [243]. It means that the $\mathrm{OH}$ group in position $6^{\prime}$ of O-DMA was crucial for its further degradation. It is interesting that dihydrogenistein was neither observed as an intermediate in this transformation nor converted itself by growing cells of E. ramulus. Genistein-7-O-glucoside was partially transformed by way of genistein to the product 2-(4-hydroxyphenyl)-propionic acid.

E. ramulus, strain CG19-1 is capable of cleaving both 6'-hydroxy-O-desmethylangolensin and $\mathrm{O}$-desmethylangolensin to phloroglucinol and resorcinol, respectively; and 2-(4hydroxyphenyl) propionic acid was additionally formed from both O-DMA and 6'-OH-ODMA [239].

A different metabolic pathway was revealed by Murota et al. [235]. They reported that the metabolites of genistein and glycitein that are primarily found in human urine were dihydrogenistein, 6'-OH-O-DMA, 2-(4-hydroxyphenyl)-propionic acid and phloroglucinol for genistein, while dihydroglycitein, 5'-methoxy-O-DMA and 6-methoxy-equol for glycitein. Moreover, strain CG19-1 cleaved both O-desmethylangolensin and 6'-hydroxyO-desmethylangolensin to yield 2-(4-dihydroxyphenyl) propionic acid. The corresponding cleavage product, resorcinol, was only observed for O-desmethylangolensin.

According to Rossi et al. [242], the metabolites arising from glycitein include dihydroglycitein, which can be further O-demethylated to 6,7, $4^{\prime}$-trihydroxyisoflavone (proved in vitro for Eubacterium limosum) and reduced to dihydro-6,7,4'-trihydroxyisoflavone, and further reduced to 6-hydroxyequol or cleaved to 5 -hydroxy-O-desmethylangolensin. The other pathway of dihydroglycitein degradation was through the C-ring cleavage producing 5'-O-methoxy-O-desmethylangolensin or reduction to 6-methoxy-equol (Figure 6).

Slackia isoflavoniconvertens is capable of contributing to the bioactivation of daidzein and genistein by the formation of equol and 5-hydroxy-equol, respectively [246].

It should be underlined that some bacteria can produce equol from either daidzein or its glycoside daidzin, but some cannot produce equol unless several other species of bacteria metabolize daidzin to aglycone daidzein and daidzein to DHD or other derivatives that are also present [235]. For example, Clostridium sp. strain HGH6 and Lactobacillus sp. Niu-O16 can reduce daidzein to dihydrodaidzein but did not convert dihydrodaidzein to equol [247]. On the other hand, Eggerthella sp. Julong 732 is capable of converting dihydrodaidzein, but not daidzein, to equol [238,247]. Eggerthella sp. Strain YY7918 converted substrates daidzein and dihydrodaidzein into S-equol but did not convert daidzin, glycitein, genistein, or formononetin into it [248]. Strain TM-40 (93\% of homology with Coprobacillus catenaformis) isolated by Tamura et al. [249] produced dihydrodaidzein from both daidzein and daidzin. Decroos et al. [240] isolated from human feces a stable mixed microbial culture (Enterococcus faecium strain EPI1, Lactobacillus mucosae strain EPI2, Finegoldia magna strain EPI3 and an as yet undescribed species related to Veillonella sp.) that was able to covert daidzein into equol.

Among intestinal bacteria that were proved to metabolize the soya isoflavone daidzein and genistein to equol, DHD and/or O-DMA are Slackia equolifaciens (DZN to equol) [250], Slackia isoflavoniconvertens, Adlercreutzia equolifaciens, Asaccharobacter celatus, Enterorhabdus mucosicola (DZN to equol), Peptoniphilus gorbachii (DZN and GN to equol and O-DMA), Gordonibacter urolithinfaciens (DZN to O-DMA), some strains of Eggerthella lenta (DZN and GN to O-DMA), Enterococcus lactis (to O-DMA), some strains of Bifidobacterium adolescentis (DZN and GN to O-DMA), B. animalis (DZN to O-DMA) and B. longum (DZN and GN to O-DMA), some members of Coriobacteriaceae, e.g., Collinsella massiliensis (DZN and GN to O-DMA) and C. aerofaciens (DZN to O-DMA) [234], Eggertella strain Julong 732 (DHD via THD to equol) [238], Lactococcus garvieae strain 20-92 [251], Eubacterium ramulus Julong 601 (DZN to O-DMA, GN to 2-(4-hydroxyphenyl) propionic acid) [252], Clostridium sp. HGH 136 (DZN to DHD) [241] and HGH6 (DZN do DHD, GN to DHG), and E. coli HGH21 (DZN to DHD and GN to DHG) [253]. 


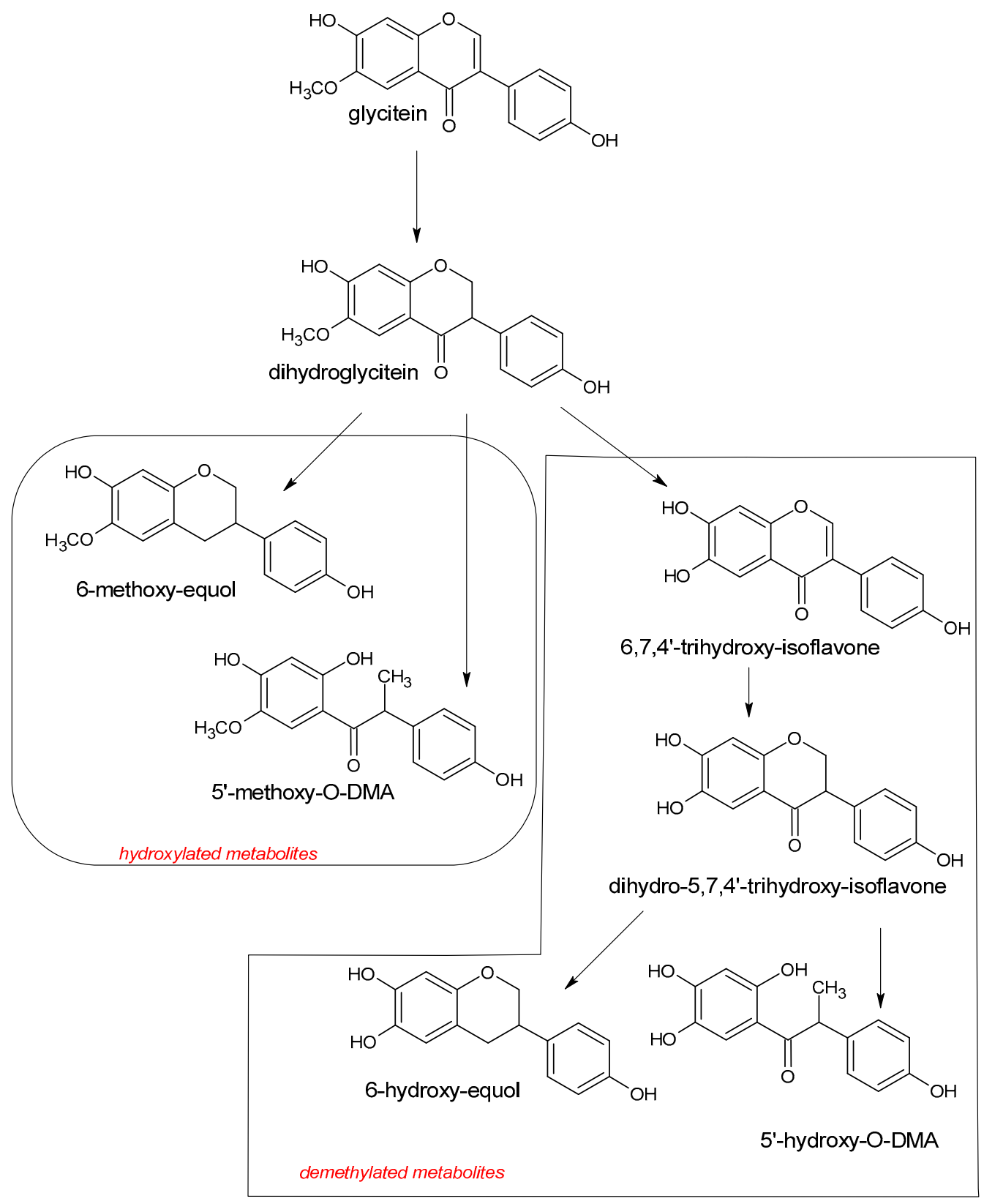

Figure 6. The pathways of bacterial metabolism of glycitin. Based on $[237,242]$.

Puerarin is a daidzein 8-C-glucoside and was reported to be metabolized to daidzein by human intestinal flora such as E. ramulus CG 19-1 [239] or intestinal strain PUE, converting puerarin to daidzein by cleaving a C-glucosyl bond [254]. Formononetin and biochanin A are the principal isoflavones of red clover (and as a consequence, equol is present in cow milk) and can be consumed in the form of dietary supplements. Hur et al. [255] demonstrated that Eubacterium limosum is able to produce daidzein and genistein from formononetin and biochanin A, respectively. It means that due to bacterial metabolism, more potent phytoestrogens have been formed in the colon, as the estrogenic potencies of the mentioned compound for both estrogen receptors $E R \alpha$ and $E R \beta$ showed the affinities in the order of genistein $>$ daidzein $>$ biochanin $A>$ formononetin. In the urine samples of volunteers consuming formononetin and biochanin A, other metabolites were also identified, such as dihydroformononetin and angolensin for formononetin and dihydrobiochanin A and 6'-hydroxyangolensin for biochanin A [256] (Figure 7). 
Antioxidants 2021, 10, 188

41 of 70

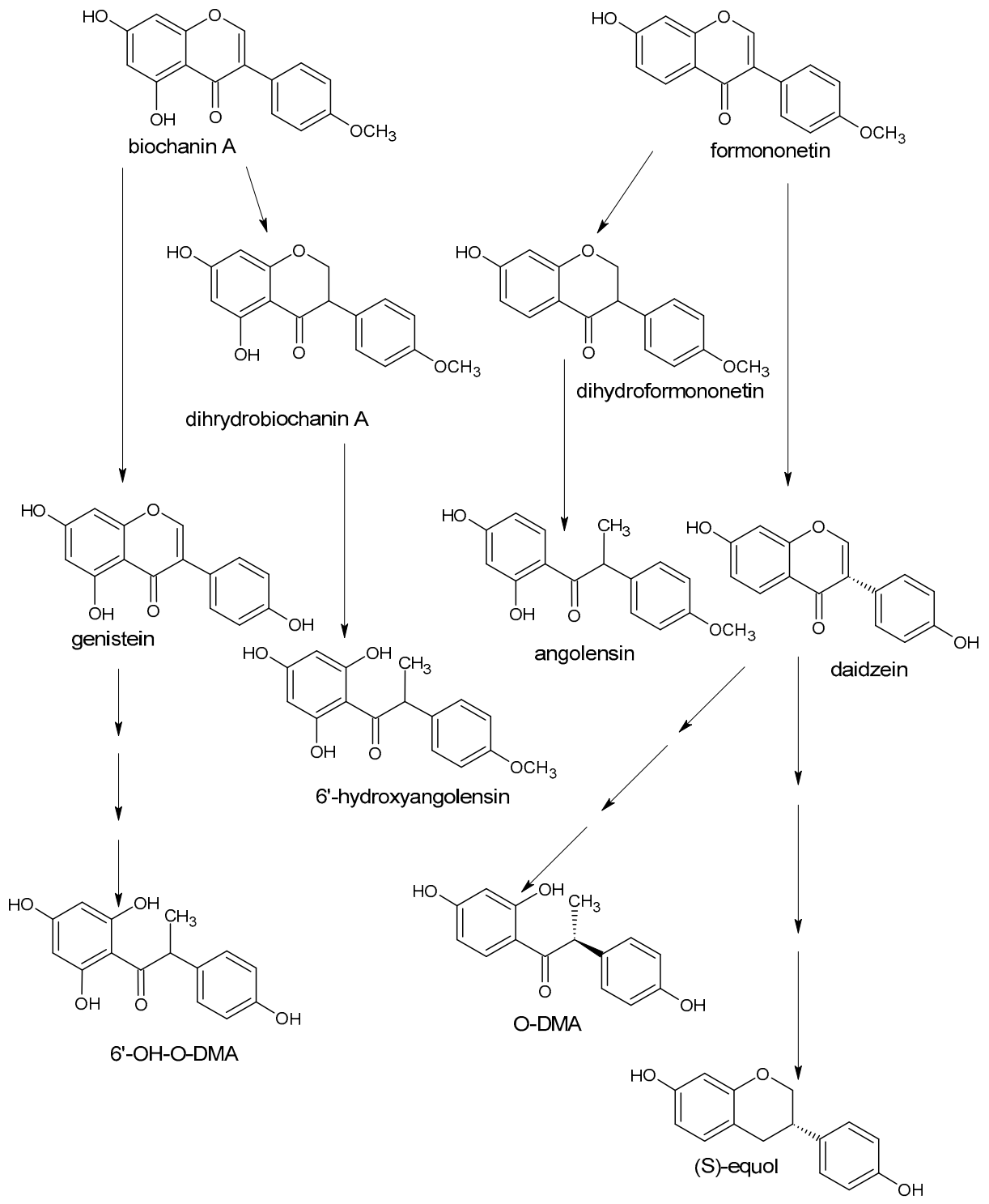

Figure 7. The human metabolism of formononetin and biochanin A. Based on $[16,255,256]$.

5.2. Other Phytoestrogens

In addition to soy isoflavonoids, there are other ligands for estrogen receptors that are produced by intestinal microbiota, such as enterolactone, enterodiol, urolithins and 8-prenylnaringenin. Enterolactone and enterodiol are derivatives of plant lignins from sesame seed or flaxseed. It was proved at concentrations that can be achieved with high consumption of products rich in lignins, both, but enterolactone to a lesser extent can potently activate human estrogen receptors ER $\alpha$ and ER $\beta$ [257]. The bacterial transformation of lignins into phytoestrogens (Figure 8) was carried out mainly by Peptostreptococcus and Eubacterium species and included their demethylation and dihydroxylation, leading to enterolactone production [258]. Enterolactone can further be converted into enterodiol, and various studies proved that both the mentioned mammalian lignins are produced by human colonic microbiota from dietary precursors. Production of enterodiol is about 2000 times more efficient, meaning that the enterodiol-producing bacteria are dominant in the human gut. 


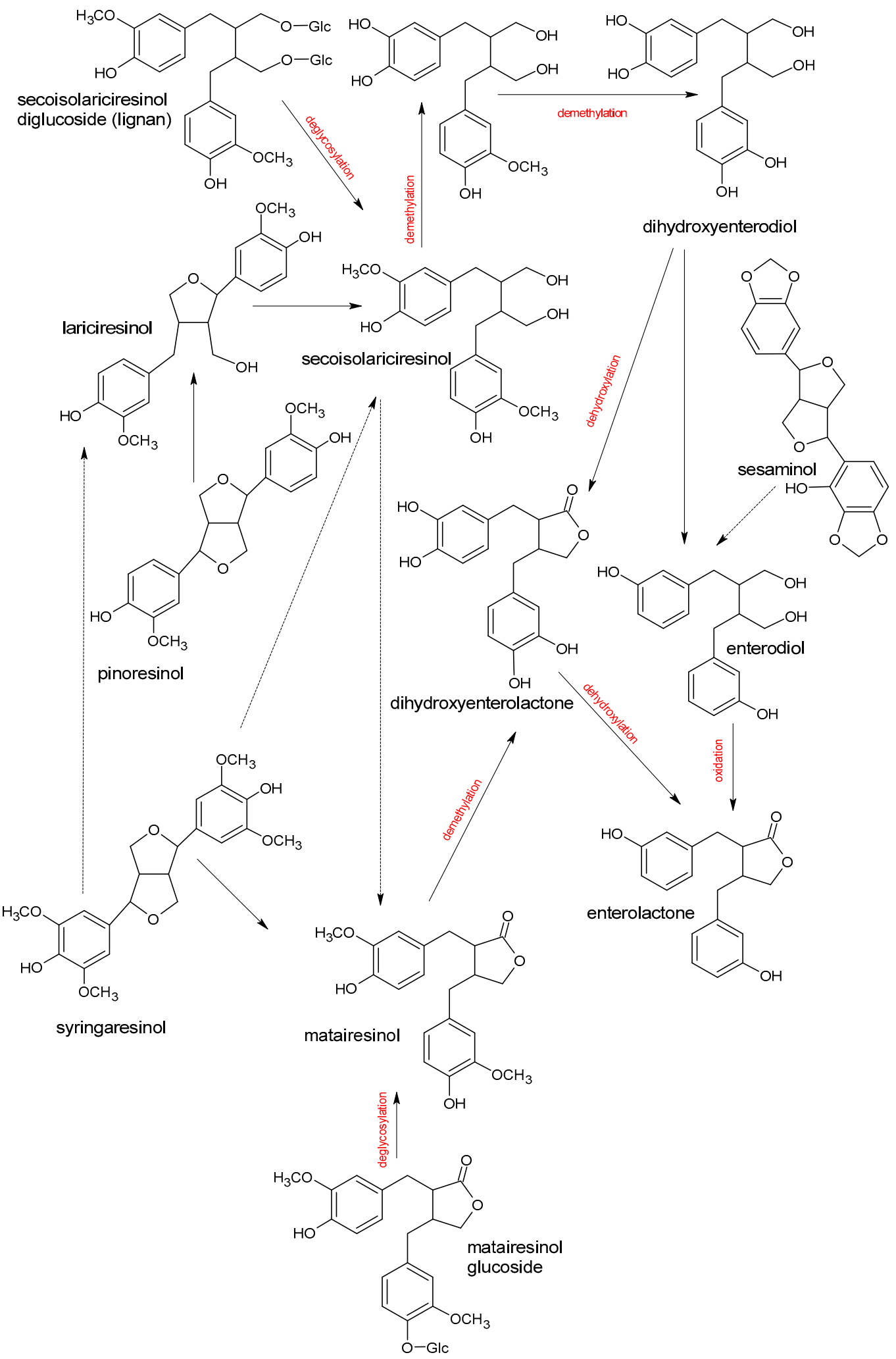

Figure 8. Lignans metabolism by gut microbiota. Based on [12,237,258-261]. The dashed arrows indicate hypothesized or multistep process.

The main bacteria converting lignans to enterolactone and enterodiol are Peptostreptococcus sp. SDG-1 and Eubacterium sp. SDG-2 [262], Bacteroides distasonis, B. fragilis, B. ovatus, Eubacterium callanderi, Eubacterium limosum, Clostridium cocleatum, Clostridium scindens, Eggerthella lenta, Butyribacterium methylotrophicum, Butyribacterium pseudocatenulatum, Bifi- 
dobacterium longum, B > breve, B. catenulatum, B. pseudocateunaltum, Enterococcus faecalis, $R u$ minococcus sp. END-1 [261], Clostridium saccharogumia and Lactonifactor longoviformis [263]. Two organisms able to demethylate and dehydroxylate secoisolariciresinol were isolated from human feces. Based on 16S rRNA gene sequence analyses, they were named Peptostreptococcus productus SECO-Mt75m3 and Eggerthella lenta SECO-Mt75m2 [264]. It was demonstrated both in vivo and in vitro that the major metabolite of sesamin in humans is enterolactone [265]. The intestinal pathways of enterolactone and enterodiol production from lignan are presented in Figure 8.

Ellagitannins (ELT) are one of the main groups of hydrolyzable tannins that are characterized by high antioxidant activity. They are common in some fruits, such as pomegranates, black raspberries, raspberries and strawberries, as well as in walnuts and almonds. Chemically they are different esters of hexahydroxydiphenic acid (HHDP) and a polyol, usually glucose or quinic acid [266]. According to the number of HHDP groups linked to the sugar moiety, ellagitannins can be classified into monomeric, oligomeric, and polymeric ELT. The main ellagitannins identified in foods are punicalagin (Figure 9), sanguiin H-6 (dimer of casuarictin) (212), lambertianin C (trimer of casuarictin) (214), pedunculagin, castalagin (209), casuarictin (210) and potentillin. Because of their size (634 Da for sanguiin H4 to up to 3740 Da for lambertianin D), these molecules are characterized by very low bioavailability and are not absorbed in the gastrointestinal tract until they are metabolized by gut bacteria. Intact ellagitannins and a product of their acidic or basic hydrolysis—ellagic acid (Figure 9), reach the distal part of the gastrointestinal tract where they are transformed by intestinal microbiota into dibenzopyran-6-one derivatives, known as urolithins, that are much better absorbed [267].

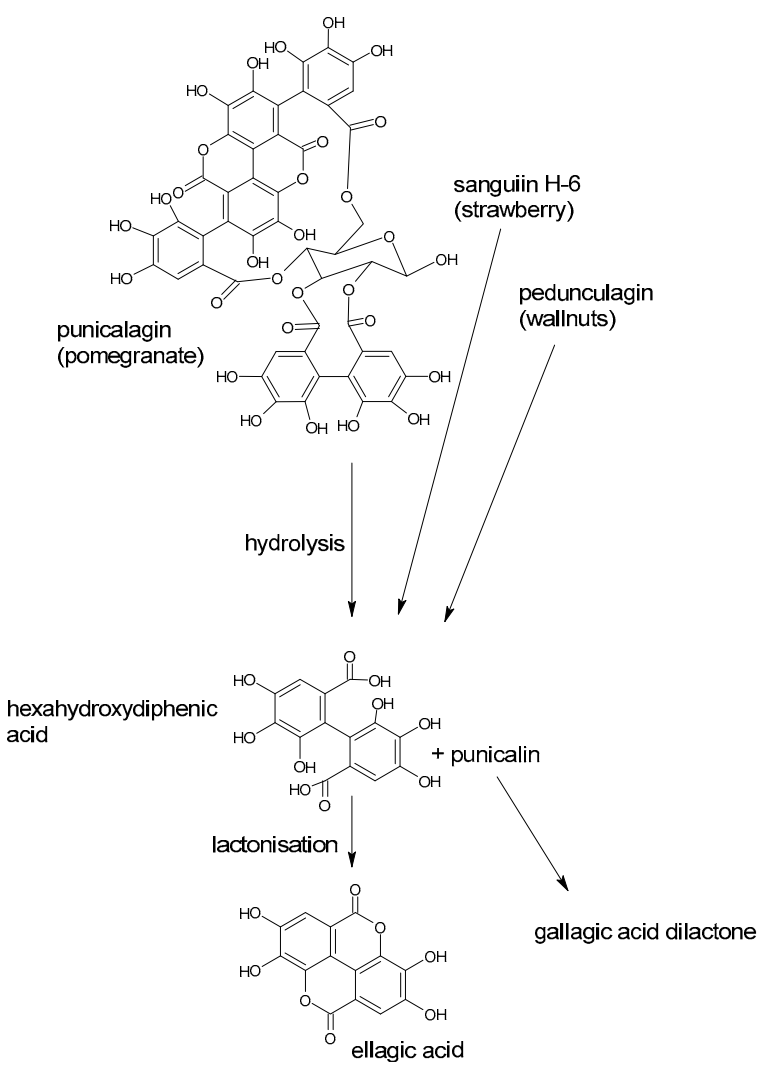

Figure 9. Degradation of ellagitannins to ellagic acid. Based on [268].

The generic name of urolithins includes different hydroxylated $6 \mathrm{H}$-dibenzo[b,d] pyran6-one derivatives. The bacterial transformation includes reduction of one of the two lactone groups followed by decarboxylation and sequential dehydroxylation involving a step-bystep reduction to tetrahydroxy (urolithin D), trihydroxy (urolithin C), dihydroxy (urolithin 
A and isourolithin A), and monohydroxy dibenzopyranones (urolithin B). The pathway of bacterial metabolism is presented in Figure 10. Bacteria able to catalyze the biotransformation of ellagitannins to urolithins are Gordonibacter urolithinfaciens and G. pamelaeae that belong to the family Coriobacteriaceae $[269,270]$ and Ellagibacter isourolithinifaciens from Eggerthellaceae [271].
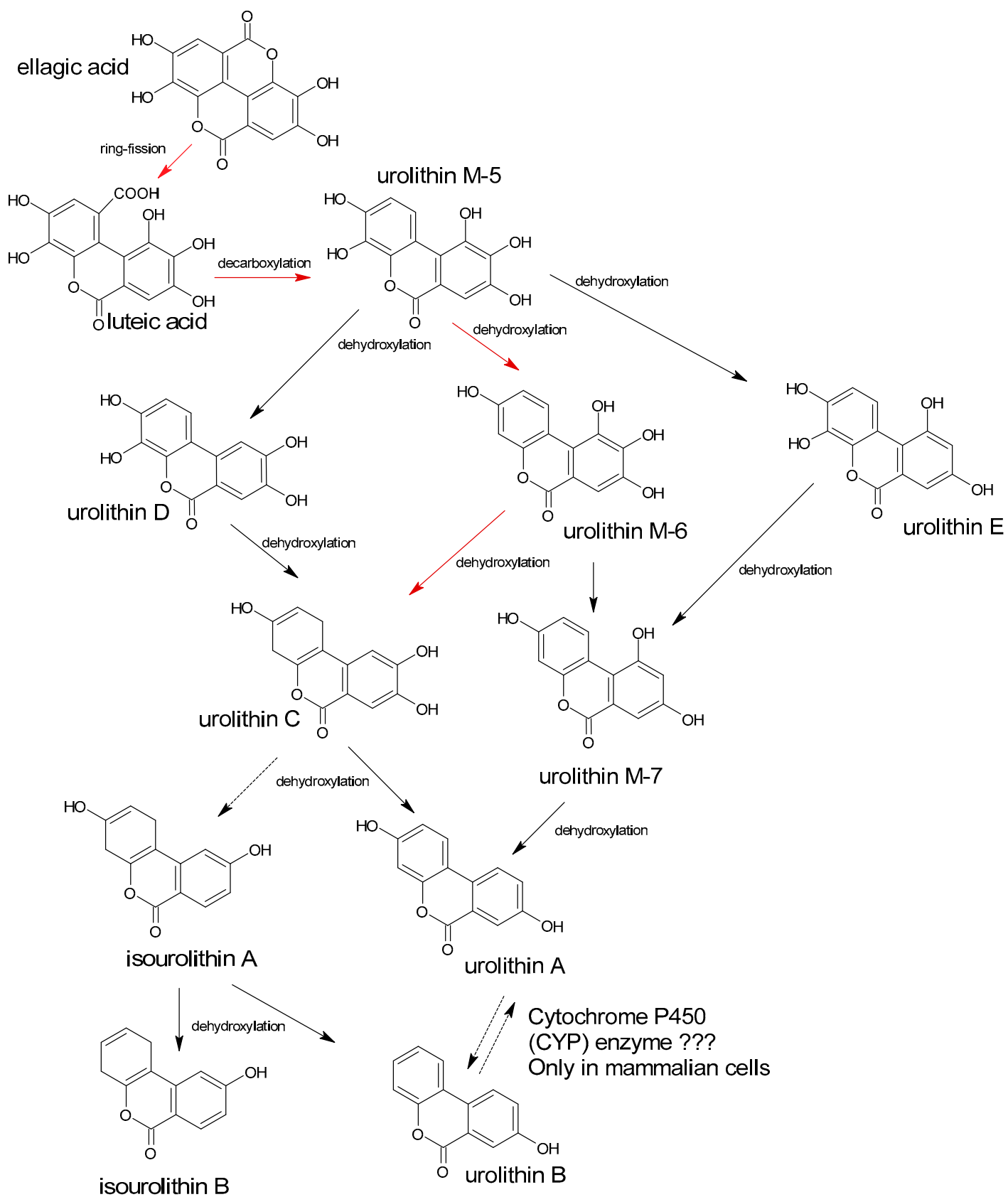

Figure 10. The bacterial metabolism of ellagic acid to urolithins and derivatives. The red arrows represent the pathways reported in Gordonibacter urolithinfaciens and G. pamelaeae. Based on [272-274].

Although urolithins are characterized by lower antioxidant activity than ellagitannins, they circulate in the plasma as glucuronide and sulfate conjugate and display benefit influence on human health due to their estrogenic and/or anti-estrogenic activity, as well as anticancer activities. It means that bacterial metabolism is crucial for the pro-healthy properties of various berries [266,272]. 
It has been shown that the production of the potent hop phytoestrogen 8prenylnaringenin (8-PN) depends on the activity of human intestinal microbiota [275]. This compound is generated from xanthohumol and isoxanthohumol that unaltered reach the small intestine (Figure 11). Among bacteria that catalyze the demethylation of isoxanthohumol into 8-PN are Eubacterium limosum and E. ramulus [275-277]. In addition to a strong impact on the ER $\alpha$ receptor, 8-prenylnaringenin inhibits angiogenesis and metastasis, prevents bone loss in rats and exhibits antiandrogenic activity [275,278].<smiles>COc1cc(O)c(CC=C(C)C)c(O)c1C(=O)/C=C/c1ccc(O)cc1</smiles>

xanthohumol

$\mathrm{X}$ hydrogenation

E. ramulus<smiles></smiles>

$\alpha, \beta$-dihydroxanthohumol

DXN<smiles>COc1cc(O)c(CC=C(C)C)c2c1C(=O)CC(c1ccc(O)cc1)O2</smiles>

isoxanthohumol IX<smiles>CC(C)=CCc1c(O)cc(O)c(C(=O)CCc2ccc(O)cc2)c1O</smiles>

desmethyl- $\alpha, \beta$-dihydroxanthohumol DDXN<smiles>CC(C)=CCc1c(O)cc(O)c2c1OC(c1ccc(O)cc1)CC2=O</smiles>

8-prenylnaringenin 8-PN

Figure 11. Bacterial biotransformation of prenylflavonoids xanthohumol and isoxanthohumol. Based on [275,276,279].

\subsection{Bacterial Transformation of Anthocyanidins}

Anthocyanidins (ACD) are plant pigments responsible for flower, fruit and vegetable color. Their structure and color depend on $\mathrm{pH}$ value and the presence of copigments. In plant tissues, ACD are generally present in the form of glycosides, called anthocyanins (ACN), that are susceptible to hydrolytic conversion into their corresponding anthocyanidins. Glucose, galactose, rhamnose and arabinose are the sugars most commonly encountered, usually as 3-O-glycosides or 3,5-O-diglycosides; however, rutinosides (6-O-Lrhamnosyl-D-glucosides), sophorosides (2-O-D-glucosyl-D-glucosides) and sambubiosides (2-O-D-xylosyl-D-glucosides) also occur, as do some 3,7-diglycosides and 3-triosides [280]. Moreover, some of the hydroxyl groups can be methylated, giving the big diversity of plant anthocyanidins. The anthocyanidins occur in the vacuole as an equilibrium of four molecular species that affects their color (Figure 12). However, after fruit and vegetable consumption, the form of the flavylium cation exists only in the stomach, while other forms are present in the lower parts of the gastrointestinal tract and in the tissues (if absorbed).

Bacterial metabolism of ACN involves the cleavage of glycosidic linkage and breakdown of the anthocyanidin heterocycle. Aura et al. [281] demonstrated that cyanidin-3rutinoside was degraded through cyanidin-3-glucoside and cyanidin aglycone as intermediary metabolites. After hydrolysis of the protective 3-glycosidic linkage, the released aglycons are stable under acidic $\mathrm{pH}$ but unstable under neutral or slightly basic $\mathrm{pH}$. It 
means that under physiological conditions in the small intestine, the cleavage of the heterocyclic flavylium ring occurs [274]. An attack of the flavylium carbon at position 2 produces an unstable hemiketal that rapidly forms a ketone (Figure 13). Through keto-enol tautomerism of the neighboring enol functionality, the resulting $\alpha$-diketone is very reactive and is easily decomposed by gut microbiota to phenolic acids (mainly protocatechuic acid, syringic acid, vanillic acid) and aldehydes (mainly phloroglucinol aldehyde) [274].

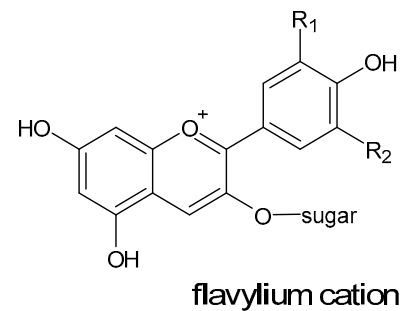<smiles></smiles><smiles>[R]c1cc(-c2oc3cc(=O)cc(O)c-3cc2O)cc([R])c1O</smiles>

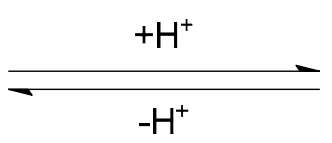<smiles>[R9]c1cc(C2(O)Oc3cc(O)cc(O)c3C=C2OC)cc(Br)c1O</smiles>

hemiketal

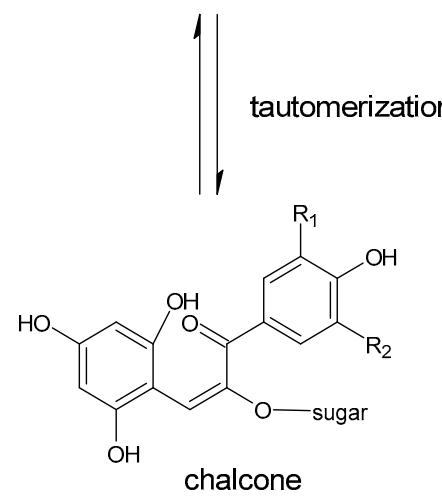

Figure 12. Anthocyanins equilibria [39].<smiles></smiles>

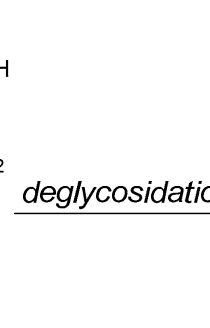

HO<smiles>[R]c1cc(C2(O)Oc3cc(O)cc(O)c3C=C2O)cc(O)c1O</smiles><smiles>[R]c1cc(C(=O)Cc2c(O)cc(O)cc2O)cc(Br)c1O</smiles>

HO<smiles>O=CCc1c(O)cc(O)cc1O</smiles>

2,4,6-trihydroxybenzoic acid (phloroglucinol acid)

\section{2,4,6-trihydroxybenzaldehyde} (phloroglucinol aldehyde)<smiles>[R6]c1c(C(=O)O)ccc(Br)c1O</smiles>

phenolic acid

Figure 13. Main steps of anthocyanin degradation. Based on [274,282].

It was demonstrated for raspberry anthocyanins; when incubated with fecal suspensions under anaerobic conditions, that they underwent a transformation by the colonic microflora. After C-ring fission in cyanidin, aglycone phenolic acids were released, originating from both the A and B rings. It was proved that some of the colonic catabolites 
entered the circulation and were further metabolized before being excreted in urine (e.g., as hippuric acid) [283].

Phenolic acids may be utilized as a source of energy by the intestinal microflora. Keppler and Humpf [282] demonstrated that bacterial metabolism of the methoxyl derivatives as syringic acid and vanillic acid was accompanied by $\mathrm{O}$-demethylation and resulted in the formation of gallic acid and protocatechuic acid (PCA), respectively. As phloroglucinol aldehyde (PHA) was degraded by the intestinal microflora very similar in comparison to the sterilized control samples, it was not possible to distinguish between the chemical or microbial transformation of the aldehyde. However, the phloroglucinol acid was detected as the oxidation product of PHA in very low amounts only in the non-sterilized inoculum filtrate [282], indicating the role of gut microbiota in the transformation.

Some in vitro studies revealed that the numbers of potentially beneficial bacteria (bifidobacteria and lactobacilli) increased after the consumption of purple sweet potato anthocyanins and grape seed extract [284]. As anthocyanins are hardly absorbed in the small intestine, they may be transformed into small molecular phenolic acids by colonic microbiota through ring cleavage, dihydroxylation and methylation reactions. Such metabolites generated from polyphenols may selectively stimulate the growth of beneficial bacterial, whereas the proliferation of harmful bacteria would be inhibited. Ávila et al. [285] analyzed various strains of Lactobacillus plantarum and L. casei, as well as probiotic strains Lactobacillus acidophilus LA-5 and Bifidobacterium lactis BB-12. They proved the enzymatic potential of selected strains for bioconversion of delphinidin and malvidin glycosides to their metabolites. Incubation of malvidin-3-glucoside with B. lactis BB-12, L. plantarum IFPL722, and L. casei LC-01 cell-free extracts led to different patterns of gallic, homogentisic and syringic acid formation.

It was also reported that gallic acid and free anthocyanins activated cell growth and the rate of malic acid degradation; vanillic acid showed a slight inhibiting effect, while protocatechuic acid had no effect. Finally, gallic acid and ACN were metabolized, especially by growing cells [88]. Incubation of malvidin-3-glucoside with fecal bacteria mainly resulted in the formation of syringic acid, while the mixture of anthocyanins resulted in the formation of gallic, syringic and $p$-coumaric acids [286].

The most abundant anthocyanins in fruit and vegetables are cyanidin, pelargonidin, petunidin, peonidin and delphinidin. The hypothesized pathways of their bacterial degradation are presented in Figures 14 and 15. Mayor ACN metabolites generated in the human colon by bacteria are protocatechuic acid, syringic acid, vanillic acid, gallic acid, phenylacetic acid, 3,4-dihydroxyphenylpropionic acid, 3,4-dihydroxyphenylacetic acid, 4-hydroxybenzoic acid, but also 4-hydroxyphenylethanol (tyrosol), catechol, benzoic acid [282,284,287-289].

Zhu et al. [284] reported that 2,4,6-trihydroxybenzoic acid, 4-hydroxybenzaldehyde, benzoic acid, phenylacetic acid, and phenylpropionic acid were found in the medium after bacterial metabolism od cyanidin-3-O-glucoside. The metabolism of cyanidin-3$\mathrm{O}$-glucoside and cyanidin-3-O-rutinoside mainly resulted in the formation of protocatechuic, vanillic, and $p$-coumaric acids, as well as 2,4,6-trihydroxybenzaldehyde, while the main metabolites of delphinidin-3-O-rutinoside were gallic acid, syringic acid and 2,4,6trihydroxybenzaldehyde. Among minor metabolites identified after microbial metabolism of mentioned glycosides were: protocatechuic acid-glucoside, caffeic acid, tartaric acid, catechol, as well as pyrogallol, ferulic acid, 4-hydroxybenzoic acid [290]. This research indicated that the intake of ACNs might result in the appearance of specific metabolites that exert a protective effect in host physiology.

The main phenolic acid detected in fecal suspensions incubated with raspberry anthocyanins were: 3-phenylacetic acid, 3-(4'-hydroxyphenyl) lactic acid, tyrosol, 3-(4'hydroxyphenyl) propionic acid, 3-(3'-hydroxyphenyl) propionic acid, 4-hydroxybenzoic acid and 3,4-dihydroxybenzoic acid, but lower amounts of catechol, resorcinol, pyrogallol and 3-( $3^{\prime}, 4^{\prime}$-dihydroxyphenyl) propionic acid were also found [283]. Seven metabolites formed by human fecal bacteria were observed by LC/MS after incubation with cyanidin- 
3-O-glucoside and cyanidin-3-O-galactoside, and protocatechuic acid (major metabolite), 2,4,5-trihydroxy-benzaldehyde, 5-hydroxy-2-(4'-hydroxyphenyl)-2H-chromen-3,7-dione, 3,5,7-trihydroxy-2-(3', $4^{\prime}$-dihydroxyphenyl)-2H-chromene, and 5-hydroxy-2-phenyl-2Hchromen-3,7-dione were identified [288]. The deglycosylation, decomposition, hydrogenation, and dihydroxylation reactions were involved in their generation.

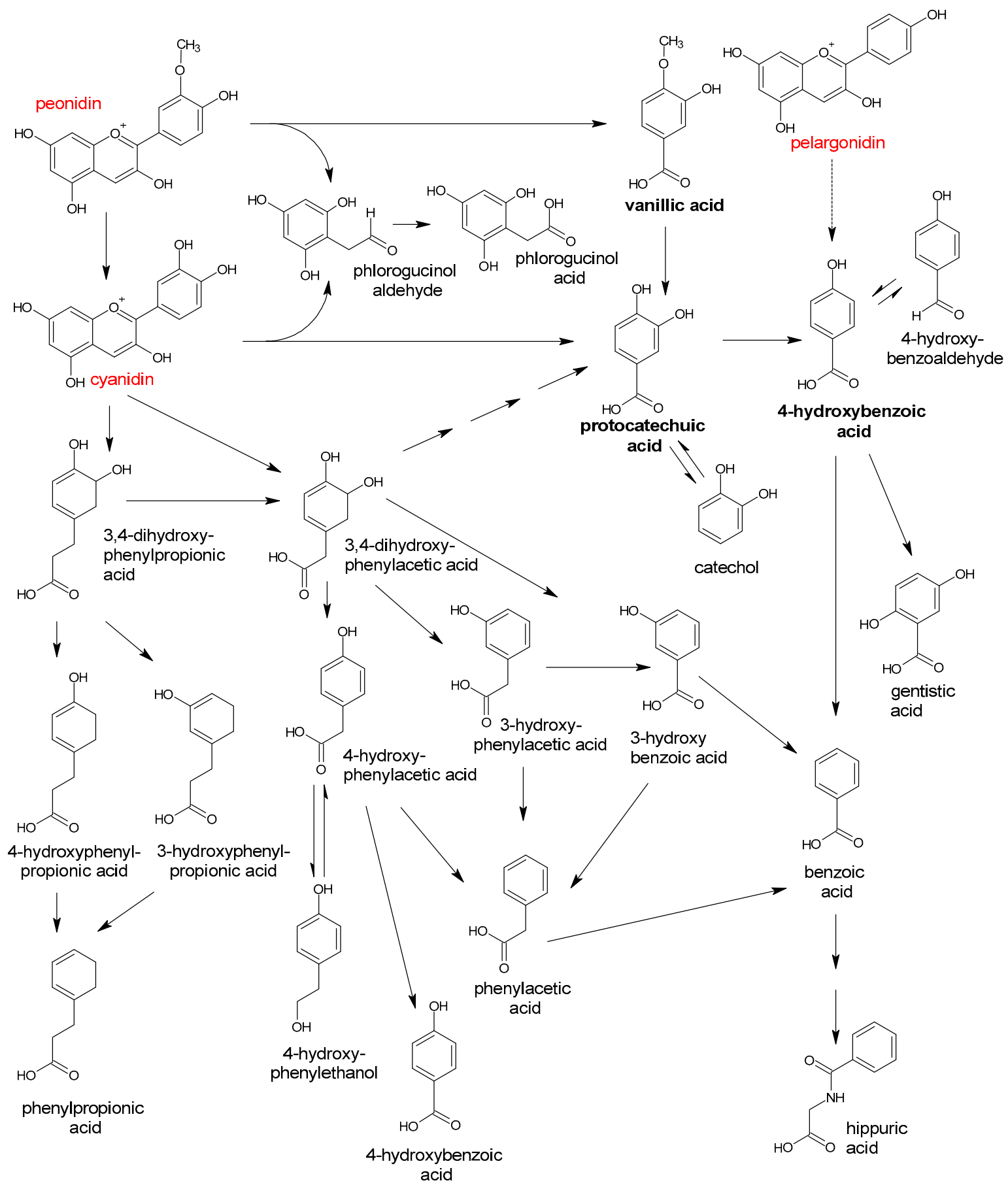

Figure 14. Biodegradation of anthocyanins and their main metabolites: cyanidin $\rightarrow 3,4$-dihydroxybenzoic acid (protocatechuic acid), peonidin $\rightarrow$ 3-methoxy-4-hydroxybenzoic acid (vanillic acid) and pelargonidin $\rightarrow$ 4-hydroxybenzoic acid. Based on $[282,284,287,288]$.

Malvidin-3-glucoside was completely degraded into syringic acid after incubation with a human fecal slurry for $24 \mathrm{~h}$, whereas gallic acid, $p$-coumaric, and syringic acid were 
formed after a mixture of various anthocyanins were incubated with healthy human fecal bacteria [291].

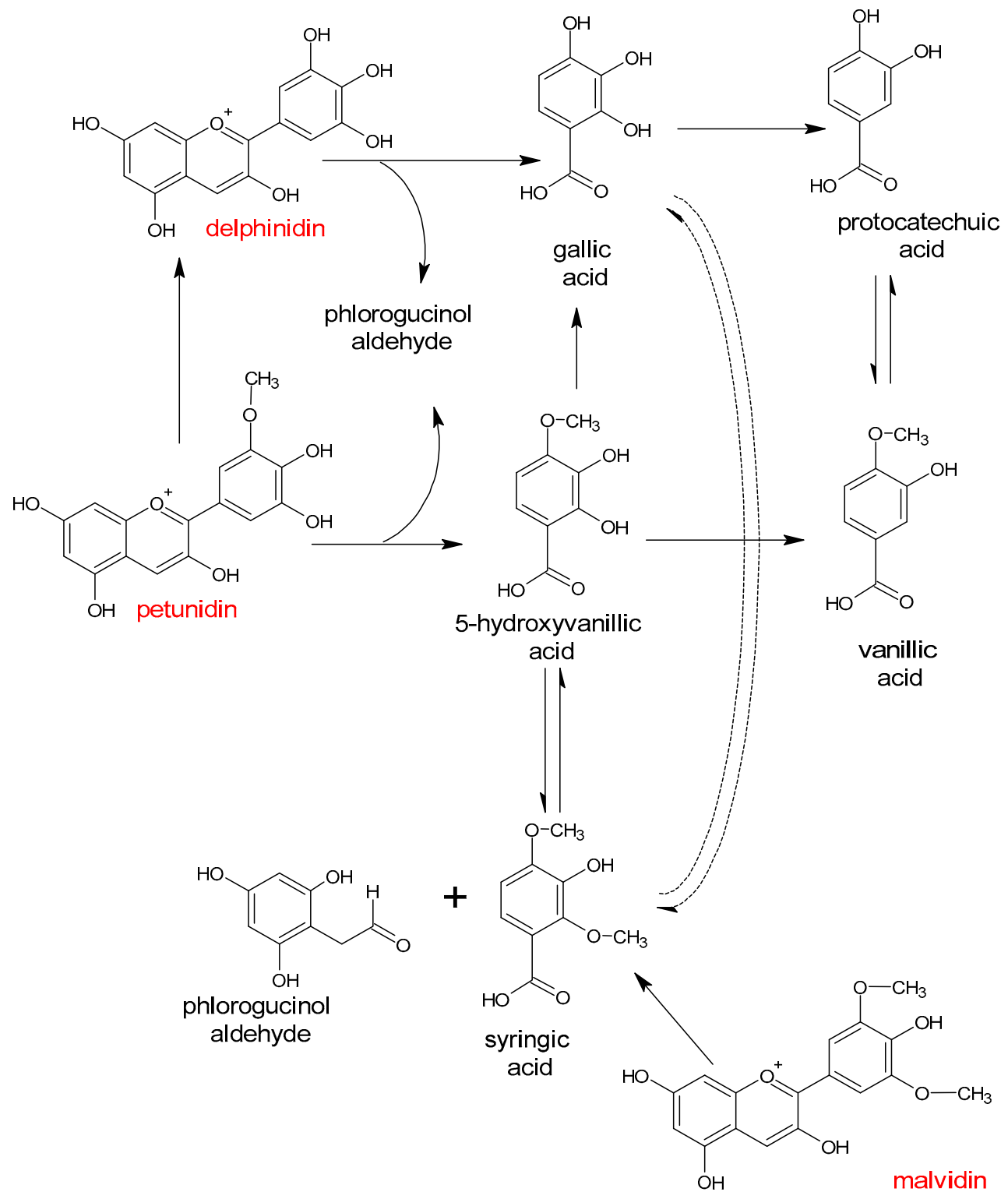

Figure 15. Biodegradation of malvidin, delphinidin and petunidin by intestinal bacteria. Based on $[285,290,292]$.

\subsection{Metabolism of Procyanidins and Catechins by Intestinal Bacteria}

Condensed tannins (also called catechol-type tannins or non-hydrolyzable tannins) are an important class of polyphenols that do not contain sugar residues. They are also called proanthocyanidins as, under oxidative conditions, they depolymerize, yielding anthocyanidins. Therefore, different types of condensed tannins exist, such as the procyanidins, propelargonidins, prodelphinidins, profisetinidins, proteracacinidins, proguibourtinidins or prorobinetidins.

Condensed tannins are formed from flavan-3-ols or flavan-4-ols. These particular types of condensed tannins are procyanidins, which are not susceptible to cleavage by hydrolysis. Procyanidins are polymers of 2 to 50 (or more) catechin units (usually catechin and epicatechin molecules) joined by carbon-carbon bonds. The most ubiquitous are B-type procyanidins, abundant in apple, cocoa, pear, blueberries; these subunits are linked by single bond $\mathrm{C} 4-\mathrm{C} 8$ or $\mathrm{C} 4-\mathrm{C} 6$. In A-type procyanidins, present in cranberries, a double 
linkage exists; the $\mathrm{C} 4-\mathrm{C} 8$ or $\mathrm{C} 4-\mathrm{C} 6$ bond is accompanied by an additional $\mathrm{C} 2-\mathrm{O}-\mathrm{C} 7$ or $\mathrm{C} 2-\mathrm{O}-\mathrm{C} 5$ ether bond.

Some studies demonstrated that highly polymeric procyanidins (PPs) administration markedly decreased the Firmicutes/Bacteroidetes ratio and increased by eight times the proportion of Akkermansia, suggesting that PPs influence the gut microbiota and the intestinal metabolome to produce beneficial effects on metabolic homeostasis [76]. On the other hand, some species of intestinal bacteria are able to degrade oligomeric procyanidins. Spencer et al. [221] proved that procyanidin oligomers (trimer to hexamer) are hydrolyzed in simulated gastric juice to mixtures of epicatechin monomer and dimer, thus enhancing the potential for their absorption in the small intestine. Proanthocyanidins that undergo partial acid-catalyzed cleavage then decompose to monomeric flavan-3-ols, which are also metabolized by colonic bacteria. The bacterial degradation of flavan-3-ols and proanthocyanidins follow a similar pathway, and both lead to a generation of a unique compound 5 -( $3^{\prime}, 4^{\prime}$-dihydroxyphenyl)- $\gamma$-valerolactone, which further undergoes dihydroxylation and oxidation to produce phenolic acids [291,293] (Figure 16).

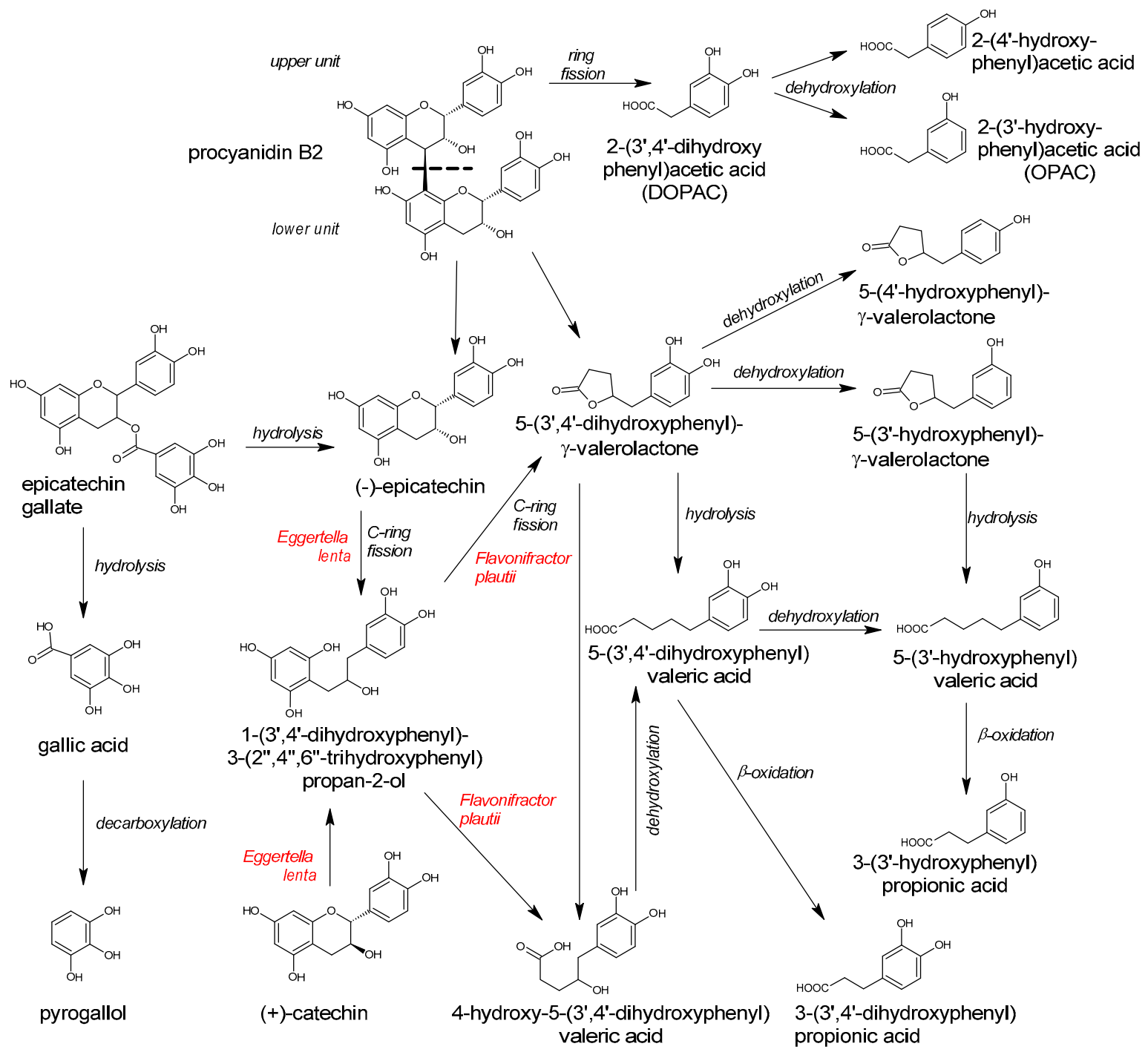

Figure 16. Microbial metabolism of procyanidin B2, (-)-epicatechin and (+)-catechin. Based on [274,291,294-297].

The incubation of purified (+)-catechin, (-)-epicatechin, procyanidins A2 and B2, as well as partially purified apple and cranberry procyanidins with human gut microbiota, resulted in their degradation. The common metabolites were benzoic acid, 2phenylacetic acid, 3-phenylpropionic acid, 2-(3'-hydroxyphenyl) acetic acid (OPAC), 2-(4'- 
hydroxyphenyl) acetic acid, 3-(3'-hydroxyphenyl) propionic acid, and hydroxyphenylvaleric acid. Interesting, that 5-( $3^{\prime}, 4^{\prime}$-dihydroxyphenyl $)-\gamma$-valerolactone and 5-( $3^{\prime}-$ hydroxyphenyl)- $\gamma$-valerolactone were identified as the bacterial metabolites of epicatechin, catechin, procyanidin $\mathrm{B} 2$, and purified apple procyanidins, but not from the procyanidin A2 or cranberry procyanidin ferments, while 2-( $3^{\prime}, 4^{\prime}$-dihydroxyphenyl) acetic acid was only found in the fermented broth of procyanidin B2, A2, apple, and cranberry procyanidins [298].

The monomeric flavan-3-ols, which are usually shared by condensed tannins, can be degraded by fecal microbiota into low molecular weight aromatic compounds, including phenylpropionic acid, 2-(3'-hydroxyphenyl) acetic acid, 3-(3'-hydroxyphenyl) propionic acid, 5-( $3^{\prime}$-hydroxyphenyl) valeric acid, phenylacetic acid, and 2-(4'-hydroxyphenyl) acetic acid [294]. Similar results have been obtained Appeldoorn et al. [296]. Purified procyanidin dimers, when incubated with human microbiota, have been transformed and among major identified metabolites were 2-( $3^{\prime}, 4^{\prime}$-dihydroxyphenyl) acetic acid (DOPAC) and 5-( $3^{\prime}, 4^{\prime}$-dihydroxyphenyl)- $\gamma$-valerolactone. Other metabolites detected were: OPAC, 2-(4'-hydroxyphenyl) acetic acid, 3-(3'-hydroxyphenyl) propionic acid, phenylvaleric acids, monohydroxylated phenylvalerolactone, and 1-( $3^{\prime}, 4^{\prime}$-dihydroxyphenyl)-3-( $2^{\prime \prime}, 4^{\prime \prime}, 6^{\prime \prime}$ trihydroxyphenyl) propan-2-ol. In studies of Deprez et al. [297], polymeric procyanidins were metabolized by colonic bacteria into low-molecular-weight phenolic acid, and the main metabolites were 3-phenylpropionic acid, 3-(4'-hydroxyphenyl) propionic acid, 3-(3'hydroxyphenyl) propionic acid, 5-(3'-hydroxyphenyl) valeric acid, 2-(3'-hydroxyphenyl) acetic acid, and 2-(4'-hydroxyphenyl) acetic acid.

Among intestinal bacteria that are able to convert catechins are Eggerthella lenta and Flavonifractor plautii (formerly Clostridium orbiscindens) [295]. Eggerthella lenta rK3 reductively cleaved the heterocyclic $\mathrm{C}$-ring of both (-)-epicatechin and (+)-catechin giving rise to 1-(3', $4^{\prime}$-dihydroxyphenyl)-3-( $2^{\prime \prime}, 4^{\prime \prime}, 6^{\prime \prime}$-trihydroxyphenyl) propan-2-ol (Figure 16). The conversion of catechin proceeded five times faster than that of epicatechin. Flavonifractor plautii aK2 and Flavonifractor plautii DSM 6740 further converted 1-( $3^{\prime}, 4^{\prime}$-dihydroxyphenyl)3-(2" $2^{\prime \prime} 4^{\prime \prime}, 6^{\prime \prime}$-trihydroxyphenyl) propan-2-ol to 5-( $3^{\prime}, 4^{\prime}$-dihydroxyphenyl)- $\gamma$-valerolactone and 4-hydroxy-5-(3', $4^{\prime}$-dihydroxyphenyl) valeric acid.

According to Tzounis et al. [59], the initial conversion of (+)-catechin to (+)-epicatechin is required to the generation of 5-( $3^{\prime}, 4^{\prime}$-dihydroxyphenyl)- $\gamma$-valerolactone, 5-phenyl- $\gamma$ valerolactone and phenylpropionic acid as metabolites. The prebiotic effects of both (+)catechin and (-)-epicatechin was observed, suggesting that the consumption of flavanolrich foods may support gut health through their ability to exert prebiotic actions.

Monagas et al. [299] demonstrated that some phenolic acids, including 3-O-methyl gallic, gallic, caffeic, 3-(4'-hydroxyphenyl) propionic, phenylpropionic, and 2-(4'-hydroxyphenyl) acetic acids derived from the microbial degradation of tea catechins, were able to inhibit the growth of several pathogenic and non-beneficial intestinal bacteria without significantly affecting the growth of beneficial bacteria (Lactobacillus spp. and Bifidobacterium spp.). It is possible that Bifidobacterium sp. are resistant to flavan-3-ols, being the are important ironchelating compounds, because these bacteria do not use heme-containing enzymes [237]. Growth of certain pathogenic bacteria such as Clostridium perfringens, Clostridium difficile, Streptococcus pyogenes, and Str. pneumoniae was significantly repressed by tea phenolics (catechin, epicatechin, gallic acid, caffeic acid), while commensal anaerobes like Clostridium spp., Bifidobacterium spp. and probiotics such as Lactobacillus sp. were less severely affected [70]. Similarly, the bacterial metabolites, such as 3-(4'-hydroxyphenyl) propionic acid, 3-phenylpropionic acid and 2-(4'-hydroxyphenyl) acetic acid, strongly inhibited the growth of E. coli, S. aureus and Salmonella sp. without influencing beneficial L. casei strain Shirota and Bifidobacterium breve.

Alakomi et al. [300] have shown that DOPAC, OPAC, 3-(3', $4^{\prime}$-dihydroxyphenyl) propionic acid, 3-(4'-hydroxyphenyl) propionic acid, 3-phenylpropionic acid, and 3-(3'hydroxyphenyl) propionic acid efficiently destabilized the outer membrane of Salmonella enterica subsp. enterica serovar Typhimurium and S. enterica subsp. enterica serovar Infantis. 
Moreover, DOPAC, OPAC and 3-(3', $4^{\prime}$-dihydroxyphenyl) propionic acid increased the susceptibility of Salmonella Typhimurium strains for novobiocin. It means that beneficial bacteria residing in the human gut can inhibit Salmonella growth by the transformation of food flavonoids to active antimicrobial metabolites.

\subsection{The Bacterial Metabolism of Flavones and Flavonols}

It is interesting that some compounds are common and can be generated by colonic microbiota during the metabolism of various polyphenols, although to a different extent. For example, flavan-3-ols, as well as flavonols and hydroxycinnamic acids, lead to the generation of 3-( $3^{\prime}, 4^{\prime}$-dihydroxyphenyl)-propionic acid, 3-(3'-hydroxyphenyl) propionic acid, and 3-(4'-hydroxyphenyl) propionic acid. It means that some enzymes and metabolic pathways are quite common among bacteria. When quercetin is metabolized by bacteria, ring fission is done, leading to the generation of DOPAC, OPAC and protocatechuic acid (PCA) (Figure 17). Braune et al. [301] examined the degradation mechanism of the flavonol quercetin and the flavone luteolin and had demonstrated that Eubacterium ramulus converted quercetin through taxifolin and alphitonin, resulting in the formation of DOPAC and phloroglucinol. Flavonol luteolin was transformed by E. ramulus to $3-\left(3^{\prime}, 4^{\prime}-\right.$ dihydroxyphenyl) propionic acid via eriodictyol and derivatives. In both pathways, ring fission had taken place. Glycosides of quercetin, such as common in onions quercetin $4^{\prime}$-O-glucoside and quercetin 3-O-glucoside, are first hydrolyzed to aglycone and then are also catabolized, giving ring-fission products [235]. Bifidobacterium animalis subsp. lactis AD011, isolated from infant feces, has been shown to catalyze quercetin 3-O-glucoside and isorhamnetin 3-O-glucoside into quercetin and isorhamnetin, respectively [302].

The degradation of flavones and flavonols by Clostridium orbiscindenss was studied by Schoefer et al. [303]. They confirmed the quercetin degradation via taxifolin and alphitonin. Flavone apigenin and luteolin were converted to 3-(4'-hydroxyphenyl) propionic acid and 3-( $3^{\prime}, 4^{\prime}$-dihydroxyphenyl) propionic acid, respectively, and phloroglucinol was released in both cases (Figure 17). The intermediate metabolites were naringenin and phloretin for apigenin and eriodictyol and dihydrochalcone for luteolin [303]. However, the isolated $C$. orbiscindens strain was unable to hydrolyze the glycosidic bonds of luteolin 3$\mathrm{O}$-glucoside, luteolin 5-O-glucoside, naringenin 7-O-neohesperidoside (naringin), quercetin 3-O-glucoside, quercetin 3-O-rutinoside (rutin), and phloretin 2'-O-glucoside, suggesting that other bacteria are required for the initial steps in the metabolism of flavonoid glycosides in the human intestine. Similar pathways were reported for degradation of myricetin, kaempferol as well as quercetin, apigenin and luteolin glycosides, and among bacteria involved in their metabolism were Enterococcus casseliflavus, Eubacterium ramulus, Eubacterium oxidoreducens, Butyrivibrio spp., Clostridium orbiscidens, Eggerthella sp., Flavonifractor plautii, Bacteroides uniformis, Bacteroides ovatus, Bifidobacterium spp., Bacteroides distasonis, and Blautia sp. [235,237,304-307].

Experiments using radiolabeled quercetin $4^{\prime}$-O-glucoside $\left(\mathrm{Q} 4^{\prime} \mathrm{G}\right)$ revealed that $\mathrm{Q} 4^{\prime} \mathrm{G}$ passes through the gastrointestinal tract of rats and that almost all of $Q 4^{\prime} G$ is converted into phenolic acids, with DOPAC and OPAC being the most abundant, and a small amount of PCA was also generated [235]. Moreover, $69 \%$ of $Q 4^{\prime} \mathrm{G}$ radioactivity was recovered in the form of phenolic acid derivatives, such as OPAC and hippuric acid, in the urine. It means that the first ring-fission product is DOPAC, which is subsequently subjected to dehydroxylation to form OPAC, followed by further catabolism into hippuric or benzoic acids (Figure 17). DOPAC also has been identified as a major catabolite of quercetin glycosides, such as rutin, as well as procyanidins (Figure 16). It is important because DOPAC is known to be a metabolite of the neurotransmitter dopamine, suggesting the existence of a metabolic pathway for DOPAC in humans. It has been demonstrated that DOPAC exerts anticancer, anti-inflammatory, cardioprotective and neuroprotective impact. However, DOPAC may inhibit mitochondrial respiration in brain mitochondria (when NO radical is present) and thus lead to mitochondrial dysfunction, which is assumed to be an important mechanism involved in Parkinson's disease [308]. 


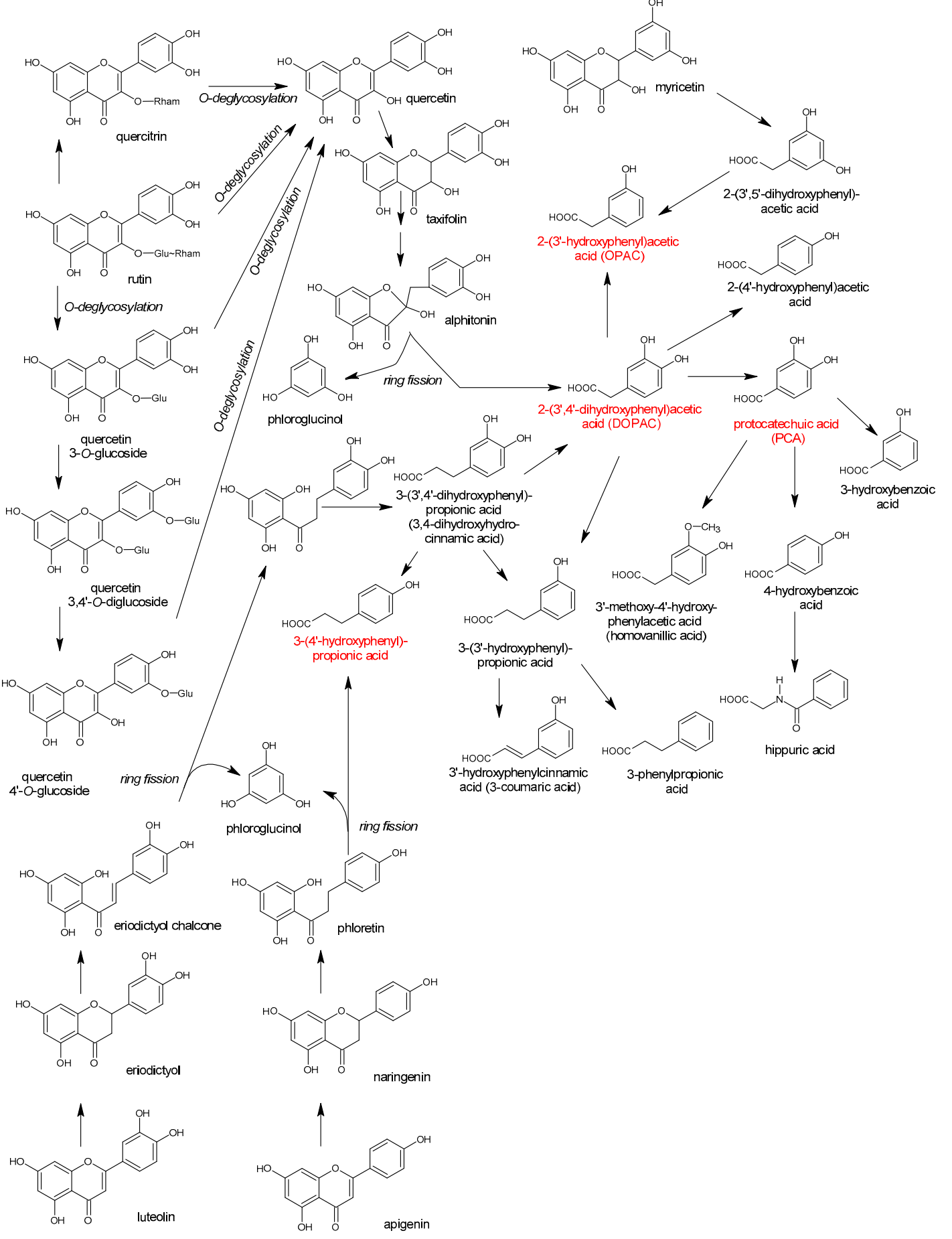

Figure 17. Possible pathways of the transformation of flavones and flavonols due to metabolism by intestinal bacteria. Based on $[239,301,304,309,310]$.

\subsection{Microbial Catabolism of Phenolic Acids}

Phenolic acids can be delivered to the intestine with food, but they are also generated as the final metabolites during the degradation of various polyphenols. Phenolic acids play an important protective role in degenerative diseases as they exert antioxidant, antitumor, apoptotic, neuroprotective, hepatoprotective, anti-inflammatory and antimicrobial properties [35]. However, there has been some controversy about the bioactivity of polyphenols after metabolism. Once ingested, these molecules are metabolized and transformed into methylated, glucuronated and sulfated metabolites, and there is much evidence proving 
both the enhanced and decreased biological activity of phenolic acid metabolites [35]. Not all phenolic acids are absorbed, and some of them reach the colon and can be metabolized by bacteria. It is supposed that the presence of an ester moiety lowers hydroxycinnamic acids (HCAs) absorption. Actually, HCAs in a free form are rapidly absorbed throughout the gastrointestinal tract, while HCAs esters or HCAs attached to cell walls require to be hydrolyzed by bacterial esterases before absorption [311]. As a large interindividual variation of phenolic acid metabolites (Figure 18) was observed, it may suggest that the catabolic pathways of both chlorogenic acid and other phenolic acids depend mainly on the colon microbiota composition.

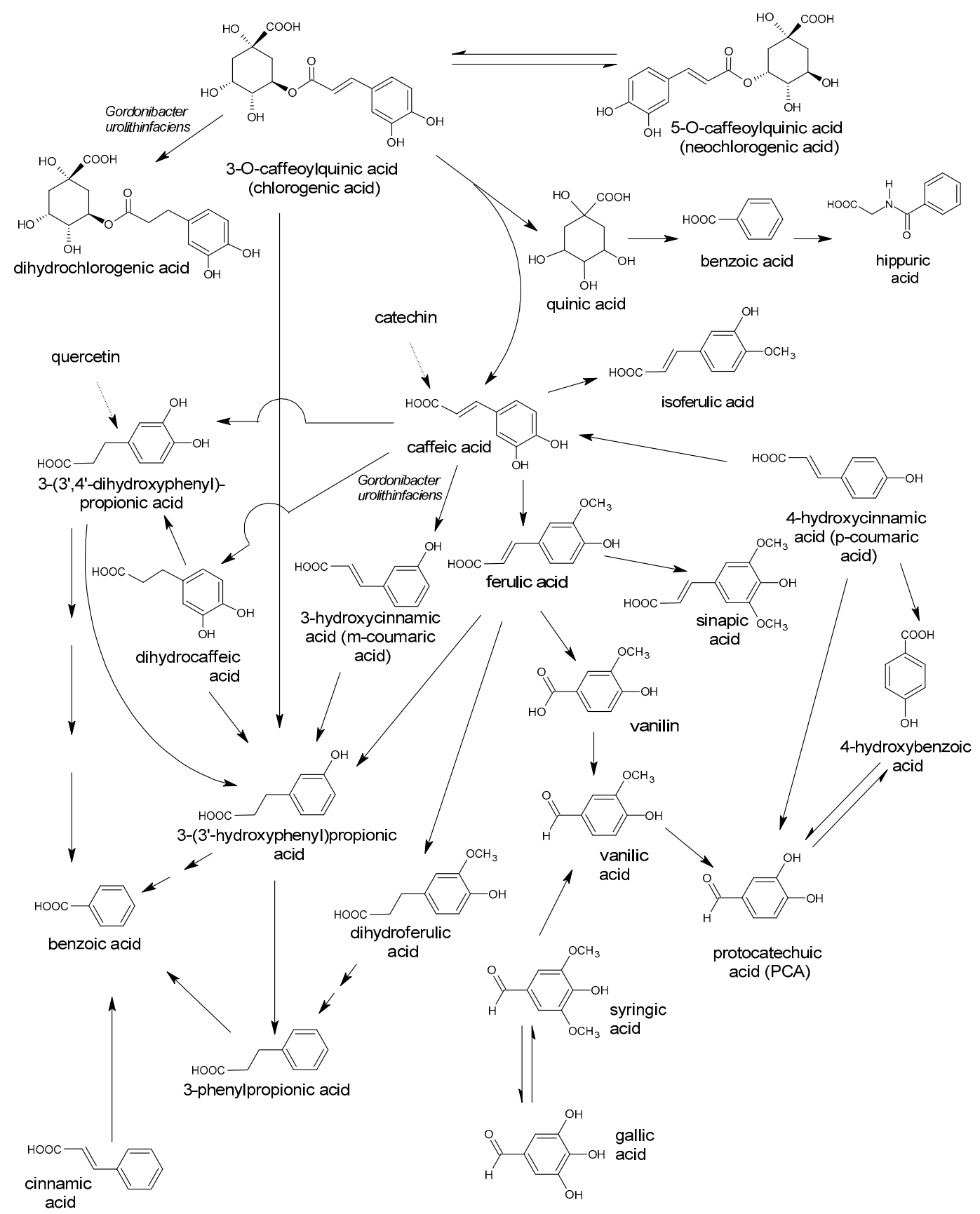

Figure 18. Pathways of some phenolic acid metabolism conducted by various bacteria. Based on [37,304,312-315].

Incubation of coffee samples (a rich source of phenolic acids) with the human fecal microbiota led to the rapid metabolism of chlorogenic acid and the production of dihydrocaffeic acid and dihydroferulic acid, while caffeine remained unmetabolized [316]. 
Caffeic acid esters can be rapidly transformed to 3-(3'-hydroxyphenyl) propionic acid by human fecal microbiota [304] by de-esterification followed by a reduction of a double bond and dehydroxylation at the C4 position (Figure 18). Monteiro et al. [317] revealed that the main chlorogenic acid metabolites identified in urine after coffee consumption were: dihydrocaffeic, gallic, isoferulic, ferulic, vanillic, caffeic, 5-O-caffeoylquinic, sinapic, 4-hydroxybenzoic, and $p$-coumaric acids, with gallic and dihydrocaffeic acids being the major ones. Similar results were reported by Clifford et al. [37]. One of the most abundant sources of caffeic acid in nature is 5-O-caffeoylquinic acid (neochlorogenic acid), which was also proved to be hydrolyzed to caffeic and quinic acids by esterases from colonic microflora and is not degraded and absorbed in the upper gastrointestinal tract [311]. The lack of colonic microbiota (e.g., in germfree rats) resulted in the inhibition of hippuric acid formation, indicating that esterase enzymes of the colonic microbiota are involved in this pathway [318].

\subsection{Bacterial Metabolism of Resveratrol and Curcumin}

Resveratrol is a natural polyphenol widely found in its trans isomer form in various fruits, especially grapes and berries, peanuts, and red wine. It was reported that purified resveratrol inhibited the growth of some pathogens, among other intestinal bacteria such as Helicobacter pylori, Enterococcus faecalis, Pseudomonas aeruginosa, Vibrio spp. [319]. However, some bacteria are able to metabolize trans-resveratrol. Slackia equolifaciens and Adlercreutzia equolifaciens [320] and Eggerthella lenta ATCC 4305 [319] converted resveratrol to dihydroresveratrol (Figure 19); while Bacillus cereus NCTR-466, Achromobacter denitrificans NCTR-774, and E. coli ATCC 47,004 metabolizes trans-resveratrol into resveratrol 3-O-glucoside (piceid) and resveratrol 4-O-glucoside (resveratroloside) [319]. Among other colonic metabolites of resveratrol, lunularin and 3,4'-dihydroxy-trans-stilbene [320] were identified. However, their bacterial producers are unknown (Figure 19). The 16S rRNA sequencing of fecal samples demonstrated the association of lunularin producers with a higher abundance of Bacteroidetes, actinobacteria, Verrucomicrobia, and Cyanobacteria and with a lower abundance of Firmicutes than either the dihydroresveratrol or mixed producers [321]. The bacterial metabolites of resveratrol can exert a beneficial impact on human health. Dihydroresveratrol reduced fatty acid-binding protein-4 expression, involved in fatty acid uptake in human macrophages treated with oxidized LDL and stimulates fatty acid oxidation in human fibroblasts, lunularin reduced the expression of proinflammatory mediators in endothelial cells [322], while 3,4'-dihydroxy-trans-stilbene increased glucose uptake and induced adenosine monophosphate kinase phosphorylation in C2C12 myotubes independently of insulin [323].

Jarosova et al. [324] examined the metabolism of six stilbenoids resveratrol, oxyresveratrol, piceatannol, thunalbene, batatasin III, and pinostilbene by colon microbiota from various donors. It was demonstrated that resveratrol, oxyresveratrol, piceatannol and thunalbene were subjected to metabolic transformation via double bond reduction, dihydroxylation, and demethylation (Figure 19), while batatasin III and pinostilbene were stable at simulated colon conditions. Authors reported strong interindividual differences in speed, intensity, and pathways of metabolism among the fecal samples obtained from the donors, suggesting that microbiota composition plays a crucial role in the influence of resveratrol on human health.

Curcumin is a lipophilic polyphenol characterized by quite poor bioavailability. It is supposed that curcumin passes through the stomach without any chemical modifications and reaches the large intestine, where it undergoes extensive phase I and II metabolism. The reductive pathways of metabolism by phase I enzymes lead to the formation of dihydrocurcumin, tetrahydrocurcumin, and hexahydrocurcumin (Figure 20) [325]. 

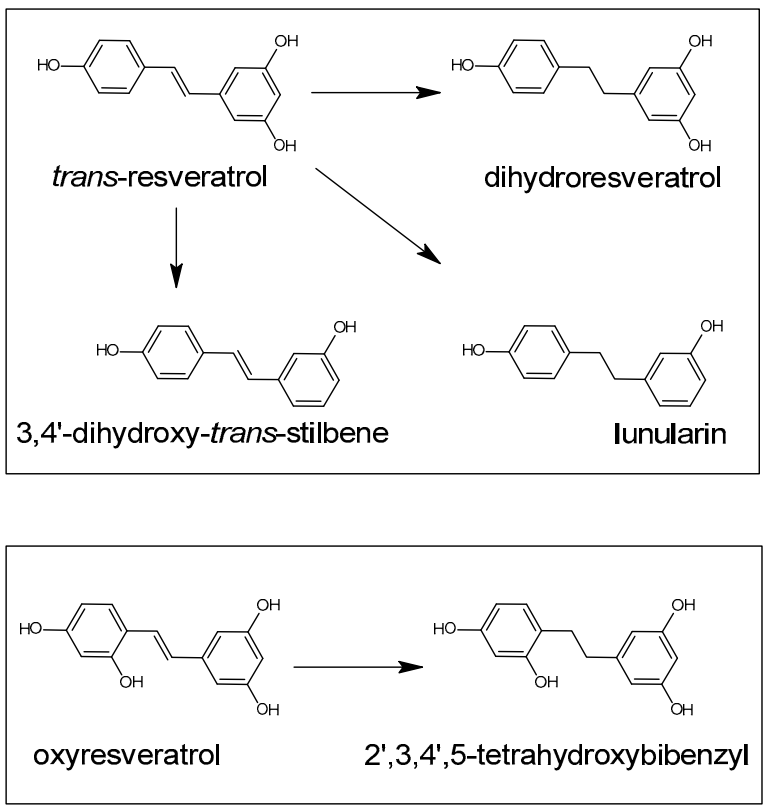

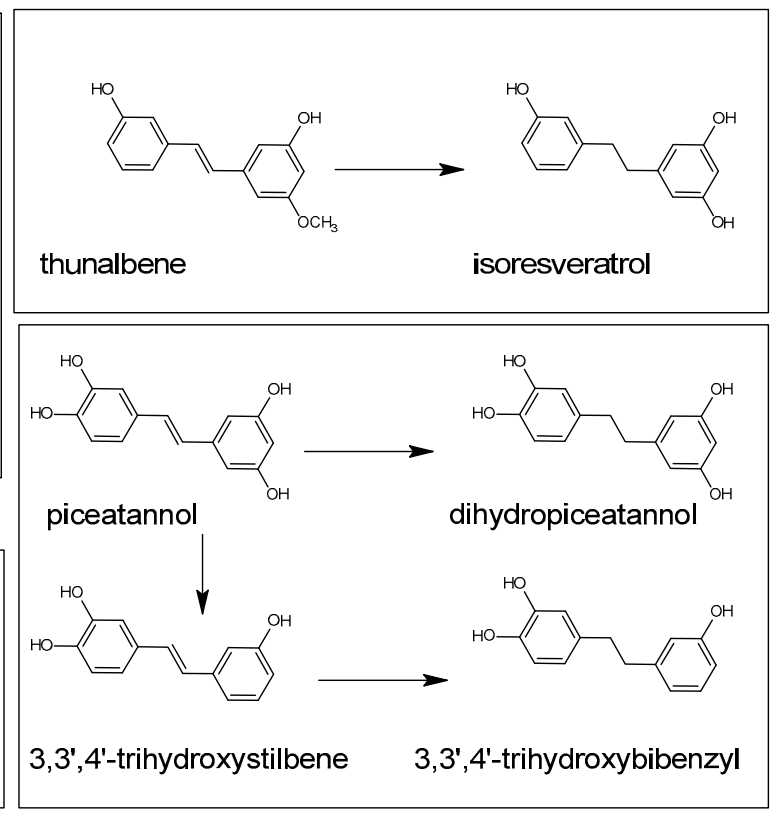

Figure 19. The effect of bacterial metabolism on resveratrol, oxyresveratrol, thunalbene and piceatannol. Based on [320,324].

However, consecutive reduction of the double bonds in the curcumin chain resulting in the formation of dihydrocurcumin, tetrahydrocurcumin, and hexahydrocurcumin can occur in the gut by a CurA reductase (NADPH-dependent curcumin/dihydrocurcumin reductase) that has been isolated from intestinal E. coli [326]. The 24-h fermentation of curcumin, demethoxycurcumin and bis-demethoxycurcumin by human fecal microbiota resulted in $24 \%, 61 \%$ and $87 \%$ degradation, respectively. Three main metabolites were identified: tetrahydrocurcumin, dihydroferulic acid and 1-(4-hydroxy-3-methoxyphenyl)-2propanol [327]. A similar experiment was performed by Burapan et al. [328], but a mixture composed of curcumin, demethoxycurcumin, and bis-demethoxycurcumin was metabolized by the human intestinal bacterium Blautia sp. MRG-PMF1. New metabolites generated from curcumin and demethoxycurcumin by the methyl aryl ether cleavage reaction were identified. Demethylcurcumin and bisdemethylcurcumin were sequentially produced from curcumin, while demethyldemethoxycurcumin was produced from demethoxycurcumin [328]. Bis(demethyl)tetrahydrocurcumin and bis(demethyl)-hexahydrocurcumin were identified among colonic metabolites of curcumin, demethoxycurcumin and bisdemethoxycurcumin [329].

All these metabolites can undergo phase II metabolism by glucuronidases and sulfotransferases that are capable of conjugating glucuronic acid or sulfate molecule, respectively, to produce the corresponding glucuronide and sulfate O-conjugated metabolites. Furthermore, gut microbiota may deconjugate the phase II metabolites and convert them back to the corresponding phase I metabolites or to fission products such as ferulic acid and dihydroferulic acid in the colon [325].

It is interesting that CurA reductase, besides the ability to conversion of curcumin to tetrahydrocurcumin, is also able to metabolize resveratrol [326]. 

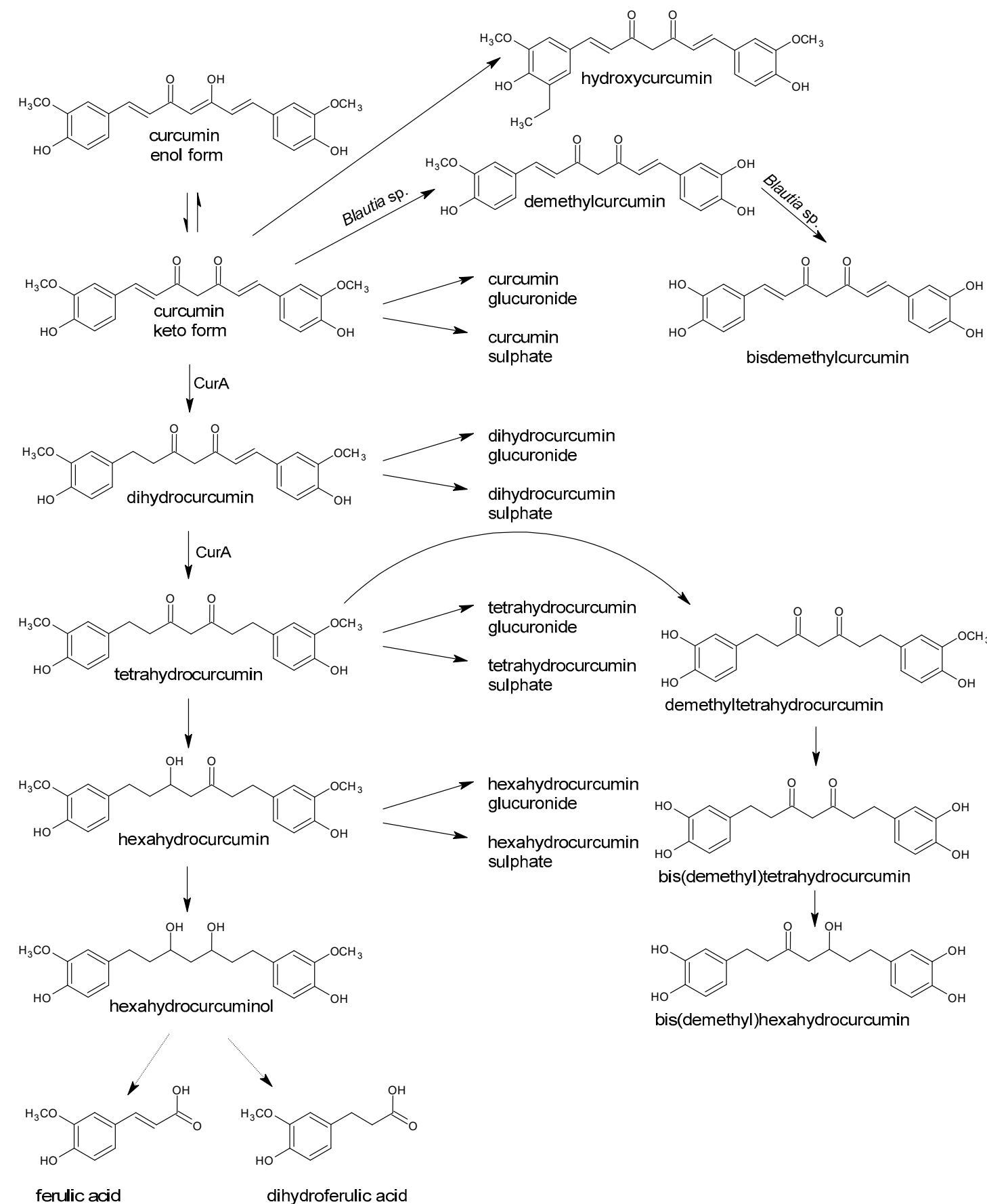

Figure 20. Metabolic pathway of curcumin. Reactions conducted by E. coli CurA and Blautia sp. are indicated. Based on $[274,325,326,328-330]$.

\section{Conclusions}

This review describes a bidirectional relationship between polyphenols delivered with food and the human gut microbiota. The manuscript presents a compilation of the knowledge from two perspectives. The first part describes the impact of various polyphenols classes on bacteria, with particular emphasis on human intestinal microbiota representatives. The mechanism of inhibitory impact of polyphenols, including protein binding, inhibition of nucleic acid synthesis, interaction with the cell wall and bacterial membranes, substrate deprivation, inhibition of energy metabolism and changes in cell attachment and biofilm formation, are discussed in details. In the second part, the role and pathways of 
bacterial biotransformation of polyphenols are described, especially those reactions where bioactive metabolites with a significant impact on the human organism (both positive and negative) are produced. The role of interindividual variation in microbiota composition in the impact of food polyphenols on human health is explained. For example, the biotransformation of isoflavonoids and other phytoestrogens to bioactive O-DMA and S-equol, the generation of urolithins, the bacterial metabolites that can cross the blood-brain barrier, the degradation of complex condensed tannins and lignans as well as catabolic pathways of low-molecular-weight phenolic acids are elucidated.

The exact structures of all discussed phenolic compounds can be found in tables and figures, which will facilitate their comparison with the structures of other food ingredients and drawing one's own conclusions about their potential activity.

Author Contributions: All authors have read and agreed to the published version of the manuscript. Conceptualization, M.M. and A.D.-C.; Writing-Original Draft Preparation, M.M., I.D., T.T. and A.D.-C.; Writing-Review \& Editing, M.M., I.D., T.T. and A.D.-C.; Visualization, M.M., I.D., T.T. and A.D.-C.; Supervision, A.D.-C.; Funding Acquisition, A.D.-C.

Funding: The APC was supported by the author's activation funds and through a research subsidy of the Department of Fermentation Technology and Microbiology, the University of Agriculture in Krakow.

Conflicts of Interest: The authors declare no conflict of interest.

\section{References}

1. Hooper, L.V.; Gordon, J.I. Commensal host-bacterial relationships in the gut. Science 2001, 292, 1115-1118. [CrossRef]

2. Zhu, B.; Wang, X.; Li, L. Human gut microbiome: The second genome of human body. Protein Cell 2010, 1, 718-725. [CrossRef]

3. Qin, J.; Li, R.; Raes, J.; Arumugam, M.; Burgdorf, K.S.; Manichanh, C.; Nielsen, T.; Pons, N.; Levenez, F.; Yamada, T.; et al. A human gut microbial gene catalogue established by metagenomic sequencing. Nature 2010, 464, 59-65. [CrossRef] [PubMed]

4. Eckburg, P.B.; Bik, E.M.; Bernstein, C.N.; Purdom, E.; Dethlefsen, L.; Sargent, M.; Gill, S.R.; Nelson, K.E.; Relman, D.A. Diversity of the human intestinal microbial flora. Science 2005, 308, 1635-1638. [CrossRef]

5. Lagier, J.-C.; Armougom, F.; Million, M.; Hugon, P.; Pagnier, I.; Robert, C.; Bittar, F.; Fournous, G.; Gimenez, G.; Maraninchi, M.; et al. Microbial culturomics: Paradigm shift in the human gut microbiome study. Clin. Microbiol. Infect. 2012, 18, 1185-1193. [CrossRef]

6. Duda-Chodak, A.; Tarko, T.; Satora, P.; Sroka, P. Interaction of dietary compounds, especially polyphenols, with the intestinal microbiota: A review. Eur. J. Nutr. 2015, 54, 325-341. [CrossRef]

7. Conlon, M.A.; Bird, A.R. The impact of diet and lifestyle on gut microbiota and human health. Nutrients 2015, 7, 17-44. [CrossRef]

8. Thursby, E.; Juge, N. Introduction to the human gut microbiota. Biochem. J. 2017, 474, 1823-1836. [CrossRef]

9. Hermon-Taylor, J. Gut pathogens: Invaders and turncoats in a complex cosmos. Gut Pathog. 2009, 1, 3. [CrossRef]

10. Acton, D.S.; Plat-Sinnige, M.J.; van Wamel, W.; de Groot, N.; van Belkum, A. Intestinal carriage of Staphylococcus aureus: How does its frequency compare with that of nasal carriage and what is its clinical impact? Eur. J. Clin. Microbiol. Infect. Dis. 2009, 28, 115-127. [CrossRef]

11. Kamada, N.; Chen, G.Y.; Inohara, N.; Núñez, G. Control of pathogens and pathobionts by the gut microbiota. Nat. Immunol. 2013, 14, 685-690. [CrossRef]

12. Rowland, I.; Gibson, G.; Heinken, A.; Scott, K.; Swann, J.; Thiele, I.; Tuohy, K. Gut microbiota functions: Metabolism of nutrients and other food components. Eur. J. Nutr. 2018, 57, 1-24. [CrossRef]

13. Possemiers, S.; Bolca, S.; Verstraete, W.; Heyerick, A. The intestinal microbiome: A separate organ inside the body with the metabolic potential to influence the bioactivity of botanicals. Fitoterapia 2011, 82, 53-66. [CrossRef]

14. Hervert-Hernández, D.; Goñi, I. Dietary polyphenols and human gut microbiota: A review. Food Rev. Int. 2011, 27, 154-169. [CrossRef]

15. Man, A.W.C.; Zhou, Y.; Xia, N.; Li, H. Involvement of gut microbiota, microbial metabolites and interaction with polyphenol in host immunometabolism. Nutrients 2020, 12, 3054. [CrossRef]

16. Del Rio, D.; Rodriguez-Mateos, A.; Spencer, J.P.E.; Tognolini, M.; Borges, G.; Crozier, A. Dietary (poly)phenolics in human health: Structures, bioavailability, and evidence of protective effects against chronic diseases. Antioxid. Redox Signal. 2013, 18, 1818-1892. [CrossRef]

17. Saarela, M.; Lähteenmäki, L.; Crittendenb, R.; Salminenc, S.; Mattila-Sandholm, T. Gut bacteria and health foods-The European perspective. Int. J. Food Microbiol. 2002, 78, 99-117. [CrossRef]

18. Marchesi, J.R.; Adams, D.H.; Fava, F.; Hermes, G.D.A.; Hirschfield, G.M.; Hold, G.; Quraishi, M.N.; Kinross, J.; Smidt, H.; Tuohy, K.M.; et al. The gut microbiota and host health: A new clinical frontier. Gut 2016, 65, 330-339. [CrossRef] 
19. Cardona, F.; Andrés-Lacueva, C.; Tulipani, S.; Tinahones, F.J.; Queipo-Ortuño, M.I. Benefits of polyphenols on gut microbiota and implications in human health. J. Nutr. Biochem. 2013, 24, 1415-1422. [CrossRef]

20. Górniak, I.; Bartoszewski, R.; Króliczewski, J. Comprehensive review of antimicrobial activities of plant flavonoids. Phytochem. Rev. 2019, 18, 241-272. [CrossRef]

21. Piasecka, A.; Jedrzejczak-Rey, N.; Bednarek, P. Secondary metabolites in plant innate immunity: Conserved function of divergent chemicals. New Phytol. 2015, 206, 948-964. [CrossRef]

22. Mao, X.; Xiao, X.; Chen, D.; Yu, B.; He, J. Tea and its components prevent cancer: A review of the redox-related mechanism. Int. J. Mol. Sci. 2019, 20, 5249. [CrossRef]

23. Schaffer, S.; Asseburg, H.; Kuntz, S.; Muller, W.E.; Eckert, G.P. Effects of polyphenols on brain ageing and Alzheimer's disease: Focus on mitochondria. Mol. Neurobiol. 2012, 46, 161-178. [CrossRef]

24. Guasch-Ferré, M.; Merino, J.; Sun, Q.; Fitó, M.; Salas-Salvadó, J. Dietary polyphenols, mediterranean diet, prediabetes, and Type 2 diabetes: A narrative review of the evidence. Oxid. Med. Cell. Longev. 2017, 2017, 1-16. [CrossRef]

25. Kim, Y.; Keogh, J.B.; Clifton, P.M. Polyphenols and glycemic control. Nutrients 2016, 8, 17. [CrossRef]

26. Öztürk, E.; Arslan, A.K.K.; Yerer, M.B.; Bishayee, A. Resveratrol and diabetes: A critical review of clinical studies. Biomed. Pharmacother. 2017, 95, 230-234. [CrossRef]

27. Roleira, F.M.F.; Tavares-da-Silva, E.J.; Varela, C.L.; Costa, S.C.; Silva, T.; Garrido, J.; Borges, F. Plant derived and dietary phenolic antioxidants: Anticancer properties. Food Chem. 2015, 183, 235-258. [CrossRef] [PubMed]

28. Wang, S.; Moustaid-Moussa, N.; Chen, L.; Mo, H.; Shastri, A.; Su, R.; Bapat, P.; Kwun, I.; Shen, C.-L. Novel insights of dietary polyphenols and obesity. J. Nutr. Biochem. 2014, 25, 1-18. [CrossRef]

29. Fraga, C.G.; Croft, K.D.; Kennedy, D.O.; Tomás-Barberán, F.A. The effects of polyphenols and other bioactives on human health. Food Funct. 2019, 10, 514-528. [CrossRef] [PubMed]

30. Oppedisano, F.; Maiuolo, J.; Gliozzi, M.; Musolino, V.; Carresi, C.; Nucera, S.; Scicchitano, M.; Scarano, F.; Bosco, F.; Macrì, R.; et al. The potential for natural antioxidant supplementation in the early stages of neurodegenerative disorders. Int. J. Mol. Sci. 2020, 21, 2618. [CrossRef]

31. Silva, R.F.M.; Pogaĉnik, L. Polyphenols from food and natural products: Neuroprotection and safety. Antioxidants 2020, 9, 61. [CrossRef] [PubMed]

32. Singh, A.; Yau, Y.F.; Leung, K.S.; El-Nezami, H.; Lee, J.C.-Y. Interaction of polyphenols as antioxidant and anti-inflammatory compounds in brain-liver-gut axis. Antioxidants 2020, 9, 669. [CrossRef] [PubMed]

33. Stalmach, A.; Mullen, W.; Nagai, C.; Crozier, A. On-line HPLC analysis of the antioxidant activity of phenolic compounds in brewed, paper-filtered coffee. Braz. J. Plant Physiol. 2006, 18, 253-262. [CrossRef]

34. Ma, J.-N.; Ma, C.-M. Antifungal inhibitory activities of caffeic and quinic acid derivatives. In Coffee in Health and Disease Prevention; Preedy, V.R., Ed.; Elsevier Inc.; Academic Press: London, UK, 2015; pp. 635-641. [CrossRef]

35. Heleno, S.A.; Martins, A.; Queiroz, M.J.R.P.; Ferreira, I.C.F.R. Bioactivity of phenolic acids: Metabolites versus parent compounds: A review. Food Chem. 2015, 173, 501-513. [CrossRef] [PubMed]

36. He, F.; Pan, Q.H.; Shi, Y.; Duan, C.Q. Biosynthesis and genetic regulation of proanthocyanidins in plants. Molecules 2008, 13, 2674-2703. [CrossRef]

37. Clifford, M.N.; Jaganath, I.B.; Ludwig, I.A.; Crozier, A. Chlorogenic acids and the acyl-quinic acids: Discovery, biosynthesis, bioavailability and bioactivity. Nat. Prod. Rep. 2017, 34, 1391-1421. [CrossRef]

38. Tasdemir, D.; Lack, G.; Brun, R.; Ruedi, P.; Scapozza, L.; Perozzo, R. Inhibition of Plasmodium falciparum fatty acid biosynthesis: Evaluation of FabG, FabZ, and FabI as drug targets for flavonoids. J. Med. Chem. 2006, 49, 3345-3353. [CrossRef]

39. Routray, W.; Orsat, V. Blueberries and their anthocyanins: Factors affecting biosynthesis and properties. Comprehen. Rev. Food Sci. Food Saf. 2011, 10, 303-320. [CrossRef]

40. Naoi, M.; Wu, Y.; Shamoto-Nagai, M.; Maruyama, W. Mitochondria in neuroprotection by phytochemicals: Bioactive polyphenols modulate mitochondrial apoptosis system, function and structure. Int. J. Mol. Sci. 2019, 20, 2451. [CrossRef]

41. Qabaha, K.I. Antimicrobial and free radical scavenging activities of five Palestinian medicinal plants. Afr. J. Tradit. Complement. Altern. Med. 2013, 10, 101-108. [CrossRef]

42. Veličković, D.T.; Randjelović, N.V.; Ristić, M.S.; Veličković, A.S.; Šmelcerović, A.A. Chemical constituents and antimicrobial activity of the ethanol extracts obtained from the flower, leaf and stem of Salvia officinalis L. J. Serb. Chem. Soc. 2003, 68, 17-24. [CrossRef]

43. Bozyel, M.E.; Şenturan, M.; Benek, A.; Bozyel, E.M.; Canli, K.; Altuner, E.M. In vitro antimicrobial activity screening of Heliotropium europaeum against wide range of microorganisms and multi drug resistant (MDR) bacteria. Eur. J. Biomed. Pharmac. Sci. 2019, 6, 113-117.

44. Al-Juraifani, A.A. Antimicrobial activity of some medicinal plants used in Saudi Arabia. CJPAS 2011, 5, $509-1512$.

45. Al-Bayati, F.A.; Sulaiman, K.D. In vitro antimicrobial activity of Salvadora persica L. extracts against some isolated oral pathogens in Iraq. Turk. J. Biol. 2008, 32, 57-62.

46. Rasooli, I.; Shayegh, S.; Taghizadeh, M.; Astaneh, S.D.A. Phytotherapeutic prevention of dental biofilm formation. Phytother. Res. 2008, 22, 1162-1167. [CrossRef] [PubMed]

47. Puupponen-Pimia, R.; Nohynek, L.; Meier, C.; Kahkonen, M.; Heinonen, M.; Hopia, A.; Oksman-Caldentey, K.-M. Antimicrobial properties of phenolic compounds from berries. J. Appl. Microbiol. 2001, 90, 494-507. [CrossRef] [PubMed] 
48. Dall'Agnol, R.; Ferraz, A.; Bernardi, A.P.; Albring, D.; Nör, C.; Sarmento, L.; Lamb, L.; Hass, M.; von Poser, G.; Schapoval, E.E.S. Antimicrobial activity of some Hypericum species. Phytomedicine 2003, 10, 511-516. [CrossRef]

49. Rauha, J.-P.; Remes, S.; Heinonen, M.; Hopia, A.; Kahkonen, M.; Kujala, T.; Pihlaja, K.; Vuorela, H.; Vuorela, P. Antimicrobial effects of Finnish plant extracts containing flavonoids and other phenolic compounds. Int. J. Food Microbiol. 2000, 56, 3-12. [CrossRef]

50. Singh, R.; Shushni, M.A.M.; Belkheir, A. Antibacterial and antioxidant activities of Mentha piperita L. Arab. J. Chem. 2015, 8, 322-328. [CrossRef]

51. Osawa, K.; Saeki, T.; Yasuda, H.; Hamashima, H.; Sasatsu, M.; Arai, T. The antibacterial activities of peppermint oil and green tea polyphenols, alone and in combination, against enterohemorrhagic Escherichia coli. Biocontrol Sci. 1999, 4, 1-7. [CrossRef]

52. Vattem, D.A.; Lina, Y.-T.; Ghaedianb, R.; Shetty, K. Cranberry synergies for dietary management of Helicobacter pylori infections. Process Biochem. 2005, 40, 1583-1592. [CrossRef]

53. Si, W.; Gong, J.; Tsao, R.; Kalab, M.; Yang, R.; Yin, Y. Bioassay-guided purification and identification of antimicrobial components in Chinese green tea extract. J. Chromatogr. A 2006, 1125, 204-210. [CrossRef] [PubMed]

54. Shin, J.-S.; Chung, H.-S. Antibacterial activities of phenolic components from Camellia sinensis L. on pathogenic microorganisms. J. Food Sci. Nutr. 2007, 12, 135-140. [CrossRef]

55. Ankolekar, C.; Johnson, D.; da Silva Pinto, M.; Johnson, K.; Labbe, R.; Shetty, K. Inhibitory potential of tea polyphenolics and influence of extraction time against Helicobacter pylori and lack of inhibition of beneficial lactic acid bacteria. J. Med. Food 2011, 14, 1321-1329. [CrossRef] [PubMed]

56. Kohda, C.; Yanagawa, Y.; Shimamura, T. Epigallocatechin gallate inhibits intracellular survival of Listeria monocytogenes in macrophages. Biochem. Biophys. Res. Commun. 2008, 365, 310-315. [CrossRef]

57. Nakayama, M.; Shimatani, K.; Ozawa, T.; Shigemune, N.; Tomiyama, D.; Yui, K.; Katsuki, M.; Ikeda, K.; Nonaka, A.; Miyamoto, T. Mechanism for the antibacterial action of epigallocatechin gallate (EGCg) on Bacillus subtilis. Biosci. Biotechnol. Biochem. 2015, 79, 845-854. [CrossRef]

58. Coppo, E.; Marchese, A. Antbacterial activity of polyphenols. Curr. Pharm. Biotechnol. 2014, 15, 380-390. [CrossRef]

59. Tzounis, X.; Vulevic, J.; Kuhnle, G.G.C.; George, T.; Leonczak, J.; Gibson, G.R.; Kwik-Uribe, C.; Spencer, J.P.E. Flavanol monomerinduced changes to the human faecal microflora. Br. J. Nutr. 2008, 99, 782-792. [CrossRef]

60. Xie, Y.; Chen, J.; Xiao, A.; Liu, L. Antibacterial activity of polyphenols: Structure-activity relationship and influence of hyperglycemic condition. Molecules 2017, 22, 1913. [CrossRef]

61. Bae, E.A.; Han, M.J.; Kim, D.H. In vitro anti-Helicobacter pylori activity of some flavonoids and their metabolites. Planta Med. 1999, 65, 442-443. [CrossRef]

62. Rodríguez Vaquero, M.J.; Alberto, M.R.; Manca de Nadra, M.C. Influence of phenolic compounds from wines on the growth of Listeria monocytogenes. Food Control 2007, 18, 587-593. [CrossRef]

63. Duda-Chodak, A. The inhibitory effect of polyphenols on human gut microbiota. J. Physiol. Pharmacol. 2012, 63, 497-503. [PubMed]

64. Cueva, C.; Moreno-Arribas, M.V.; Martín-Álvarez, P.J.; Bills, G.; Vicente, M.F.; Basilio, A.; Rivas, C.L.; Requena, T.; Rodríguez, J.M.; Bartolome, B. Antimicrobial activity of phenolic acids against commensal, probiotic and pathogenic bacteria. Res. Microbiol. 2010, 161, 372-382. [CrossRef] [PubMed]

65. Takahashi, T.; Kokubo, R.; Sakaino, M. Antimicrobial activities of eucalyptus leaf extracts and flavonoids from Eucalyptus maculata. Lett. Appl. Microbiol. 2004, 39, 60-64. [CrossRef]

66. Roldán, L.P.; Díaz, G.J.; Duringer, J.M. Composition and antibacterial activity of essential oils obtained from plants of the Lamiaceae family against pathogenic and beneficial bacteria. Rev. Colomb. Cienc. Pec. 2010, 23, 451-461.

67. Adamczak, A.; Ożarowski, M.; Karpiński, T.M. Antibacterial activity of some flavonoids and organic acids widely distributed in plants. J. Clin. Med. 2020, 9, 109. [CrossRef]

68. Tabasco, R.; Sánchez-Patán, F.; Monagas, M.; Bartolomé, B.; Moreno-Arribas, M.V.; Peláez, C.; Requena, T. Effect of grape polyphenols on lactic acid bacteria and bifidobacteria growth: Resistance and metabolism. Food Microbiol. 2011, 28, 1345-1352 [CrossRef]

69. Gwiazdowska, D.; Juś, K.; Jasnowska-Małecka, J.; Kluczyńska, K. The impact of polyphenols on Bifidobacterium growth. Acta Biochim. Pol. 2015, 62, 895-901. [CrossRef]

70. Lee, H.C.; Jenner, A.M.; Low, C.S.; Lee, Y.K. Effect of tea phenolics and their aromatic fecal bacterial metabolites on intestinal microbiota. Res. Microbiol. 2006, 157, 876-884. [CrossRef]

71. Dolara, P.; Luceri, C.; De Filippo, C.; Femia, A.P.; Giovannelli, L.; Caderni, G.; Cecchini, C.; Silvi, S.; Orpianesi, C.; Cresci, A. Red wine polyphenols influence carcinogenesis, intestinal microflora, oxidative damage and gene expression profiles of colonic mucosa in F344 rats. Mutat. Res. 2005, 591, 237-246. [CrossRef]

72. Smith, A.H.; Zoetendal, E.; Mackie, R.I. Bacterial mechanisms to overcome inhibitory effects of dietary tannins. Microb. Ecol. 2005, 50, 197-205. [CrossRef] [PubMed]

73. Henning, S.M.; Summanen, P.H.; Lee, R.-P.; Yang, J.; Finegold, S.M.; Heber, D.; Li, Z. Pomegranate ellagitannins stimulate the growth of Akkermansia muciniphila in vivo. Anaerobe 2017, 43, 56-60. [CrossRef] [PubMed] 
74. Chen, M.-I.; Yi, L.; Zhang, Y.; Zhou, X.; Ran, L.; Yang, J.; Zhu, J.; Zhang, Q.; Mi, M. Resveratrol attenuates trimethylamine-N-oxide (TMAO)-induced atherosclerosis by regulating TMAO synthesis and bile acid metabolism via remodeling of the gut microbiota. mBio 2016, 7, 02210-02215. [CrossRef] [PubMed]

75. Qiao, Y.; Sun, J.; Xia, S.; Tang, X.; Le, Y.S.G. Effects of resveratrol on gut microbiota and fat storage in a mouse model with high-fat-inducedobesity. Food Funct. 2014, 5, 1241-1249. [CrossRef] [PubMed]

76. Masumoto, S.; Terao, A.; Yamamoto, Y.; Mukai, T.; Miura, T.; Shoji, T. Non-absorbable apple procyanidins prevent obesity associated with gut microbial and metabolomic changes. Sci. Rep. 2016, 6, 31208. [CrossRef] [PubMed]

77. Roopchand, D.E.; Carmody, R.N.; Kuhn, P.; Moskal, K.; Rojas-Silva, P.; Turnbaugh, P.J.; Raskin, I. Dietary polyphenols promote growth of the gut bacterium Akkermansia muciniphila and attenuate high-fat diet-induced metabolic syndrome. Diabetes 2015, 64, 2847-2858. [CrossRef] [PubMed]

78. Fogliano, V.; Corollaro, M.L.; Vitaglione, P.; Napolitano, A.; Ferracane, R.; Travaglia, F.; Arlorio, M.; Costabile, A.; Klinder, A.; Gibson, G. In vitro bioaccessibility and gut biotransformation of polyphenols present in the water-insoluble cocoa fraction. Mol. Nutr. Food Res. 2011, 55, S44-S55. [CrossRef] [PubMed]

79. Queipo-Ortuño, M.I.; Boto-Ordóñez, M.; Murri, M.; Gomez-Zumaquero, J.M.; Clemente-Postigo, M.; Estruch, R.; Diaz, F.C.; Andrés-Lacueva, C.; Tinahones, F.J. Influence of red wine polyphenols and ethanol on the gut microbiotaecology and biochemical biomarkers. Am. J. Clin. Nutr. 2012, 95, 1323-1334. [CrossRef] [PubMed]

80. Vendrame, S.; Guglielmetti, S.; Riso, P.; Arioli, S.; Klimis-Zacas, D.; Porrini, M. Six-week consumption of a wild blueberry powder drink increases bifidobacteria in the human gut. J. Agric. Food Chem. 2011, 59, 12815-12820. [CrossRef]

81. Moreno-Indias, I.; Sánchez-Alcoholado, L.; Pérez-Martínez, P.; Andrés-Lacueva, C.; Cardona, F.; Tinahones, F.; Queipo-Ortuño, M.I. Red wine polyphenols modulate fecal microbiota and reduce markers of the metabolic syndrome in obese patients. Food Funct. 2016, 7, 1775-1787. [CrossRef]

82. Bustos, I.; Garcia-Cayuela, T.; Hernández-Ledesma, B.; Peláez, C.; Requena, T.; Martinez-Cuesta, M.C. Effect of flavan-3-ols on the adhesion of potential probiotic Lactobacilli to intestinal cells. J. Agric. Food Chem. 2012, 60, 9082-9088. [CrossRef] [PubMed]

83. Volstatova, T.; Marsik, P.; Rada, V.; Geigerova, M.; Havlik, J. Effect of apple extracts and selective polyphenols on the adhesion of potential probiotic strains of Lactobacillus gasseri R and Lactobacillus casei FMP. J. Funct. Foods 2017, 35, 391-397. [CrossRef]

84. Howell, A.B. Bioactive compounds in cranberries and their role in prevention of urinary tract infections. Mol. Nutr. Food Res. 2007, 51, 732-737. [CrossRef] [PubMed]

85. Foo, L.Y.; Lu, Y.; Howell, A.B.; Vorsa, N. The structure of cranberry proanthocyanidins which inhibit adherence of uropathogenic P-fimbriated Escherichia coli in vitro. Phytochemistry 2000, 54, 173-181. [CrossRef]

86. Sánchez-Patán, F.; Cueva, C.; Monagas, M.; Walton, G.E.; Gibson, G.R.M.; Quintanilla-López, J.E.; Lebrón-Aguilar, R.; MartínÁlvarez, P.J.; Moreno-Arribas, M.V.; Bartolomé, B. In vitro fermentation of a red wine extract by human gut microbiota: Changes in microbial groups and formation of phenolic metabolites. J. Agric. Food Chem. 2012, 60, 2136-2147. [CrossRef]

87. Hervert-Hernández, D.; Pintado, C.; Rotger, R.; Goñi, I. Stimulatory role of grape pomace polyphenols on Lactobacillus acidophilus growth. Int. J. Food Microbiol. 2009, 136, 119-122. [CrossRef]

88. Vivas, N.; Lonvaud-Funel, A.; Glories, Y. Effect of phenolic acids and anthocyanins on growth, viability and malolactic activity of a lactic acid bacterium. Food Microbiol. 1997, 14, 291-300. [CrossRef]

89. Naito, Y.; Uchiyama, K.; Takagi, T. A next-generation beneficial microbe: Akkermansia muciniphila. J. Clin. Biochem. Nutr. 2018, 63, 33-35. [CrossRef]

90. Dehghanbanadaki, H.; Aazami, H.; Raftar, S.K.A.; Ashrafian, F.; Ejtahed, H.-S.; Hashemi, E.; Tavassol, H.Z.; Badi, S.A.; Siadat, S.D. Global scientific output trend for Akkermansia muciniphila research: A bibliometric and scientometric analysis. BMC Med. Inform. Decis. Mak. 2020, 20, 291. [CrossRef]

91. Farhadi, F.; Khameneh, B.; Iranshahi, M.; Iranshahy, M. Antibacterial activity of flavonoids and their structure-activity relationship: An update review. Phytother. Res. 2019, 33, 13-40. [CrossRef]

92. Mickymaray, S.; Alfaiz, F.A.; Paramasivam, A. Efficacy and mechanisms of flavonoids against the emerging opportunistic nontuberculous Mycobacteria. Antibiotics 2020, 9, 450. [CrossRef] [PubMed]

93. Pandey, A.K.; Kumar, S. Perspective on Plant Products as Antimicrobial Agents: A Review. Pharmacologia 2013, 4, 469-480. [CrossRef]

94. Papuc, C.; Goran, G.V.; Predescu, C.N.; Nicorescu, V.; Stefan, G. Plant polyphenols as antioxidant and antibacterial agents for shelf-life extension of meat and meat products: Classification, structures, sources, and action mechanisms. Compr. Rev. Food Sci. Food Saf. 2017, 16, 1243-1268. [CrossRef] [PubMed]

95. Cushnie, T.P.T.; Lamb, A.J. Antimicrobial activity of flavonoids. Int. J. Antimicrob. Agents 2005, 26, 343-356. [CrossRef] [PubMed]

96. Cushnie, T.P.T.; Lamb, A.J. Recent advances in understanding the antibacterial properties of flavonoids. Int. J. Antimicrob. Agents 2011, 38, 99-107. [CrossRef] [PubMed]

97. Matilla-Cuenca, L.; Gil, C.; Cuesta, S.; Rapún-Araiz, B.; Žiemytė, M.; Mira, A.; Lasa, I.; Valle, J. Antibiofilm activity of flavonoids on staphylococcal biofilms through targeting BAP amyloids. Sci. Rep. 2020, 10, 18968. [CrossRef]

98. Xie, Y.; Yang, W.; Tang, F.; Chen, X.; Ren, L. Antibacterial activities of flavonoids: Structure-activity relationship and mechanism. Curr. Med. Chem. 2015, 22, 132-149. [CrossRef]

99. Kumar, S.; Pandey, A.K. Chemistry and biological activities of flavonoids: An overview. Sci. World J. 2013, 162750. [CrossRef] 
100. Brudzynski, K.; Maldonado-Alvarez, L. Polyphenol-protein complexes and their consequences for the redox activity, structure and function of honey. A current view and new hypothesis-A review. Pol. J. Food Nutr. Sci. 2015, 65, 71-80. [CrossRef]

101. Seczyk, Ł.; Świeca, M.; Kapusta, I.; Gawlik-Dziki, U. Protein-phenolic interactions as a factor affecting the physicochemical properties of White Bean Proteins. Molecules 2019, 24, 408. [CrossRef]

102. Boath, A.S.; Grussu, D.; Stewart, D.; McDougall, G.J. Berry polyphenols inhibit digestive enzymes: A source of potential health benefits? Food Dig. 2012, 3, 1-7. [CrossRef]

103. Gonçalves, S.; Romano, A. Inhibitory properties of phenolic compounds against enzymes linked with human diseases. In Phenolic Compounds—Biological Activity; Soto-Hernandez, M., Palma-Tenango, M., Garcia-Mateos, M., Eds.; IntechOpen: Rijeka, Croatia, 2017; pp. 99-118. ISBN 978-953-51-5090-9. [CrossRef]

104. Martinez-Gonzalez, A.I.; Díaz-Sánchez, Á.G.; de la Rosa, L.A.; Vargas-Requena, C.L.; Bustos-Jaimes, I.; Alvarez-Parrilla, E. Polyphenolic compounds and digestive enzymes: In vitro non-covalent interactions. Molecules 2017, 22, 669. [CrossRef] [PubMed]

105. Sun, L.; Wang, Y.; Miao, M. Inhibition of $\alpha$-amylase by polyphenolic compounds: Substrate digestion, binding interactions and nutritional intervention. Trends Food Sci. Technol. 2020, 104, 190-207. [CrossRef]

106. Tadera, K.; Minami, Y.; Takamatsu, K.; Matsuoka, T. Inhibition of alpha-glucosidase and alpha-amylase by flavonoids. J. Nutr. Sci. Vitaminol. 2006, 52, 149-153. [CrossRef]

107. Cowan, M.M. Plant products as antimicrobial agents. Clin. Microbiol. Rev. 1999, 12, 564-582. [CrossRef]

108. Yang, N.Y.; Hinner, M.J. Getting across the cell membrane: An overview for small molecules, peptides, and proteins. Methods Mol. Biol. 2015, 1266, 29-53. [CrossRef]

109. Hu, P.; Huang, P.; Chen, M.W. Curcumin reduces Streptococcus mutans biofilm formation by inhibiting sortase A activity. Arch. Oral Biol. 2013, 58, 1343-1348. [CrossRef]

110. Kang, S.S.; Kim, J.-G.; Lee, T.-H.; Oh, K.-B. Flavonols inhibit sortases and sortase-mediated Staphylococcus aureus clumping to fibrynogen. Biol. Pharm. Bull. 2006, 29, 1751-1755. [CrossRef]

111. Edziri, H.; Mastouri, M.; Mahjoub, M.A.; Mighri, Z.; Mahjoub, A.; Verschaeve, L. Antibacterial, antifungal and cytotoxic activities of two flavonoids from Retama raetam flowers. Molecules 2012, 17, 7284-7293. [CrossRef]

112. Chen, Y.; Liu, T.; Wang, K.; Hou, C.; Cai, S.; Huang, Y.; Du, Z.; Huang, H.; Kong, J.; Chen, Y. Baicalein inhibits Staphylococcus aureus biofilm formation and the quorum sensing system in vitro. PLoS ONE 2016, 11, e0153468. [CrossRef]

113. Yoda, Y.; Hu, Z.-Q.; Zhao, W.-H.; Shimamura, T. Different susceptibilities of Staphylococcus and Gram-negative rods to epigallocatechin gallate. J. Infect. Chemother. 2004, 10, 55-58. [CrossRef] [PubMed]

114. Nakayama, M.; Shimatani, K.; Ozawa, T.; Shigemune, N.; Tsugukuni, T.; Tomiyama, D.; Kurahachi, M.; Nonaka, A.; Miyamoto, T. A study of the antibacterial mechanism of catechins: Isolation and identification of Escherichia coli cell surface proteins that interact with epigallocatechin gallate. Food Sci. Biotechnol. 2013, 33, 433-439. [CrossRef]

115. Taylor, P.W.; Hamilton-Miller, J.M.T.; Stapleton, P.D. Antimicrobial properties of green tea catechins. Food Sci. Technol. Bull. 2005, 2, 71-81. [CrossRef] [PubMed]

116. Fowler, Z.L.; Shah, K.; Panepinto, J.C.; Jacobs, A.; Koffas, M.A.G. Development of non-natural flavanones as antimicrobial agents. PLoS ONE 2011, 6, e25681. [CrossRef] [PubMed]

117. Omosa, L.K.; Midiwo, J.O.; Mbaveng, A.T.; Tankeo, S.B.; Seukep, J.A.; Voukeng, I.K.; Dzotam, J.K.; Isemeki, J.; Derese, S.; Omolle, R.A.; et al. Antibacterial activities and structure-Activity relationships of a panel of 48 compounds from Kenyan plants against multidrug resistant phenotypes. SpringerPlus 2016, 5, 901. [CrossRef] [PubMed]

118. Randhawa, H.K.; Hundal, K.K.; Ahirrao, P.N.; Jachak, S.M.; Nandanwar, H.S. Efflux pump inhibitory activity of flavonoids isolated from Alpinia calcarata against methicillin-resistant Staphylococcus aureus. Biologia 2016, 71, 484-493. [CrossRef]

119. Brown, A.K.; Papaemmanouil, A.; Bhowruth, V.; Bhatt, A.; Dover, L.G.; Besra, G.S. Flavonoid inhibitors as novel antimycobacterial agents targeting Rv0636, a putative dehydratase enzyme involved in Mycobacterium tuberculosis fatty acid synthase II. Microbiology 2007, 153, 3314-3322. [CrossRef]

120. Zhang, Y.M.; Rock, C.O. Evaluation of epigallocatechin gallate and related plant polyphenols as inhibitors of the FabG and FabI reductases of bacterial type II fatty-acid synthase. J. Biol. Chem. 2004, 279, 30994-31001. [CrossRef]

121. Xiao, Z.-T.; Zhu, Q.; Zhang, H.-Y. Identifying antibacterial targets of flavonoids by comparative genomics and molecular modelling. Open J. Genom. 2014, 3, 1-8. [CrossRef]

122. Zhang, L.; Kong, Y.; Wu, D.; Zhang, H.; Wu, J.; Chen, J.; Ding, J.; Hu, L.; Jiang, H.; Shen, X. Three flavonoids targeting the $\beta$-hydroxyacyl-acyl carrier protein dehydratase from Helicobacter pylori: Crystal structure characterization with enzymatic inhibition assay. Protein Sci. 2008, 17, 1971-1978. [CrossRef]

123. Jeong, K.-W.; Lee, J.-Y.; Kang, D.-I.; Lee, J.-U.; Shin, S.Y.; Kim, Y. Screening of flavonoids as candidate antibiotics against Enterococcus faecalis. J. Nat. Prod. 2009, 72, 719-724. [CrossRef] [PubMed]

124. Hertel, W.; Peschel, G.; Ozegowski, J.-H.; Müller, P.-J. Inhibitory effects of triterpenes and flavonoids on the enzymatic activity of hyaluronic acid-splitting enzymes. Arch. Pharm. Chem. Life Sci. 2006, 339, 313-318. [CrossRef] [PubMed]

125. Brahmachari, G.; Mandal, N.C.; Jash, S.K.; Roy, R.; Mandal, L.C.; Mukhopadhyay, A.; Biswajit Behera, B.; Majhi, S.; Mondal, A.; Gangopadhyay, A. Evaluation of the antimicrobial potential of two flavonoids isolated from Limnophila plants. Chem. Biodivers. 2011, 8, 1139-1151. [CrossRef] [PubMed]

126. Xiao, Z.-P.; Shi, D.-H.; Li, H.-Q.; Zhang, L.N.; Xua, C.; Zhua, H.-L. Polyphenols based on isoflavones as inhibitors of Helicobacter pylori urease. Bioorg. Med. Chem. 2007, 15, 3703-3710. [CrossRef] 
127. Ulrey, R.K.; Barksdale, S.M.; Zhou, W.; van Hoek, M.L. Cranberry proanthocyanidins have anti-biofilm properties against. BMC Complement. Altern. Med. 2014, 14, 499. [CrossRef]

128. Mori, A.; Nishino, C.; Enoki, N.; Tawata, S. Antibacterial activity and mode of action of plant flavonoids against Proteus vulgaris and Staphylococcus aureus. Phytochem. 1987, 26, 2231-2234. [CrossRef]

129. Lou, Z.; Wang, H.; Rao, S.; Sun, J.; Ma, C.; Li, J. p-Coumaric acid kills bacteria through dual damage mechanisms. Food Control 2012, 25, 550-554. [CrossRef]

130. Dzoyem, J.P.; Hamamoto, H.; Ngameni, B.; Ngadjui, B.T.; Sekimizu, K. Antimicrobial action mechanism of flavonoids from Dorstenia species. Drug Discov. Ther. 2013, 7, 66-72. [CrossRef]

131. Suriyanarayanan, B.; Shanmugam, K.; Santhosh, R.S. Synthetic quercetin inhibits mycobacterial growth possibly by interacting with DNA gyrase. Rom. Biotechnol. Lett. 2013, 18, 8587-8593.

132. Bandele, O.J.; Clawson, S.J.; Osheroff, N. Dietary polyphenols as topoisomerase II poisons: B ring and C ring substituents determine the mechanism of enzyme-mediated DNA cleavage enhancement. Chem. Res. Toxicol. 2008, 21, 1253-1260. [CrossRef]

133. Bandele, O.J.; Osheroff, N. (-)-Epigallocatechin gallate, a major constituent of green tea, poisons human type II topoisomerases Chem. Res. Toxicol. 2008, 21, 936-943. [CrossRef] [PubMed]

134. Oblak, M.; Kotnik, M.; Solmajer, T. Discovery and Development of ATPase inhibitors of DNA gyrase as antibacterial agents. Curr. Med. Chem. 2007, 14, 2033-2047. [CrossRef] [PubMed]

135. Plaper, A.; Golob, M.; Hafner, I.; Oblak, M.; Solmajer, T.; Jerala, R. Characterization of quercetin binding site on DNA gyrase. Biochem. Biophys. Res. Commun. 2003, 306, 530-536. [CrossRef]

136. Gradišar, H.; Pristovšek, P.; Plaper, A.; Jerala, R. Green Tea catechins inhibit bacterial DNA gyrase by interaction with its ATP binding site. J. Med. Chem. 2007, 50, 264-271. [CrossRef] [PubMed]

137. Ohemeng, K.A.; Podlogar, B.L.; Nguyen, V.N.; Bernstein, J.I.; Krause, H.M.; Hilliard, J.J.; Barrett, J.F. DNA gyrase inhibitory and antimicrobial activities of some diphenic acid monohydroxamides. J. Med. Chem. 1997, 40, 3292-3296. [CrossRef] [PubMed]

138. Fang, Y.; Lu, Y.; Zang, X.; Wu, T.; Qi, X.J.; Pan, S.; Xu, X. 3D-QSAR and docking studies of flavonoids as potent Escherichia coli inhibitors. Sci. Rep. 2016, 6, 1-13. [CrossRef] [PubMed]

139. Bernard, F.-X.; Sable, S.; Cameron, B.; Provost, J.; Desnottes, J.-F.; Crouzet, J.; Blanche, F. Glycosylated flavones as selective inhibitors of topoisomerase IV. Antimicrob. Agents Chemother. 1997, 41, 992-998. [CrossRef] [PubMed]

140. Arima, H.; Hitoshi Ashida, H.; Danno, G. Rutin-enhanced antibacterial activities of flavonoids against Bacillus cereus and Salmonella enteritidis. Biosci. Biotechnol. Biochem. 2002, 66, 1009-1014. [CrossRef]

141. Khan, N.S.; Ahmad, A.; Hadi, S.M. Anti-oxidant, pro-oxidant properties of tannic acid and its binding to DNA. Chem. Biol. Interact. 2000, 125, 177-189. [CrossRef]

142. Cetin-Karaca, H.; Newman, M.C. Antimicrobial efficacy of plant phenolic compounds against Salmonella and Escherichia coli. Food Biosci. 2015, 11, 8-16. [CrossRef]

143. Stepanović, S.; Antić, N.; Dakić, I.; Švabić-Vlahović, M. In vitro antimicrobial activity of propolis and synergism between propolis and antimicrobial drugs. Microbiol. Res. 2003, 158, 353-357. [CrossRef] [PubMed]

144. Ikigai, H.; Nakae, T.; Hara, Y.; Shimamura, T. Bactericidal catechins damage the lipid bilayer. Biochim. Biophys. Acta 1993, 1147, 132-136. [CrossRef]

145. Vattem, D.A.; Lin, Y.-T.; Labbe, R.G.; Shetty, K. Phenolic antioxidant mobilization in cranberry pomace by solid-state bioprocessing using food grade fungus Lentinus edodes and effect on antimicrobial activity against select food borne pathogens. Innov. Food Sci. Emerg. Technol. 2004, 5, 81-91. [CrossRef]

146. Wu, D.; Kong, Y.; Han, C.; Chen, J.; Hu, L.; Jiang, H.; Shen, X. d-Alanine:d-alanine ligase as a new target for the flavonoids quercetin and apigenin. Int. J. Antimicrob. Agents 2008, 32, 421-426. [CrossRef] [PubMed]

147. Xiao, Z.-P.; Wei, W.; Liu, Q.; Wang, P.-F.; Luo, X.; Chen, F.-Y.; Cao, Y.; Huang, H.-X.; Liua, M.-M.; Zhu, H.L. C-7 modified flavonoids as novel tyrosyl-tRNA synthetase inhibitors. RSC Adv. 2017, 7, 6193-6201. [CrossRef]

148. Cai, W.; Fu, Y.; Zhang, W.; Chen, X.; Zhao, J.; Song, W.; Li, Y.; Huang, Y.; Wu, Z.; Sun, R.; et al. Synergistic effects of baicalein with cefotaxime against Klebsiella pneumonia through inhibiting CTX-M-1 gene expression. BMC Microbiol. 2016, 16, 181. [CrossRef]

149. Farooq, S.; Wahab, A.-T.; Fozing, C.D.A.; Rahman, A.-U.; Choudhary, M.I. Artonin I inhibits multidrug resistance in Staphylococcus aureus and potentiates the action of inactive antibiotics in vitro. J. Appl. Microbiol. 2014, 117, 996-1011. [CrossRef]

150. Zhao, W.-H.; Hu, Z.-Q.; Okubo, S.; Hara, Y.; Shimamura, T. Mechanism of synergy between epigallocatechin gallate and $\beta$-lactams against Methicillin-Resistant Staphylococcus aureus. Antimicrob. Agents Chemother. 2001, 45, 1737-1742. [CrossRef]

151. Delehanty, J.B.; Johnson, B.J.; Hickey, T.E.; Pons, T.; Ligler, F.S. Plant proanthocyanidins bind to and neutralize bacterial lipopolysaccharides. In Naval Research Laboratory Reviews; 2008; pp. 101-107.

152. Nohynek, L.J.; Alakomi, H.L.; Kähkönen, M.P.; Heinonen, M.; Helander, I.M.; Oksman-Caldentey, K.-M.; Puupponen-Pimiä, R.H. Berry phenolics: Antimicrobial properties and mechanisms of action against severe human pathogens. Nutr. Cancer 2006, 54, 18-32. [CrossRef]

153. Hartmann, M.; Berditsch, M.; Hawecker, J.; Ardakani, M.F.; Gerthsen, D.; Ulrich, A.S. Damage of the bacterial cell envelope by antimicrobial peptides gramicidin $\mathrm{S}$ and PGLa as revealed by transmission and scanning electron microscopy. Antimicrob. Agents Chemother. 2010, 54, 3132-3142. [CrossRef]

154. Reygaert, W.C. The antimicrobial possibilities of green tea. Front. Microbiol. 2014, 5, 434. [CrossRef] [PubMed] 
155. Lee, H.; Woo, E.-R.; Lee, D.G. Apigenin induces cell shrinkage in Candida albicans by membrane perturbation. FEMS Yeast Res. 2018, 18, 1-9. [CrossRef] [PubMed]

156. Perumal, S.; Mahmud, R.; Ismail, S. Mechanism of action of isolated caffeic acid and epicatechin 3-gallate from Euphorbia hirta against Pseudomonas aeruginosa. Pharmacogn. Mag. 2017, 13 (Suppl. 2), S311-S315. [CrossRef]

157. Matijašević, D.; Pantić, M.; Rašković, B.; Pavlović, V.; Duvnjak, D.; Sknepnek, A.; Nikšić, M. The antibacterial activity of Coriolus versicolor methanol extract and its effect on ultrastructural changes of Staphylococcus aureus and Salmonella Enteritidis. Front. Microbiol. 2016, 7, 1226. [CrossRef] [PubMed]

158. Fathima, A.; Rao, J.R. Selective toxicity of Catechin-A natural flavonoid towards bacteria. Appl. Microbiol. Biotechnol. 2016, 100, 6395-6402. [CrossRef]

159. Tagousop, C.N.; Tamokou, J.d.D.; Ekom, S.E.; Ngnokam, D.; Voutquenne-Nazabadioko, L. Antimicrobial activities of flavonoid glycosides from Graptophyllum grandulosum and their mechanism of antibacterial action. BMC Complement. Altern. Med. 2018, 18, 252. [CrossRef]

160. Ollila, F.; Halling, K.; Vuorela, P.; Vuorela, H.; Slotte, J.P. Characterization of flavonoid-biomembrane interactions. Arch. Biochem. Biophys. 2002, 399, 103-108. [CrossRef]

161. Chabot, S.; Bel-Rhlid, R.; Chenevert, R.; Piche, Y. Hyphal growth promotion in vitro of the VA mycorrhizal fungus, Gigaspora margarita Becker \& Hall, by the activity of structurally specific flavonoid compounds under $\mathrm{CO}_{2}$-enriched conditions. New Phytol. 1992, 122, 461-467.

162. Tsuchiya, H. Stereospecificity in membrane effects of catechins. Chem. Biol. Inter. 2001, 134, 41-54. [CrossRef]

163. Carson, C.F.; Mee, B.J.; Riley, T.V. Mechanism of action of Melaleuca alternifolia (Tea Tree) oil on Staphylococcus aureus determined by time-kill, lysis, leakage, and salt tolerance assays and electron microscopy. Antimicrob. Agents Chemother. 2002, 46, 1914-1920. [CrossRef]

164. Tsuchiya, H. Membrane interactions of phytochemicals as their molecular mechanism applicable to the discovery of drug leads from plants. Molecules 2015, 20, 18923-18966. [CrossRef]

165. Selvaraj, S.; Krishnaswamy, S.; Devashya, V.; Sethuraman, S.; Krishnan, U.M. Influence of membrane lipid composition on flavonoid-membrane interactions: Implications on their biological activity. Progr. Lipid Res. 2015, 58, 1-13. [CrossRef] [PubMed]

166. Arora, A.; Byrem, T.M.; Nair, M.G.; Strasburg, G.M. Modulation of liposomal membrane fluidity by flavonoids and isoflavonoids Arch. Biochem. Biophys. 2000, 373, 102-109. [CrossRef] [PubMed]

167. Van Dijk, C.; Driessen, A.J.M.; Recourt, K. The Uncoupling efficiency and affinity of flavonoids for vesicles. Biochem. Pharmacol. 2000, 60, 1593-1600. [CrossRef]

168. Wu, T.; He, M.; Zang, X.; Zhou, Y.; Qio, T.; Pan, S.; Xu, X. A structure-activity relationship study of flavonoids as inhibitors of $E$. coli by membrane interaction effect. Biochim. Biophys. Acta 2013, 1828, 2751-2756. [CrossRef]

169. He, M.; Wu, T.; Pan, S.; Xu, X. Antimicrobial mechanism of flavonoids against Escherichia coli ATCC25922 by model membrane study. Appl. Surf. Sci. 2014, 305, 515-521. [CrossRef]

170. Mun, S.-H.; Joung, D.-K.; Kim, S.-B.; Park, S.-J.; Seo, Y.-S.; Gong, R.; Choi, J.-G.; Shin, D.-W.; Rho, J.-R.; Kang, O.-H.; et al. The mechanism of antimicrobial activity of sophoraflavanone B against methicillin-resistant Staphylococcus aureus. Foodborne Pathog. Dis. 2014, 11, 234-239. [CrossRef]

171. Savoia, D. Plant-derived antimicrobial compounds: Alternatives to antibiotic. Future Microbiol. 2012, 7, 979-990. [CrossRef]

172. Chinnam, N.; Dadi, P.K.; Sabri, S.A.; Ahmad, M.; Kabir, M.A.; Ahmad, Z. Dietary bioflavonoids inhibit Escherichia coli ATP synthase in a differential manner. Int. J. Biol. Macromol. 2010, 46, 478-486. [CrossRef]

173. Dadi, P.K.; Ahmad, M.; Ahmad, Z. Inhibition of ATPase activity of Escherichia coli ATP synthase by polyphenols. Int. J. Biol. Macromol. 2009, 45, 72-79. [CrossRef]

174. Gill, A.O.; Holley, R.A. Inhibition of membrane bound ATPases of Escherichia coli and Listeria monocytogenes by plant oil aromatics. Int. J. Food Microbiol. 2006, 111, 170-174. [CrossRef] [PubMed]

175. Ahmad, Z.; Laughlin, T.F.; Kady, I.O. Thymoquinone inhibits Escherichia coli ATP synthase and cell growth. PLoS ONE 2015, 10, e0127802. [CrossRef] [PubMed]

176. Haraguchi, H.; Tanimoto, K.; Tamura, Y.; Mizutanit, K.; Kinoshita, T. Mode of antibacterial action of retrochalcones from Glycyrrhiza inflata. Phytochemistry 1998, 48, 125-129. [CrossRef]

177. Kim, H.-S.; Quon, M.J.; Kim, J. New insights into the mechanisms of polyphenols beyond antioxidant properties; lessons from the green tea polyphenol, epigallocatechin 3-gallate. Redox Biol. 2014, 2, 187-195. [CrossRef] [PubMed]

178. Castillo-Juárez, I.; Maeda, T.; Mandujano-Tinoco, E.A.; Tomás, M.; Pérez-Eretza, B.; García-Contreras, S.J.; Wood, T.K.; GarcíaContreras, R. Role of quorum sensing in bacterial infections. World J. Clin. Cases 2015, 3, 575-598. [CrossRef] [PubMed]

179. Packiavathy, I.A.S.V.; Priya, S.; Pandian, S.K.; Ravi, A.V. Inhibition of biofilm development of uropathogens by curcumin-An anti-quorum sensing agent from Curcuma longa. Food Chem. 2014, 148, 453-460. [CrossRef]

180. Wang, T.-Y.; Li, Q.; Bi, K.-S. Bioactive flavonoids in medicinal plants: Structure, activity and biological fate. Asian J. Pharm. Sci. 2018, 13, 12-23. [CrossRef]

181. Gopu, V.; Meena, C.K.; Shetty, P.H. Quercetin influences quorum sensing in food borne bacteria: In-vitro and in-silico evidence. PLoS ONE 2015, 10, e0134684. [CrossRef] 
182. Al Azzaz, J.; Al Tarraf, A.; Heumann, A.; Da Silva Barreira, D.; Laurent, J.; Assifaoui, A.; Rieu, A.; Guzzo, J.; Lapaquette, P. Resveratrol favors adhesion and biofilm formation of Lacticaseibacillus paracasei subsp. paracasei Strain ATCC334. Int. J. Mol. Sci. 2020, 21, 5423. [CrossRef]

183. Lee, J.-H.; Regmi, S.C.; Kim, J.-A.; Cho, M.H.; Yun, H.; Lee, C.-S.; Lee, J. Apple flavonoid phloretin inhibits Escherichia coli O157:H7 biofilm formation and ameliorates colon inflammation in rats. Infect. Immun. 2011, 79, 4819-4827. [CrossRef]

184. Serra, D.O.; Mika, F.; Richter, A.M.; Hengge, R. The green tea polyphenol EGCG inhibits E. coli biofilm formation by impairing amyloid curli fibre assembly and downregulating the biofilm regulator CsgD via the r E -dependent sRNA RybB. Mol. Microbiol. 2016, 101, 136-151. [CrossRef] [PubMed]

185. Hengge, R. Targeting bacterial biofilms by the Green Tea polyphenol EGCG. Molecules 2019, 24, 2403. [CrossRef] [PubMed]

186. Bai, L.; Takagi, S.; Ando, T.; Yoneyama, H.; Ito, K.; Mizugai, H.; Isogai, E. Antimicrobial activity of tea catechin against canine oral bacteria and the functional mechanisms. J. Vet. Med. Sci. 2016, 78, 1439-1445. [CrossRef] [PubMed]

187. Wu, C.-Y.; Su, T.Y.; Wang, M.Y.; Yang, S.-F.; Mar, K.; Hung, S.-L. Inhibitory effects of tea catechin epigallocatechin-3-gallate against biofilms formed from Streptococcus mutans and a probiotic Lactobacillus strain. Arch. Oral Biol. 2018, 94, 69-77. [CrossRef]

188. Veloz, J.J.; Alvear, M.; Salazar, L.A. Antimicrobial and antibiofilm activity against Streptococcus mutans of individual and mixtures of the main polyphenolic compounds found in chilean propolis. BioMed Res. Int. 2019, 2019, 7602343. [CrossRef]

189. Xu, X.; Zhou, X.D.; Wu, C.D. Tea catechin epigallocatechin gallate inhibits Streptococcus mutans biofilm formation by suppressing gtf genes. Arch. Oral Biol. 2012, 57, 678-683. [CrossRef]

190. Xu, X.; Zhou, X.D.; Wu, C.D. The tea catechin epigallocatechin gallate suppresses cariogenic virulence factors of Streptococcus mutans. Antimicrob. Agents Chemother. 2011, 55, 1229-1236. [CrossRef]

191. Sivaranjani, M.; Gowrishankar, S.; Kamaladevi, A.; Pandian, S.K.; Balamurugan, K.; Ravi, A.V. Morin inhibits biofilm production and reduces the virulence of Listeria monocytogenes-An in vitro and in vivo approach. Int. J. Food Microbiol. 2016, 237, 73-82. [CrossRef]

192. Upadhyay, A.; Upadhyaya, I.; Kollanoor-Johny, A.; Venkitanarayanan, K. Antibiofilm effect of plant derived antimicrobials on Listeria monocytogenes. Food Microbiol. 2013, 36, 79-89. [CrossRef]

193. Borges, A.; Saavedra, M.J.; Simões, M. The activity of ferulic and gallic acids in biofilm prevention and control of pathogenic bacteria. J. Bioadh. Biofilm Res. 2012, 28, 755-767. [CrossRef]

194. Borges, A.; Ferreira, C.; Saavedra, M.J.; Simões, M. Antibacterial activity and mode of action of ferulic and gallic acids against pathogenic bacteria. Microb. Drug Resist. 2013, 19, 256-265. [CrossRef] [PubMed]

195. Muñoz-Cazares, N.; García-Contreras, R.; Pérez-López, M.; Castillo-Juárez, I. Phenolic compounds with anti-virulence properties. In Phenolic Compounds—Biological Activity; Soto-Hernandez, M., Palma-Tenango, M., del Rosario Garcia-Mateos, M., Eds.; IntechOpen: Rijeka, Croatia, 2017; pp. 139-167. [CrossRef]

196. Daglia, M. Polyphenols as antimicrobial agents. Curr. Opin. Biotechnol. 2012, 23, 174-181. [CrossRef] [PubMed]

197. Scalbert, A. Antimicrobial properties of tannins. Phytochemistry 1991, 30, 3875-3883. [CrossRef]

198. Field, S.A.; Lettinga, G. Toxicity of tannic compounds to microorganisms. In Plant Polyphenols, 1st ed.; Hemingway, R.W., Laks, P.E., Eds.; Plenum Press: New York, NY, USA, 1992; pp. 673-692.

199. Chung, K.T.; Lu, Z.; Chou, M.W. Mechanism of inhibition of tannic acid and related compounds on the growth of intestinal bacteria. Food Chem. Toxicol. 1998, 36, 1053-1060. [CrossRef]

200. Andrews, S.C.; Robinson, A.K.; Rodriguez-Quiñones, F. Bacterial iron homeostasis. FEMS Microbiol. Rev. 2003, $27,215-237$. [CrossRef]

201. Perron, N.R.; Brumaghim, J.L. A Review of the antioxidant mechanisms of polyphenol compounds related to iron binding. Cell Biochem. Biophys. 2009, 53, 75-100. [CrossRef]

202. Fernandez, M.T.; Mira, M.L.; Florencio, M.H.; Jennings, K.R. Iron and copper chelation by flavonoids: An electrospray mass spectrometry study. J. Inorg. Biochem. 2002, 92, 105-111. [CrossRef]

203. Mladěnka, P.; Macáková, K.; Filipský, T.; Zatloukalová, L.; Jahodář, L.; Bovicelli, P.; Silvestri, I.P.; Hrdina, R.; Saso, L. In vitro analysis of iron chelating activity of flavonoids. J. Inorg. Biochem. 2011, 105, 693-701. [CrossRef]

204. Rajakovich, L.J.; Balskus, E.P. Metabolic functions of the human gut microbiota: The role of metalloenzymes. Nat. Prod. Rep. 2019, 36, 593. [CrossRef]

205. Wang, W.-L.; Chai, S.C.; Huang, M.; He, H.-Z.; Hurley, T.D.; Ye, Q.-Z. Discovery of inhibitors of Escherichia coli methionine aminopeptidase with the Fe(II)-form selectivity and antibacterial activity. J. Med. Chem. 2008, 51, 6110-6120. [CrossRef]

206. Lagha, A.B.; Haas, B.; Grenier, D. Tea polyphenols inhibit the growth and virulence properties of Fusobacterium nucleatum. Sci. Rep. 2017, 7, 44815. [CrossRef] [PubMed]

207. Lee, P.; Tan, K.S. Effects of epigallocatechin gallate against Enterococcus faecalis biofilm and virulence. Arch. Oral Biol. 2015, 60, 393-399. [CrossRef] [PubMed]

208. Echeverría, J.; Opazo, J.; Mendoza, L.; Urzúa, A.; Wilkens, M. Structure-activity and lipophilicity relationships of selected antibacterial natural flavones and flavanones of Chilean flora. Molecules 2017, 22, 608. [CrossRef]

209. Botta, B.; Vitali, A.; Menendez, P.; Misiti, D.; Delle Monache, G. Prenylated flavonoids: Pharmacology and biotechnology. Curr. Med. Chem. 2005, 12, 713-739. [CrossRef] [PubMed] 
210. Cermak, P.; Olsovska, J.; Mikyska, A.; Dusek, M.; Kadleckova, Z.; Vanicek, J.; Nyc, O.; Sigler, K.; Bostikova, V.; Bostik, P. Strong antimicrobial activity of xanthohumol and other derivatives from hops (Humulus lupulus L.) on gut anaerobic bacteria. APMIS 2017, 125, 1033-1038. [CrossRef] [PubMed]

211. Stompor, M.; Zarowska, B. Antimicrobial activity of xanthohumol and its selected structural analogues. Molecules 2016, 21, 608. [CrossRef] [PubMed]

212. Jamil, S.; Lathiff, S.M.A.; Abdullah, S.A.; Jemaon, N.; Sirat, H.M. Antimicrobial flavonoids from Artocarpus anisophyllus Miq. and Artocarpus lowii King. J. Tekchnologi 2014, 71, 95-99. [CrossRef]

213. Campos, F.M.; Couto, J.A.; Figueiredo, A.R.; Tóth, I.V.; Rangel, A.O.S.S.; Hogg, T.A. Cell membrane damage induced by phenolic acids on wine lactic acid bacteria. Int. J. Food Microbiol. 2009, 135, 144-151. [CrossRef]

214. Thakur, D.; Das, S.C.; Sabhapondit, S.; Tamuly, P.; Deka, D.K. Antimicrobial activities of Tocklai vegetative tea clones. Indian J. Microbiol. 2011, 51, 450-455. [CrossRef]

215. Puljula, E.; Walton, G.; Woodward, M.J.; Karonen, M. Antimicrobial activities of ellagitannins against Clostridiales perfringens, Escherichia coli, Lactobacillus plantarum and Staphylococcus aureus. Molecules 2020, 25, 3714. [CrossRef]

216. Tarko, T.; Duda-Chodak, A.; Wajda, Ł.; Satora, P.; Sroka, P.; Semik-Szczurak, D. Application of principal component analysis for optimization of polyphenol extraction from alternative plant sources. J. Food Nutr. Res. 2017, 56, 61-72.

217. Boeing, J.S.; Barizão, E.O.; Costa e Silva, B.; Montanher, F.P.; de Cinque Almeida, V.; Visentainer, J.V. Evaluation of solvent effect on the extraction of phenolic compounds and antioxidant capacities from the berries: Application of principal component analysis. Chem. Cent. J. 2014, 8, 48. [CrossRef] [PubMed]

218. Borges, A.; José, H.; Homem, V.; Simões, M. Comparison of techniques and solvents on the antimicrobial and antioxidant potential of extracts from Acacia dealbata and Olea europaea. Antibiotics 2020, 9, 48. [CrossRef] [PubMed]

219. Tarko, T.; Duda-Chodak, A.; Soszka, A. Changes in phenolic compounds and antioxidant activity of fruit musts and fruit wines during simulated digestion. Molecules 2020, 25, 5574. [CrossRef] [PubMed]

220. Renard, C.M.G.C.; Watrelot, A.A.; Le Bourvellec, C. Interactions between polyphenols and polysaccharides: Mechanisms and consequences in food processing and digestion. Trends Food Sci. Technol. 2017, 60, 43-51. [CrossRef]

221. Spencer, J.P.E. Metabolism of tea flavonoids in the gastrointestinal tract. J. Nutr. 2003, 133, 3255S-3261S. [CrossRef]

222. Thomas, M.; Thibault, J.-F. Cell-wall polysaccharides in the fruits of Japanese quince (Chaenomeles japonica): Extraction and preliminary characterisation. Carbohydr. Polym. 2002, 49, 345-355. [CrossRef]

223. Ma, Y.; Luo, J.; Xu, Y. Co-preparation of pectin and cellulose from apple pomace by a sequential process. J. Food. Sci. Technol. 2019, 56, 4091-4100. [CrossRef]

224. Bindon, K.A.; Bacic, A.; Kennedy, J.A. Tissue-specific and developmental modifications of grape cell walls influence the adsorption of proanthocyanidins. J. Agric. Food Chem. 2012, 60, 9249-9260. [CrossRef]

225. Phan, A.D.T.; Flanagan, B.M.; D'Arcy, B.R.; Gidley, M.J. Binding selectivity of dietary polyphenols to different plant cell wall components: Quantification and mechanism. Food Chem. 2017, 233, 216-227. [CrossRef]

226. Voragen, A.G.J.; Coenen, G.-J.; Verhoef, R.P.; Schols, H.A. Pectin, a versatile polysaccharide present in plant cell walls. Struct. Chem. 2009, 20, 263-275. [CrossRef]

227. Thomas, M.; Guillemin, F.; Guillon, F.; Thibault, J.-F. Pectins in the fruits of Japanese quince (Chaenomeles japonica). Carbohydr. Polym. 2003, 53, 361-372. [CrossRef]

228. Liu, Y.; Ying, D.; Sanguansri, L.; Cai, Y.; Le, X. Adsorption of catechin onto cellulose and its mechanism study: Kinetic models, characterization and molecular simulation. Food Res. Int. 2018, 112, 225-232. [CrossRef] [PubMed]

229. Selma, M.V.; Espin, J.C.; Tomás-Barberán, F.A. Interaction between phenolics and gut microbiota: Role in human health. J. Agric. Food Chem. 2009, 57, 6485-6501. [CrossRef] [PubMed]

230. Healey, G.R.; Murphy, R.; Brough, L.; Butts, C.A.; Coad, J. Interindividual variability in gut microbiota and host response to dietary interventions. Nutr Rev. 2017, 75, 1059-1080. [CrossRef]

231. Gross, G.; Jacobs, D.M.; Peters, S.; Possemiers, S.; van Duynhoven, J.; Vaughan, E.E.; van de Wiele, T. In vitro bioconversion of polyphenols from black tea and red wine/grape juice by human intestinal microbiota displays strong interindividual variability. J. Agric. Food Chem. 2010, 58, 10236-10246. [CrossRef]

232. Hwang, C.S.; Kwak, H.S.; Lim, H.J.; Lee, S.H.; Kang, Y.S.; Choe, T.B.; Hur, H.G.; Han, K.O. Isoflavone metabolites and their in vitro dual functions: They can act as an estrogenic agonist or antagonist depending on the estrogen concentration. J. Steroid. Biochem. Mol. Biol. 2006, 101, 246-253. [CrossRef]

233. Frankenfeld, C.L. O-desmethylangolensin: The importance of equol's lesser known cousin to human health. Adv. Nutr. 2011, 2, 317-324. [CrossRef]

234. Vázquez, L.; Llórez, A.B.; Redruello, B.; Mayo, B. Metabolism of soy isoflavones by intestinal bacteria: Genome analysis of an Adlercreutzia equolifaciens strain that does not produce equol. Biomolecules 2020, 10, 950. [CrossRef]

235. Murota, K.; Nakamura, Y.; Uehara, M. Flavonoid metabolism: The interaction of metabolites and gut microbiota. Biosci. Biotechnol. Biochem. 2018, 82, 600-610. [CrossRef]

236. Mace, T.A.; Ware, M.B.; King, S.A.; Loftus, S.; Farren, M.R.; McMichael, E.; Scoville, S.; Geraghty, C.; Young, G.; Carson, W.E., III; et al. Soy isoflavones and their metabolites modulate cytokine-induced natural killer cell function. Sci. Rep. 2019, 9, 5068. [CrossRef] [PubMed] 
237. Marín, L.; Miguélez, E.M.; Villar, C.J.; Lombó, F. Bioavailability of dietary polyphenols and gut microbiota metabolism: Antimicrobial properties. Biomed Res. Int. 2015, 2015, 905215. [CrossRef] [PubMed]

238. Kim, M.; Kim, S.-I.; Han, J.; Wang, X.-L.; Song, D.-G.; Kim, S.-U. Stereospecific biotransformation of dihydrodaidzein into (3S)equol by the human intestinal bacterium Eggerthella strain Julong 732. Appl. Environ. Microbiol. 2009, 75, 3062-3068. [CrossRef] [PubMed]

239. Braune, A.; Blaut, M. Bacterial species involved in the conversion of dietary flavonoids in the human gut. Gut Microbes 2016, 7 , 216-234. [CrossRef] [PubMed]

240. Decroos, K.; Vanhemmens, S.; Cattoir, S.; Boon, N.; Verstraete, W. Isolation and characterisation of an equol-producing mixed microbial culture from a human faecal sample and its activity under gastrointestinal conditions. Arch. Microbiol. 2005, 183, 45-55. [CrossRef]

241. Hur, H.-G.; Beger, R.D.; Heinze, T.M.; Lay, J.O., Jr.; Freeman, J.P.; Dore, J.; Rafii, F. Isolation of an anaerobic intestinal bacterium capable of cleaving the C-ring of the isoflavonoid daidzein. Arch. Microbiol. 2002, 178, 8-12. [CrossRef]

242. Rossi, M.; Amaretti, A.; Roncaglia, L.; Leonardi, A.; Raimondi, S. Dietary isoflavones and intestinal microbiota: Metabolism and transformation into bioactive compounds. In Isoflavones Biosynthesis, Occurence and Health Effects; Thompson, M.J., Ed.; Nova Science Publishers Inc.: New York, NY, USA, 2010; pp. 137-216. ISBN 9781617281136.

243. Schoefer, L.; Mohan, R.; Braune, A.; Birringer, M.; Blaut, M. Anaerobic C-ring cleavage of genistein and daidzein by Eubacterium ramulus. FEMS Microbiol. Lett. 2002, 208, 197-202. [CrossRef]

244. Kim, M.; Han, J.; Kim, S.-U. Isoflavone daidzein: Chemistry and bacterial metabolism. J. Appl. Biol. Chem. 2008, 51, $253-261$. [CrossRef]

245. Matthies, A.; Clavel, T.; Gütschow, M.; Engst, W.; Haller, D.; Blaut, M.; Braune, A. Conversion of daidzein and genistein by an anaerobic bacterium newly isolated from the mouse intestine. Appl. Environ. Microbiol. 2008, 74, 4847-4852. [CrossRef]

246. Matthies, A.; Loh, G.; Blaut, M.; Braune, A. Daidzein and genistein are converted to equol and 5-hydroxy-equol by human intestinal Slackia isoflavoniconvertens in gnotobiotic rats. J. Nutr. 2012, 142, 40-46. [CrossRef]

247. Wang, X.-L.; Kim, H.-K.; Kang, S.-I.; Kim, S.-U.; Hur, H.-G. Production of phytoestrogen S-equol from daidzein in mixed culture of two anaerobic bacteria. Arch. Microbiol. 2007, 187, 155-160. [CrossRef] [PubMed]

248. Yokoyama, S.-i.; Suzuki, T. Isolation and characterization of a novel equol-producing bacterium from human feces. Biosci. Biotechnol. Biochem. 2008, 72, 2660-2666. [CrossRef] [PubMed]

249. Tamura, M.; Tsushida, T.; Shinohara, K. Isolation of an isoflavone-metabolizing, Clostridium-like bacterium, strainTM-40, from human faeces. Anaerobe 2007, 13, 32-35. [CrossRef]

250. Jin, J.-S.; Kitahara, M.; Sakamoto, M.; Hattori, M.; Benno, Y. Slackia equolifaciens sp. nov., a human intestinal bacterium capable of producing equol. Int. J. Syst. Evol. Microbiol. 2010, 60, 1721-1724. [CrossRef] [PubMed]

251. Shimada, Y.; Yasuda, S.; Takahashi, M.; Hayashi, T.; Miyazawa, N.; Sato, I.; Abiru, Y.; Uchiyama, S.; Hishigaki, H. Cloning and expression of a novel NADP(H)-dependent daidzein reductase, an enzyme involved in the metabolism of daidzein, from equol-producing Lactococcus Strain 20-92. Appl. Environ. Microbiol. 2010, 76, 5892-5901. [CrossRef]

252. Wang, X.L.; Kim, K.T.; Lee, J.H.; Hur, H.G.; Kim, S.I. C-Ring cleavage of isoflavones daidzein and genistein by a newly-isolated human intestinal bacterium Eubacterium ramulus Julong 601. J. Microbiol. Biotechnol. 2004, 14, 766-771.

253. Hur, H.-G.; Lay, J.O., Jr.; Beger, R.D.; Freeman, J.P.; Rafii, F. Isolation of human intestinal bacteria metabolizing the natural isoflavone glycosides daidzin and genistin. Arch. Microbiol. 2000, 174, 422-428. [CrossRef]

254. Jin, J.-S.; Nishihata, T.; Kakiuchi, N.; Hattori, M. Biotransformation of C-glucosylisoflavone puerarin to estrogenic (3S)-equol in co-culture of two human intestinal bacteria. Biol. Pharm. Bull. 2008, 31, 1621-1625. [CrossRef]

255. Hur, H.-G.; Raffi, F. Biotransformation of the isoflavonoids biochanin A, formononetin, and glycitein by Eubacterium limosum. FEMS Microbiol. Lett. 2000, 192, 21-25. [CrossRef]

256. Heinonen, S.-M.; Wähälä, K.; Adlercreutz, H. Identification of urinary metabolites of the red clover isoflavones formononetin and biochanin A in human subjects. J. Agric. Food Chem. 2004, 52, 6802-6809. [CrossRef]

257. Carreau, C.; Flouriot, G.; Bennetau-Pelissero, C.; Potier, M. Enterodiol and enterolactone, two major diet-derived polyphenol metabolites have different impact on ER_transcriptional activation in human breast cancer cells. J. Steroid Biochem. Mol. 2008, 110, 176-185. [CrossRef] [PubMed]

258. Wang, L.-Q. Mammalian phytoestrogens: Enterodiol and enterolactone. J. Chromatogr. B 2002, 777, 289-309. [CrossRef]

259. Dinkova-Kostova, A.T.; Gang, D.R.; Davin, L.B.; Bedgar, D.L.; Chu, A.; Lewis, N.G. (1)-pinoresinol/(1)-lariciresinol reductase from Forsythia intermedia. J. Biol. Chem. 1996, 271, 29473-29482. [CrossRef] [PubMed]

260. Landete, J.M. Plant and mammalian lignans: A review of source, intake, metabolism, intestinal bacteria and health. Food Res. Int. 2012, 46, 410-424. [CrossRef]

261. Yoder, S.C.; Lancaster, S.M.; Hullar, M.A.J.; Lampe, J.W. Gut microbial metabolism of plant lignans: Influence on human health. In Diet-Microbe Interactions in the Gut. Effects on Human Health and Disease; Tuohy, K., Del Rio, D., Eds.; Elsevier Inc.: Oxford, UK, 2015; pp. 103-117. [CrossRef]

262. Wang, L.-Q.; Meselhy, M.R.; Li, Y.; Qin, G.-W.; Hattori, M. Human intestinal bacteria capable of transforming secoisolariciresinol diglucoside to mammalian lignans, enterodiol and enterolactone. Chem. Pharm. Bull. 2000, 48, 1606-1610. [CrossRef] [PubMed] 
263. Clavel, T.; Lippman, R.; Gavini, F.; Dore', J.; Blaut, M. Clostridium saccharogumia sp. nov. and Lactonifactor longoviformis gen. nov., sp. nov., two novel human faecal bacteria involved in the conversion of the dietary phytoestrogen secoisolariciresinol diglucoside. Syst. Appl. Microbiol. 2007, 30, 16-26. [CrossRef]

264. Clavel, T.; Henderson, G.; Alpert, C.-A.; Philippe, C.; Rigottier-Gois, L.; Doré, J.; Blaut, M. Intestinal bacterial communities that produce active estrogen-like compounds enterodiol and enterolactone in humans. Appl. Environ. Microbiol. 2005, 71, 6077-6085. [CrossRef]

265. Peñalvo, J.L.; Heinonen, S.-M.; Aura, A.-M.; Adlercreutz, H. Dietary sesamin is converted to enterolactone in humans. J. Nutr. 2005, 135, 1056-1062. [CrossRef]

266. Villalba, K.J.O.; Barka, F.V.; Pasos, C.V.; Rodríguez, P.E. Food ellagitannins: Structure, metabolomic fate, and biological properties. In Tannins-Structural Properties, Biological Properties and Current Knowledge Food Ellagitannins: Structure, Metabolomic Fate, and Biological Properties; Aires, A., Ed.; IntechOpen: London, UK, 2019. [CrossRef]

267. Wu, S.; Tian, L. Diverse phytochemicals and bioactivities in the ancient fruit and modern functional food pomegranate (Punica granatum). Molecules 2017, 22, 1606. [CrossRef]

268. Larrosa, M.; Tomás-Barberán, F.A.; Espín, J.C. The dietary hydrolysable tannin punicalagin releases ellagic acid that induces apoptosis in human colon adenocarcinoma Caco-2 cells by using the mitochondrial pathway. J. Nutr. Biochem. 2006, 17, 611-625. [CrossRef]

269. Selma, M.V.; Beltrán, D.; García-Villalba, R.; Espín, J.C.; Tomás-Barberán, F.A. Description of urolithin production capacity from ellagic acid of two human intestinal Gordonibacter species. Food Funct. 2014, 5, 1779-1784. [CrossRef] [PubMed]

270. Selma, M.V.; Tomás-Barberán, F.A.; Beltran, D.; Garcı-Villalba, R.; Espın, J.C. Gordonibacter urolithinfaciens sp. nov., a urolithinproducing bacterium isolated from the human gut. Int. J. Syst. Evol. Microbiol. 2014, 64, 2346-2352. [CrossRef] [PubMed]

271. Beltrản, D.; Romo-Vaquero, M.; Espín, J.C.; Tomȧs-Barberản, F.A.; Selma, M.V. Ellagibacter isourolithinifaciens gen. nov., sp. nov., a new member of the family Eggerthellaceae, isolated from human gut. Int. J. Syst. Evol. Microbiol. 2018, 68, 1707-1712. [CrossRef] [PubMed]

272. Espín, J.C.; Larrosa, M.; García-Conesa, M.T.; Tomás-Barberán, F. Biological significance of urolithins, the gut microbial ellagic acid-derived metabolites: The evidence so far. Evid.-Based Complementary Altern. Med. 2013, 2013, 1-16. [CrossRef]

273. Tomás-Barberán, F.A.; González-Sarrías, A.; García-Villalba, R.; Núñez-Sánchez, M.A.; Selma, M.V.; García-Conesa, M.T.; Espín, J.C. Urolithins, the rescue of "old" metabolites to understand a "new" concept: Metabotypes as a nexus among phenolic metabolism, microbiota dysbiosis, and host health status. Mol. Nutr. Food Res. 2017, 61, 1500901. [CrossRef]

274. Kawabata, K.; Yoshioka, Y.; Terao, J. Role of intestinal microbiota in the bioavailability and physiological functions of dietary polyphenols. Molecules 2019, 24, 370. [CrossRef]

275. Possemiers, S.; Heyerick, A.; Robbens, V.; Keukeleire, D.D.; Verstraete, W. Activation of proestrogens from hops (Humulus lupulus L.) by intestinal microbiota; conversion of isoxanthohumol into 8-prenylnaringenin. J. Agric. Food Chem. 2005, 53, 6281-6288. [CrossRef]

276. Paraiso, I.L.; Plagmann, L.S.; Yang, L.; Zielke, R.; Gombart, A.F.; Maier, C.S.; Sikora, A.E.; Blakemore, P.R.; Stevens, J.F. Reductive metabolism of xanthohumol and 8-prenylnaringenin by the intestinal bacterium Eubacterium ramulus. Mol. Nutr. Food Res. 2019, 63, 1800923. [CrossRef]

277. Nikolic, D.; Li, Y.; Chadwick, L.R.; Pauli, G.F.; van Breemen, R.B. Metabolism of xanthohumol and isoxanthohumol, prenylated flavonoids from hops (Humulus lupulus L.), by human liver microsomes. J. Mass Spectrom. 2005, 40, 289-299. [CrossRef]

278. Pepper, M.S.; Hazel, S.J.; Hümpel, M.; Schleuning, W.-D. 8-prenylnaringenin, a novel phytoestrogen, inhibits angiogenesis in vitro and in vivo. J. Cell. Physiol. 2004, 199, 98-107. [CrossRef]

279. Hameed, A.S.S.; Rawat, P.S.; Meng, X.; Liu, W. Biotransformation of dietary phytoestrogens by gut microbes: A review on bidirectional interaction between phytoestrogen metabolism and gut microbiota. Biotechnol. Adv. 2020, 43, 107576. [CrossRef] [PubMed]

280. Clifford, M.N. Review. Anthocyanins-Nature, occurrence and dietary burden. J. Sci. Food Agric. 2000, 80, 1063-1072. [CrossRef]

281. Aura, A.-M.; Martin-Lopez, P.; O’Leary, K.A.; Williamson, G.; Oksman-Caldentey, K.-M.; Poutanen, K.; Santos-Buelga, C. In vitro metabolism of anthocyanins by human gut microflora. Eur. J. Nutr. 2005, 44, 133-142. [CrossRef] [PubMed]

282. Keppler, K.; Humpf, H.-U. Metabolism of anthocyanins and their phenolic degradation products by the intestinal microflora. Bioorg. Med. Chem. 2005, 13, 5195-5205. [CrossRef] [PubMed]

283. Gonzalez-Barrio, R.; Edwards, C.A.; Crozier, A. Colonic catabolism of ellagitannins, ellagic acid, and raspberry anthocyanins: In vivo and in vitro studies. Drug Metab. Dispos. 2011, 39, 1680-1688. [CrossRef]

284. Zhu, Y.; Sun, H.; He, S.; Lou, Q.; Yu, M.; Tang, M.; Tu, L. Metabolism and prebiotics activity of anthocyanins from black rice (Oryza sativa L.) in vitro. PLoS ONE 2018, 13, e0195754. [CrossRef]

285. Ávila, M.; Hidalgo, M.; Sánchez-Moreno, C.; Pelaez, C.; Requena, T.; de Pascual-Teresa, S. Bioconversion of anthocyanin glycosides by Bifidobacteria and Lactobacillus. Food Res. Int. 2009, 42, 1453-1461. [CrossRef]

286. Hidalgo, M.; Oruna-Concha, J.; Kolida, S.; Walton, G.E.; Kallithraka, S.; Spencer, J.P.E.; Gibson, G.; de Pascual-Teresa, S. Metabolism of anthocyanins by human gut microflora and their influence on gut bacterial growth. J. Agric. Food Chem. 2012, 60, 3882-3890. [CrossRef]

287. Fleschhut, J.; Kratzer, F.; Rechkemmer, G.; Kulling, S.E. Stability and biotransformation of various dietary anthocyanins in vitro. Eur. J. Nutr. 2006, 45, 7-18. [CrossRef] 
288. Racova, Z.; Anzenbacherova, E.; Papouskova, B.; Poschner, S.; Kucova, P.; Gausterer, J.C.; Gabor, F.; Kolar, M.; Anzenbacher, P. Metabolite profiling of natural substances in human: in vitro study from fecal bacteria to colon carcinoma cells (Caco-2). J. Nutr. Biochem. 2020, 85, 108482. [CrossRef]

289. Xie, L.; Lee, S.G.; Vance, T.M.; Wang, Y.; Kim, B.; Lee, J.-Y.; Chun, O.K.; Bolling, B.W. Bioavailability of anthocyanins and colonic polyphenol metabolites following consumption of aronia berry extract. Food Chem. 2016, 211, 860-868. [CrossRef]

290. Chen, Y.; Li, Q.; Zhao, T.; Zhang, Z.; Mao, G.; Feng, W.; Wu, X.; Yang, L. Biotransformation and metabolism of three mulberry anthocyanin monomers by rat gut microflora. Food Chem. 2017, 237, 887-894. [CrossRef] [PubMed]

291. Li, H.; Christman, L.M.; Li, R.; Gu, L. Synergic interactions between polyphenols and gut microbiota in mitigating inflammatory bowel diseases. Food Funct. 2020, 11, 4878-4891. [CrossRef] [PubMed]

292. Barbosa, P.; Araújo, P.; Oliveira, J.; Fraga, I.; Pissarra, J.; Amaral, C. Metabolic pathways of degradation of malvidin-3-Omonoglucoside by Candida oleophila. Int. Biodeterior. Biodegrad. 2019, 144, 104768. [CrossRef]

293. Sánchez-Patán, F.; Cueva, C.; Monagas, M.; Walton, G.E.; Gibson, G.R.; Martín-Álvarez, P.J.; Moreno-Arribas, M.V.; Bartolomé, B. Gut microbial catabolism of grape seed flavan-3-ols by human faecal microbiota. Targetted analysis of precursor compounds, intermediate metabolites and end-products. Food Chem. 2012, 131, 337-347. [CrossRef]

294. Mena, P.; Calani, L.; Bruni, R.; Del Rio, D. Bioactivation of high-molecular-weight polyphenols by the gut microbiome. In Diet-Microbe Interactions in the Gut. Effects on Human Health and Disease; Tuohy, K., Del Rio, D., Eds.; Elsevier Inc.: Oxford, UK, 2015; pp. 73-101. [CrossRef]

295. Kutschera, M.; Engst, W.; Blaut, M.; Braune, A. Isolation of catechin-converting human intestinal bacteria. J. Appl. Microbiol. 2011, 111, 165-175. [CrossRef] [PubMed]

296. Appeldoorn, M.M.; Vincken, J.-P.; Gruppen, H.; Hollman, P.C.H. Procyanidin dimers A1, A2, and B2 are absorbed without conjugation or methylation from the small intestine of rats. J. Nutr. 2009, 139, 1469-1473. [CrossRef] [PubMed]

297. Déprez, S.; Brezillon, C.; Rabot, S.; Philippe, C.; Mila, I.; Lapierre, C.; Scalbert, A. Polymeric proanthocyanidins are catabolized by human colonic microflora into low-molecular-weight phenolic acids. J. Nutr. 2000, 130, 2733-2738. [CrossRef]

298. Ou, K.; Sarnoski, P.; Schneider, K.R.; Song, K.; Khoo, C.; Gu, L. Microbial catabolism of procyanidins by human gut microbiota. Mol. Nutr. Food Res. 2014, 58, 2196-2205. [CrossRef]

299. Monagas, M.; Urpi-Sarda, M.; Sánchez-Patán, F.; Llorach, R.; Garrido, I.; Gómez-Cordovés, C.; Andres-Lacueva, C.; Bartolomé, B. Insights into the metabolism and microbial biotransformation of dietary flavan-3-ols and the bioactivity of their metabolites. Food Funct. 2010, 1, 233-253. [CrossRef]

300. Alakomi, H.L.; Puupponen-Pimiä, R.; Aura, A.M.; Helander, I.M.; Nohynek, L.; Oksman-Caldentey, K.M.; Saarela, M. Weakening of Salmonella with selected microbial metabolites of berry-derived phenolic compounds and organic acids. J. Agric. Food Chem. 2007, 55, 3905-3912. [CrossRef] [PubMed]

301. Braune, A.; Blaut, M. Deglycosylation of puerarin and other aromatic C-glucosides by a newly isolated human intestinal bacterium. Environ. Microbiol. 2011, 13, 482-494. [CrossRef] [PubMed]

302. Ahn, H.J.; You, H.L.; Park, M.S.; Li, Z.; Choe, D.; Johnston, T.V.; Ku, S.; Ji, G.E. Microbial biocatalysis of quercetin-3-glucoside and isorhamnetin-3-glucoside in Salicornia herbacea and their contribution to improved anti-inflammatory activity. RSC Adv. 2020, 10, 5339-5350. [CrossRef]

303. Schoefer, L.; Mohan, R.; Schwiertz, A.; Braune, A.; Blaut, M. Anaerobic degradation of flavonoids by Clostridium orbiscindens. Appl. Environ. Microbiol. 2003, 69, 5849-5854. [CrossRef]

304. Aura, A.-M. Microbial metabolism of dietary phenolic compounds in the colon. Phytochem. Rev. 2008, 7, 407-429. [CrossRef]

305. Corrêa, T.A.F.; Rogero, M.M.; Hassimotto, N.M.A.; Lajolo, F.M. The two-way polyphenols-microbiota interactions and their effects on obesity and related metabolic diseases. Front. Nutr. 2019, 6, 188. [CrossRef]

306. Hanske, L.; Loh, G.; Sczesny, S.; Blaut, M.; Braune, A. The bioavailability of apigenin-7-glucoside is influenced by human intestinal microbiota in rats. J. Nutr. 2009, 139, 1095-1102. [CrossRef]

307. Schneider, H.; Blaut, M. Anaerobic degradation of flavonoids by Eubacterium ramulus. Arch. Microbiol. 2000, 173, 71-75. [CrossRef]

308. Nunes, C.; Almeida, L.; Laranjinha, J. Synergistic inhibition of respiration in brain mitochondria by nitric oxide and dihydroxyphenylacetic acid (DOPAC): Implications for Parkinson's disease. Neurochem. Int. 2005, 47, 173-182. [CrossRef] [PubMed]

309. Najmanová, I.; Pourová, J.; Vopršalová, M.; Pilařová, V.; Semecký, V.; Nováková, L.; Mladěnka, P. Flavonoid metabolite 3-(3hydroxyphenyl)propionic acid formed by human microflora decreases arterial blood pressure in rats. Mol. Nutr. Food Res. 2016, 60, 981-991. [CrossRef] [PubMed]

310. Rechner, A.R.; Smith, M.A.; Kuhnle, G.; Gibson, G.R.; Debnam, E.S.; Srai, S.K.S.; Moore, K.P.; Rice-Evans, C.A. Colonic metabolism of dietary polyphenols: Influence of structure on microbial fermentation products. Free Rad. Biol. Med. 2004, 36, 212-225. [CrossRef] [PubMed]

311. Sova, M.; Saso, L. Natural sources, pharmacokinetics, biological activities and health benefits of hydroxycinnamic acids and their metabolites. Nutrients 2020, 12, 2190. [CrossRef] [PubMed]

312. Zhang, L.; Gao, W.; Chen, X.; Wang, H. The effect of bioprocessing on the phenolic acid composition and antioxidant activity of wheat bran. Cereal Chem. 2014, 91, 255-261. [CrossRef]

313. Farah, A.; Monteiro, M.; Donangelo, C.M.; Lafay, S. Chlorogenic acids from green coffee extract are highly bioavailable in humans. J. Nutr. 2008, 138, 2309-2315. [CrossRef] [PubMed] 
314. Gonthier, M.P.; Verny, M.A.; Besson, C.; Rémésy, C.; Scalbert, A. Chlorogenic acid bioavailability largely depends on its metabolism by the gut microflora in rats. J. Nutr. 2003, 133, 1853-1859. [CrossRef] [PubMed]

315. García-Villalba, R.; Beltrán, D.; Frutos, M.D.; Selma, M.V.; Espín, J.C.; Tomás-Barberán, F.A. Metabolism of different dietary phenolic compounds by the urolithin-producing human-gut bacteria Gordonibacter urolithinfaciens and Ellagibacter isourolithinifaciens. Food Funct. 2020, 11, 7012-7022. [CrossRef]

316. Mills, C.E.; Tzounis, X.; Oruna-Concha, M.J.; Mottram, D.S.; Gibson, G.R.; Spencer, J.P. In vitro colonic metabolism of coffee and chlorogenic acid results in selective changes in human faecal microbiota growth. Br. J. Nutr. 2015, 113, 1220-1227. [CrossRef]

317. Monteiro, M.; Farah, A.; Perrone, D.; Trugo, L.C.; Donangelo, C. Chlorogenic acid compounds from coffee are differentially absorbed and metabolized in humans. J. Nutr. 2007, 137, 2196-2201. [CrossRef]

318. Ogawa, M. Coffee and hippuric acid. In Coffee in Health and Disease Prevention; Preedy, V.R., Ed.; Academic Press: Cambridge, MA, USA, 2014; pp. 209-216.

319. Jung, C.M.; Heinze, T.M.; Schnackenberg, L.K.; Mullis, L.B.; Elkins, S.A.; Elkins, C.A.; Steele, R.S.; Sutherland, J.B. Interaction of dietary resveratrol with animal-associated bacteria. FEMS Microbiol. Lett. 2009, 297, 266-273. [CrossRef]

320. Bode, L.M.; Bunzel, D.; Huch, M.; Cho, G.S.; Ruhland, D.; Bunzel, M.; Bub, A.; Franz, C.M.; Kulling, S.E. In vivo and in vitro metabolism of trans-resveratrol by human gut microbiota. Am. J. Clin. Nutr. 2013, 97, 295-309. [CrossRef]

321. Springer, M.; Moco, S. Resveratrol and its human metabolites-effects on metabolic health and obesity. Nutrients 2019, 11, 143. [CrossRef] [PubMed]

322. Chaplin, A.; Carpéné, C.; Mercader, J. Resveratrol, metabolic syndrome, and gut microbiota. Nutrients 2018, 10, 1651. [CrossRef] [PubMed]

323. Ito-Nagahata, T.; Kurihara, C.; Hasebe, M.; Ishii, A.; Yamashita, K.; Iwabuchi, M.; Sonoda, M.; Fukuhara, K.; Sawada, R.; Matsuoka, A.; et al. Stilbene analogs of resveratrol improve insulin resistance through activation of AMPK. Biosci. Biotechnol. Biochem. 2013, 77, 1229-1235. [CrossRef] [PubMed]

324. Jarosova, V.; Vesely, O.; Marsik, P.; Jaimes, J.D.; Smejkal, K.; Kloucek, P.; Havlik, J. Metabolism of stilbenoids by human faecal microbiota. Molecules 2019, 24, 1155. [CrossRef]

325. Scazzocchio, B.; Minghetti, L.; D'Archivio, M. Interaction between gut microbiota and curcumin: A new key of understanding for the health effects of curcumin. Nutrients 2020, 12, 2499. [CrossRef]

326. Tan, S.; Calani, L.; Bresciani, L.; Dall'asta, M.; Faccini, A.; Augustin, M.A.; Gras, S.L.; Del Rio, D. The degradation of curcuminoids in a human faecal fermentation model. Int. J. Food Sci. Nutr. 2015, 66, 790-796. [CrossRef]

327. Hassaninasab, A.; Hashimoto, Y.; Tomita-Yokotani, K.; Kobayashi, M. Discovery of the curcumin metabolic pathway involving a unique enzyme in an intestinal microorganism. Proc. Natl. Acad. Sci. USA 2011, 108, 6615-6620. [CrossRef]

328. Burapan, S.; Kim, M.; Han, J. Curcuminoid demethylation as an alternative metabolism by human intestinal microbiota. J. Agric. Food Chem. 2017, 65, 3305-3310. [CrossRef]

329. Bresciani, L.; Favari, C.; Calani, L.; Francinelli, V.; Riva, A.; Petrangolini, G.; Allegrini, P.; Mena, P.; Del Rio, D. The effect of formulation of curcuminoids on their metabolism by human colonic microbiota. Molecules 2020, 25, 940. [CrossRef]

330. Anand, P.; Kunnumakkara, A.J.; Newman, R.A.; Aggarwal, B.B. Bioavailability of curcumin: Problems and promises. Mol. Pharmac. 2007, 4, 807-818. [CrossRef] 